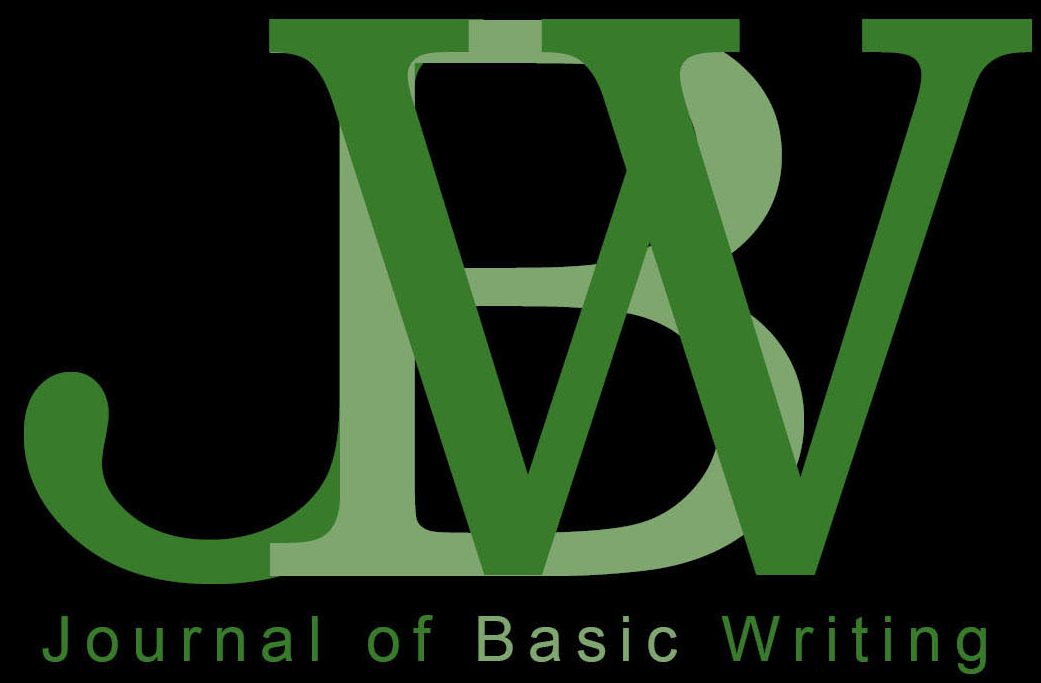

Beyond the Dark Closet: Reconsidering Literacy Narratives as Performative Artifacts Shereen Inayatulla

iBooks Portfolios: Interfaces, Audiences, and the Making of Online Identities

Thomas Peele and Melissa Antinori

"Me/We": Building an Embodied Writing Classroom for Socially Networked, Socially Distracted Basic Writers Kendra N. Bryant

Seeking Texts in All Available Forms: Invisible Writing and a New Reading Rhetoric of Sight and Sound Kati Fargo Ahern

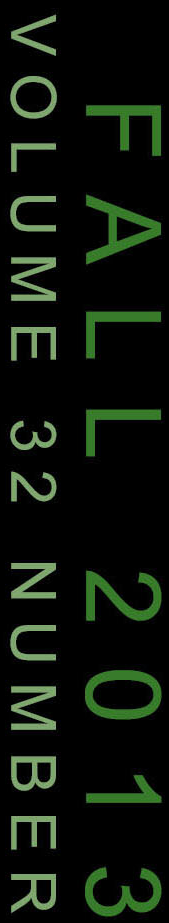





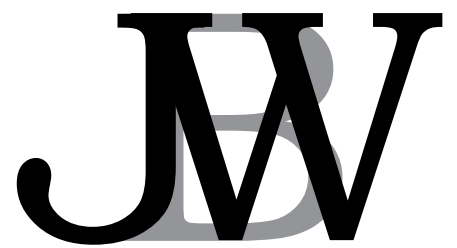

Journal of Basic Writing

VOLUME 32 NUMBER 2

FALL 2013

The Journal of Basic Writing publishes articles of theory, research, and teaching practices related to basic writing. Articles are refereed by members of the Editorial Board (see overleaf) and the Editors.

\section{Hope Parisi and Cheryl C. Smith}

Editors

\section{Karen Weingarten \\ Web Editor}

\section{Rebecca Mlynarczyk and Bonne August} Consulting Editors

\section{Angela J. Francis and Andrew Lucchesi Editorial Assistants}

The Journal of Basic Writing is published twice a year, in the spring and fall, with support from the City University of New York, Office of Academic Affairs. We welcome unsolicited manuscripts and ask authors to consult the detailed "Call for Articles" in this issue. Subscriptions for individuals are $\$ 20.00$ for one year and $\$ 35.00$ for two years; subscriptions for institutions are $\$ 30.00$ for one year and $\$ 45.00$ for two years. Foreign postage is $\$ 10.00$ extra per year. For subscription inquiries or updates, contact:

Journal of Basic Writing

P.O. Box 465

Hanover, PA 17331

Phone: (717) 632-3535

Fax: (717) 633-8920

e-mail:pubsvc@tsp.sheridan.com

Published by the City University of New York since 1975

Cover and logo design by Kimon Frank

Copyright $(\mathrm{C} 2012$ by the Journal of Basic Writing

ISSN 0147-1635 


\section{JOURNAL OF BASIC WRITING}

\section{EDITORIAL BOARD}

Linda Adler-Kassner

University of California, Santa Barbara

Christopher Anson

North Carolina State University

Hannah Ashley

West Chester University

David Bartholomae

University of Pittsburgh

Sarah Benesch

College of Staten Island, CUNY

Susan Naomi Bernstein

Arizona State University

Lisa Blankenship

Baruch College, CUNY

Lynn Z. Bloom

University of Connecticut, Storrs

Gay Brookes

Borough of Manhattan Comm. College, CUNY

Martha Clark Cummings

Kingsborough Community College, CUNY

Suellynn Duffey

Georgia Southern University

Chitralekha Duttagupta

Utah Valley University

Gregory Glau

Northern Arizona University

Laura Gray-Rosendale

Northern Arizona University

Karen L. Greenberg

Hunter College, CUNY

Kim Gunter

Appalachian State University

Susanmarie Harrington

University of Vermont

Donald J. Kraemer

California Polytechnic State University

Patricia O. Laurence

City College, CUNY

Andrea A. Lunsford

Stanford University

Jane Maher

Nassau Community College, SUNY

Paul Kei Matsuda

Arizona State University

Mark McBeth

John Jay College \& Graduate Center, CUNY
Geraldine McNenny

Chapman University

Susan Miller

University of Utah

Deborah Mutnick

Long Island University

Nathaniel Norment, Jr.

Temple University

\section{George Otte}

Graduate Center, CUNY

Matthew Pavesich

Georgetown University

Thomas Peele

City College, CUNYy

Kevin Roozen

University of Central Florida

Wendy Ryden

Longlsland University

Yolanda Sealey-Ruiz

Teachers College, Columbia University

\section{Charles I. Schuster}

University of Wisconsin, Milwaukee

Tony Silva

Purdue University

Trudy Smoke

Hunter College, CUNY

Linda Stine

Lincoln University

Lynn Quitman Troyka

Queensborough Comm. College, Cuny, ret. 


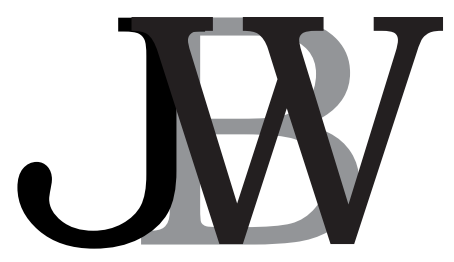

Journal of Basic Writing

Beyond the Dark Closet: Reconsidering Literacy

Narratives as Performative Artifacts

\section{Shereen Inayatulla}

iBooks Portfolios: Interface, Audiences, and the 


\title{
CALL FOR ARTICLES
}

We welcome manuscripts of 15-25 pages, double spaced, on topics related to basic and ESL writing, broadly interpreted. Submissions should follow current MLA guidelines. Manuscripts are refereed anonymously. To assure impartial review, include name(s), affiliation(s), mailing and e-mail addresses, and a short biographical note for publication on the cover page only. The second page should include the title but no author identification, an abstract of about 150 words, and a list of 4-5 key words. Endnotes should be kept to a minimum. It is the author's responsibility to obtain written permission for including excerpts from student writing.

We prefer that contributions be submitted as Word document attachments via email to: hopekcc@aol.com and Cheryl.Smith@baruch.cuny.edu. If electronic submission is not possible, mail five copies of the manuscript and abstract to:

\author{
Professor Hope Parisi \\ Co-Editor, JBW \\ Department of English \\ Kingsborough Community College, CUNY \\ 2001 Oriental Blvd. \\ Brooklyn, NY 11235
}

You will receive a confirmation of receipt; a report on the status of your submission will follow in about sixteen weeks.

All manuscripts must focus clearly on basic writing and must add substantively to the existing literature. We seek manuscripts that are original, stimulating, well-grounded in theory, and clearly related to practice. Work that reiterates what is known or work previously published will not be considered.

We invite authors to write about such matters as classroom practices in relation to basic-writing or second-language theory; cognitive and rhetorical theories and their relation to basic writing; social, psychological, and cultural implications of literacy; discourse theory; grammar, spelling, and error analysis; linguistics; computers and new technologies in basic writing; assessment and evaluation; writing center practices; teaching logs and the development of new methodologies; and cross-disciplinary studies combining basic writing with psychology, anthropology, journalism, and art. We publish observational studies as well as theoretical discussions on relationships between basic writing and reading, or the study of literature, or speech, or listening. The term "basic writer" is used with wide diversity today, sometimes referring to a student from a highly oral tradition with little experience in writing academic discourse, and sometimes referring to a student whose academic writing is fluent but otherwise deficient. To help readers, therefore, authors should describe clearly the student population which they are discussing.

We particularly encourage a variety of manuscripts: speculative discussions which venture fresh interpretations; essays which draw heavily on student writing as supportive evidence for new observations; research reports, written in non-technical language, which offer observations previously unknown or unsubstantiated; and collaborative writings which provocatively debate more than one side of a central controversy. 


\section{EDITORS' COLUMN}

The beginning of a new semester is a particularly apt time to reflect on what slips beneath the surface of visibility in the classroom. There are certain ways we see students right from the start, based on the little we know about them. We know, for example, the demographic information we get from class lists, such as declared areas of study or class year. We know what students tell us in initial introductions and profiles they may write. And we build assumptions about them based on attitudes, postures, behaviors, and comments that come out during class. Where students choose to sit, how they contribute to discussions and interact with classmates, if they linger to speak with us after class-all of these factors contribute to our view of students and help build our sense of who they might be. But the information we use to construct our understanding of students consists of carefully filtered details. That is, their written profiles and behaviors in class are performances of a school identity aimed at a very particular audience-the one holding the red pen. For while we are constructing our view of them, students are busy forming their own ideas about us, based on our performances.

As we do this dance in the classroom, we draw from everything we have learned over the years about human behavior in school and classroom dynamics. That is, our knowledge of one another is at once deeply informed by experience and profoundly limited in scope, bounded by fourteen weeks and the academic spaces we share. Hopefully, our assumptions develop throughout the semester, growing with each class discussion, interaction, conference, and assignment. But even as our knowledge of one another expands, there is almost certainly more that we do not know than we know. Similarly, there is likely more institutional or social influence behind our ways of knowing than we may recognize. The articles in this issue explore different ways that our work with students and their writing is laced with the invisible and bears traces of social and academic structures that we may not be actively aware of. We see students and their writing, we respond to and evaluate them, hopefully we value and learn from them. But just as important as what we see and directly respond to are the gaps, the traces of the unknown that may be asking for recognition (or not), and the potential they bear for the construction and negotiation of identities.

Our first article calls these gaps and traces "the unknowable, uncodable, behind-the-scenes space." In "Beyond the Dark Closet: Reconsidering Literacy Narratives as Performative Artifacts," Shereen Inayatulla puts the ubiquitous literacy narrative in conversation with coming out narratives to 
explore how tropes of darkness and enlightenment play out in both. In each case, these tropes lend themselves to narrow, totalizing interpretations of an individual human experience. Still, as Inayatulla points out, discussions of coming out narratives have begun to offer a more nuanced view of the closet as not only or always a space of darkness and oppression. As Inayatulla argues, "the closet, taken not as a site of unawareness, can redirect the ways in which darkness in literacy narratives is depicted." Inayatulla challenges assumptions about how literacy maps a trajectory from darkness to light to explore how a writer's experience with literacy and its sponsors might be captured-and reclaimed-in the literacy narrative assignment. Writers may choose to perform identities and experiences in order to trace "truths" about literacy that do not correspond to common cultural assumptions about enlightenment through language acquisition and education. Inayatulla calls for a reconsideration of the literacy narrative assignment to liberate writers, not only from limited expectations of their experiences, but also from teachers' internalized narratives about students' - and our own—enlightenment.

Thomas Peele and Melissa Antinori also look at common assumptions about how and why students write. Peele and Antinori see a lack of transparency about faculty and administrative agendas when it comes to student writing, fueled by discrepancies in their priorities and expectations. The lack of transparency, however, has positive results for Peele and Antinori, laying the groundwork for an initiative using the power of technology and social networking sites (SNSs) to bridge the reading and writing that students do at home and in school. In "iBooks Portfolios: Interface, Audiences, and the Making of Online Identities," the authors describe this initiative: students receive iPads loaded with the iBooks platform for the purpose of creating a portfolio of their work. Peele and Antinori report finding that the iPads "provided a context in which students could, if given the chance, make use of the rhetorical skills they'd honed voluntarily on SNSs and apply those skills to their academic writing." As they develop iBooks Portfolios, students craft identities that blur the lines between online and academic spaces. In the process, they draw from divergent networks and literacies and transcend some of the unseen agendas that quietly shape and delimit what we value in writing for school. That is, writing spaces and practices that tend to remain invisible in school are afforded value in the iBooks Portfolios.

Like Peele and Antinori, our next author, Kendra N. Bryant, explores the role of technology and SNSs for developing students' authorial identities in college and beyond. In "'Me/We': Building an Embodied Writing Classroom for Socially Networked, Socially Distracted Basic Writers," Bryant 
acknowledges the value of social media in offering accessible platforms for writers. She worries, however, about how these platforms may interfere with our efforts to build communities of trust and collaboration in face-to-face writing classrooms. Bryant describes a reality that will be familiar to many of us: "teachers often enter into silent spaces in their classrooms, where students are not discussing the latest reading, reviewing last night's homework, or even gossiping about the latest reality television program, but are sitting there, 'alone'-distracted and reaching for a sense of belonging via texts, tweets, selfies and Facebook updates." Bryant addresses her concerns about building class community in the age of Facebook by drawing on Janet Emig's theory of embodied learning to develop a curriculum in which students blog together. In this blogging classroom community, students and teacher work collaboratively, support one another's efforts, and reveal personal parts of themselves in order to build a collective based on compassion, individual humanity, and belonging. The goal is to provide a space where writers can be known, understood, and encouraged in ways not possible in disconnected spaces, be they virtual or physical, home- or school-based.

Finally, Katie Fargo Ahern underscores the metaphorical workings of the often invisible assumptions we carry into the classroom. In "Seeking Texts in All Available Forms: Invisible Writing and a New Reading Rhetoric of Sight and Sound," Ahern explores our largely unexamined reliance on metaphors of sight to articulate the work we do with basic writers and readers. When we use words like insight and clarity to describe how we want students to perceive meaning in a text, or how we want them to articulate their own meaning so that it may be perceptible to others, we imagine this work as an act of seeing, which "has become metaphorically synonymous with knowing." To push back on the ascendency of sight in our constructions of reading and writing, Ahern develops the concept of invisible writing "to encourage student readers to find new ways to 'see' forms of writing as writing" and "to reconfigure 111 and shift the idea of a lack of sight or lack of perception from the reader to the text." The goal, she says, is "to have students understand texts as possessing contingent, complex qualities that they as readers must seek out, perceive, name, listen for, and explore in their analysis, rather than to see themselves as so named, basic readers." In this description of reading practice, students are agents of their own knowledge construction, bringing to the surface and actively shaping their own narratives of reading and writing.

Seeing out, perceiving, naming, listening for, and exploring_these are the things we imagine ourselves doing as scholars and teachers. In the articles 
featured in this issue, we can trace a conviction that students should have access to the same kind of intellectual authority, should not have to submit to being "so named, basic." Such labels bear a heavy burden of institutional and social assumptions, not to mention the weight of accumulated, negative selfperception. The authors here push back against the pervasive, unexamined notions about "skills" and what a basic writer "needs." They seek instead to privilege basic writers' agency to perceive for themselves, name themselves, and listen for and explore their own narratives-released from some of the blindness and distraction that encumber one another's fuller stories, both in our classrooms and the wider world.

—Cheryl C. Smith and Hope Parisi 


\title{
Beyond the Dark Closet: Reconsidering Literacy Narratives as Performative Artifacts
}

\author{
Shereen Inayatulla
}

\begin{abstract}
Pedagogical theories celebrate and romanticize literacy narratives as emancipatory to the lives of students and teachers. In the particular context of basic writing, such discussions warrant critique. The author argues that perceptions of literacy narratives as transformative to writers and readers often reinforce a "model minority" belief along with "storyteller-subject" and "pedagogue-master" asymmetries, even when intending to challenge these dynamics. Furthermore, these perceptions enable and sustain a problematic trajectory that polarizes darkness and enlightenment. Through an examination of coming out narrative conventions that align with and depart from literacy narratives, this article explores key debates about closetedness that can reframe storytellers as making performative choices rather than being characterized as passive objects of study.
\end{abstract}

KEYWORDS: literacy narratives; coming out narratives; basic writing; underrepresentation; storytelling; performance

When creating a personal narrative, you also co-create the group/cultural story. You examine the description handed to you of the world, picking holes in the paradigms currently constructing reality. You doubt that traditional Western science is the best knowledge system, the only true, impartial arbiter of reality. You turn the established narrative on its head, seeing through, resisting, and subverting its assumptions.

Anzaldúa ("Beyond" 103)

For over two decades, compositionists have analyzed the pedagogical benefits of assigning literacy narratives to students in writing courses. Research on literacy narratives took rise during the 1990s when this genre began to circulate in English and more specifically composition and rhetorical studies. This work emerged from the field's desire to address greater "diversity," respond to "multiculturalism," and reflect upon the marginalization of multilingual writers (Clark and Medina; Karls). To advance this pursuit, Wendy Bishop lists seven goals the literacy narrative can accomplish, including that it "encourages you to explore cultural and racial diversity,"

Shereen Inayatulla is an Assistant Professor of English at York College-CUNY, where she teaches composition and rhetoric with emphases in literacy studies, autoethnography, and queer theory. 
"provides a place where you can look at and critique your schooling and challenge your education," and enables the study of "writing processes and growth as a writer and reader" (67). These goals subsequently shape the ways in which students' literacy narratives are read, analyzed, and discussed from a theoretical standpoint.

As with much of the research done in composition, scholarship on literacy narratives has tended to be a discussion between pedagogues about (and in the absence of) students, often through analyses of the texts students compose. Generally speaking, the analysis of student writing functions as a valuable research practice in the field, for, to say the least, this work transgresses traditional perspectives on what counts as a text worthy of analysis. Literacy narratives are taken up through a kind of meta-analysis in which pedagogue-readers calculate and assess learning outcomes (Bishop; DunbarOdom). These discussions of students' sample narratives have struck a familiar and sometimes unsettling chord; I am reminded of the critical debates surrounding "coming out" narratives as a strategy for self-actualization versus so-called "mainstream assimilation" (Sycamore). Coming out narratives occupy a broader social discourse that measures "progress" and living in one's "truth" in a way that is limiting if not singularizing and prescriptive.

I have observed the ways in which both literacy and coming out narratives often examine and celebrate growth and self-awareness as the embodiment of a "once was lost, now am found" trajectory. Literacy narratives produced in the context of basic writing classrooms become further complicated by the institutional politicization of underrepresented, "minority," and "remedial" status. The expectation is not that one can transgress these labels but rather, that material conditions can (and should) change for "the better" as a reward for the labor of acquiring privileged forms of literacy. To be certain, these theoretical discussions emerge from a desire to encourage or centralize narratives that are otherwise dismissed, discredited, and silenced, but as Janet Carey Eldred and Peter Mortensen argue, "Romance and literacy are often intimately connected genres" (531). They caution that literacy is a site from which "both liberal and conservative agendas make the same claim," that literacy enables meaningful participation in society (516). My efforts lie in analyzing discussions that, similar to broader commentaries on coming out narratives, fuel, foster, and reside within the agendas Eldred and Mortensen identify. I put forward these observations for consideration:

Firstly, within discussions of literacy narratives, dichotomizing tropes of darkness and enlightenment become markers for how the storyteller- 
subject moves forward in pursuit of language acquisition. I explore some of the ways in which these tropes take hold, specifically in relation to basic writers already positioned as underrepresented (and sometimes minority) communities on an institutional level. This exploration calls into question the (inadvertent) formation of "model minorities" in which specific dark to light trajectories are privileged, praised, and celebrated as conventions central to the narrative itself. One consequence of this formation is that a pedagogical reversal takes place wherein the "subject" (storyteller/practitioner) is positioned to teach the "master" (reader/pedagogue) about the challenges of underrepresentation and marginalization. This reversal twists the script where an already asymmetrical power dynamic exists, but rather than challenging the asymmetry, a new falsely emancipatory dynamic takes shape in which the sufferer's "truth" is sanctioned by a savior-witness in order for the latter to be absolved and the former to be released from subjugation.

Secondly, discussions of coming out narratives also rely on a darkto-light trajectory in terms of how closetedness and coming out are said to release storyteller-subjects from the strictures of secrecy. Stories about coming out are popularized as narratives in which lesbian, gay, bisexual, transgendered, queer (LGBTQ) individuals "come out of the closet," thus disclosing significant moments in the process of naming, understanding, accepting, and revealing sexuality and/or gender. Coming out functions at the local level of storytelling in ways that reflect a macro social narrative, one with important implications for literacy narrative research. Some of the theoretical discussions surrounding coming out narratives investigate the closet as a more nuanced concept than an in versus out binary could realistically allow. Describing debates that have emerged, I argue that the closet, taken not as a site of unawareness, can redirect the ways in which darkness in literacy narratives is depicted.

The section that follows draws upon analyses of closetedness to further explore subject-master relationships. It examines why and how discussions of literacy narratives at times slip into framing the storyteller-subject as the object of study. This framing has to do with the ways in which life events are characterized as inseparable from the subject. As a way to reroute discussions from a voyeuristic, exoticizing kind of objectification, and in the process, identify critical moments for teacher self-reflection, I propose reading storytellers' choices as performative acts: to make a rhetorical shift away from perceptions that these stories contain innate or "authentic" displays of selfhood. 


\section{Literacy Narratives Through the Dark, Toward the Light}

Scholarship in composition recounts the ways in which asking students to read and write about language acquisition can rouse dynamic opportunities for reflection, critique, and creative engagement. (Eldred and Mortensen; Daniell; Soliday; Bishop; Dunbar-Odom; Scott). This research considers what students and teachers can learn from analyzing schooling and reading or writing practices. For Donna Dunbar-Odom, "The thrust of the literacy narrative is how literacy-usually characterized as a love of fiction-changes the writer's life" (26). It is worth ruminating on how and why these texts are said to enlighten or change individuals; from and to what states of awareness might these changes be taking place? Many of these broader discussions in composition research claim that stories about language acquisition can offer and reveal useful critiques of the belief systems that "romanticize" literacy. If, indeed, "we have romanticized the power of education, have internalized the fantasy that a flower girl can become a duchess through education" (a reference Eldred and Mortensen make in their discussion of Pygmalion), then literacy narratives, it is hoped, can complicate this trajectory (515). But upon closer examination, what are these broader discussions trying to remedy or address? I question if, perhaps, there is an exoticizing, "orientalist" quality present when analyzing students' engagement with these texts about socalled language acquisition.

I was introduced to literacy narrative assignments over a decade ago when teaching in a basic writing program for the first time. The sequence of basic writing courses I taught, not dissimilar to those in basic writing programs nationwide, was comprised mainly of students historically labeled (and marginalized as) minority, first-generation, sometimes "at risk," and "remedial" writers. In some instances, students had carried these labels for years, only to see them further sanctioned upon admission to college. While the labels basic and remedial have themselves been scrutinized in the field, and debates about the appropriate term to use continue today, they shape and galvanize the ways in which literacy narratives function in composition curricula.

Undoubtedly, my students at this time were underrepresented within the scope of our academic institution in part because of their racial, linguistic, socioeconomic, and regional identities and backgrounds. Thus, as a strategy to include engaging and relevant texts in the basic writing course, I was encouraged to teach works by writers such as Gloria Anzaldúa and Richard Rodriguez who explicitly describe the struggles, rewards, assimilationist/ 
revolutionary politics, and tacit values associated with language acquisition. My students had mixed responses to these texts; some viewed them favorably and made connections between the authors' experiences to their own, while others did not, and many students shifted and revised their positions throughout the conversation. Through our class discussions, it was made clear that in spite of the classifications that placed students into our shared learning space, heterogeneity was inevitable; this was not a surprising discovery, but it did confirm that basic writing and underrepresented students read, respond, and write back to literacy narratives in a variety of ways for reasons that may be unknowable to instructors and often to each other. In other words, the motives behind their interpretations and written responses were just as varied as the contributions they made to the class discussion.

This experience contrasts the broader historical discussions of literacy narratives that, at times, seek to define generic conventions. According to Dunbar-Odom, "literacy narratives reveal that a desire to read and write is not as easily extinguished as we might imagine" (106). This desire to read and write has become, I would argue, another romanticized convention of literacy narratives-one that influences writers and readers and the ways in which these texts are assigned or taught. For as I observed in conversations with my students, desire to read and write was multifaceted if not illusory at times. Desire, for many of these students, veiled or was veiled by a spectrum of competing concerns ranging from basic survival or social acceptability to an uncertainty of what else could be done and mechanical compliance with what's expected within the parameters of the course.

Interpretations of a desire to read and write may be additionally loaded in the context of a program or course that encourages mostly underrepresented students to read published literacy narratives written by mostly underrepresented authors. Underrepresentation plays out in ways that can obscure access to and accounts of whose desires are articulated, valued, and met. As Morris Young suggests, the literacy narrative offers "minority" writers a chance to participate in the "common cultural script of American individualism and achievement." These writers are told they can participate by way of "hard work and education." But Young also points out that the literacy narrative gives minority writers an opportunity to "[subvert] this story through their use of minority discourse" (53). Furthermore, "the racialized subject reconfigures the literacy narrative as a strategy for resisting appropriation by a dominant American culture," perhaps by using the narrative as a tool for critique, an opportunity to write against a glossy romanticization of literacy that (unwittingly) advances assimilationist goals. According to 
Young, American culture "imagines a unifying narrative of citizenship," through the use of "naturalized discourse of Standard English." The "racialized subject" then resists this notion by composing literacy narratives in which they are "denaturalizing Standard English [emphasis in the original]" (35). Within this configuration, minorities can use the literacy narrative as a powerful tool of resistance and reappropriation.

The prevalence of texts written by historically underrepresented writers with heightened, conflicting attitudes and experiences toward English literacies follows a certain logic; could there even be a narrative arc if acquisition of language takes place without conflict or remains unfettered by a challenging situation? This would be difficult to imagine, particularly if one pedagogical goal is to encourage audience engagement with these texts. Likewise, it would seem counterproductive, if not disingenuous and unlikely, to encounter narratives in which there is only conflict and strife without reconciliation of some kind. Perhaps it is the narratives that strike a strategic balance of these features that get valued and popularized. This is certainly the case with Rodriguez's essay, "Public and Private Language," in which he describes personal struggles and successes in acquiring English literacy. Still the circulation of literacy narratives by underrepresented writers raises questions about characterizations of Otherness, especially when the analyses of these narratives then rely on trajectories of darkness to enlightenment.

According to Bishop, "we tell stories in order to share-but that sharing can include self-learning, self-defining, and self-shaping as well as entertaining, beguiling, and performing. We make and remake, calibrate and recreate, we move from one understanding to a new, more enlightened understanding" (70). The responsibility of sharing is complex; the minority as pedagogue can appear-albeit deceivingly-to reverse or disrupt top-down models of instruction and institutional power dynamics. But this can also conjure a familiar scenario in which "subjects" must teach "masters" what they have had to endure in order to arrive at this moment, this dialogue. On one hand, it may seem as though the subject poised as teacher creates an opportunity for equalizing agency and power. Citing Clark and Medina, Caleb Corkery states: "Narratives by women and people of color enable readers to understand their struggle; they are a means to negotiate the process of literacy and development of identity" (52). These narratives may, however, set up an archetypal relationship in which the subject imparts knowledge unto a well-meaning master, perhaps to raise consciousness or, in some cases, to absolve responsibility for a legacy of injustice. A counter scenario to the subject as agent and actor is one in which the (well-intentioned) master is 
advantaged by acquiescing to this role reversal; the master appears altruistic for disrupting a regressive power dynamic, and is, thus, deserving of absolution from guilt.

This reversed relationship is reflected in Mary Soliday's claim that,

"students' stories of everyday life enhance their personal success as writers in the university; these stories can also deepen their teachers' understanding of difference and shape their responses to today's competing versions of multiculturalism" (522-3). But to what extent is a student responsible for or inadvertently poised to shed light on difference to their teacher-audience? When underrepresented individuals tell and retell a literacy-equals-success story, it establishes and confirms perceptions of the "model minority." The narrative upholds a minority experience that is palatable to a status quo ideology—one that may be more desirable for unproblematized public consumption. Model minority narratives fit an evangelical script in which the savior uplifts the savage, where the untamed Other moves from darkness to enlightenment. The scenario of practitioner as pedagogue, however, adds a twist to the script but only to say that the minority can occupy one of two positions: subjugated in darkness or enlightened on a pedestal.

An enriching response to this duality of darkness and enlightenment can be found in critical theories about closetedness. Darkness, traditionally characterized as "savage" ignorance, is substandard and antithetical to enlightenment, but oversimplifying an individual's experience to one of two positions eliminates the possibility of occupying, holding, and moving between so-called darkness and enlightenment at once. Polarization of this sort can oversimplify the multiple states of consciousness one might possess, making it impossible to account for savvy acts of intervention based in selfawareness and cognizance of the broader material and circumstantial realities at play. This duality plays a significant role, also, in coming out narratives, which offer strategies to rethink the oversimplification of the dark (lost) to light (found) trajectory.

\section{Coming Out Narratives and Complexities of "The Dark Closet"}

Coming out narratives exemplify, more heavy-handedly, the master narrative of darkness to enlightenment. They often share features of personal growth and the kind of personal journeying present in coming of age stories, although the focal point of coming out tends to be sexuality and gender. This genre has radically changed the political landscape for LGBTQ individuals and allies, giving voice to communities often barred from public 
involvement and cultural production. This genre has also been critiqued for sanctioning a unidirectional journey from closetedness to liberation-for producing a trajectory carrying cultural biases that permeate and shape larger scripts for social action and participation. Closetedness is stigmatized in ways that bolster the moral imperative of coming out as the most courageous, self-loving, self-actualizing, authentic, and sincere way to live. By way of comparison, literacy and coming out narratives are frequently characterized as autobiographical or personal stories based in lived experience that are carried out and presented within a public sphere. Both narrative forms are also discussed more broadly as pedagogically valuable to the authors and readers alike (Bishop; Adams).

Examining what counts as valuable, pedagogically and beyond, can reveal how certain acts of revelation become prescriptive. Coming out "moments" are commonly characterized as liberating in some way and, indeed, conflicting in others. The broader script encountered in public discourses, media sites, and certainly celebrity representations is that coming out is a necessary step toward self-acceptance and pride, which are fundamental aspects of healthy and meaningful social participation. As part of an internetbased video series called "Moral Courage," one woman, Sabrina, tells her story of coming out to extended family members who do not support her because of their cultural and religious beliefs. In the video, Sabrina reads the letter she wrote to them:

Hello Everyone! I'm writing to tell you some great news that may surprise you. I got married this past summer to an amazing woman named Shauna. I know your initial reactions may fear [sic] that something "went wrong" or I've "chosen" a bad path ... I promise you that I've been gay since I've been Bina. I would be happy to answer any questions about it. All of my love and best wishes for the holidays . . . Yours, Bina. (Jalees)

As this narrative demonstrates, the very idea of coming out hinges upon language acquisition (self-identifying) and language sharing (identifying oneself before a public body). Some writers have identified the presence of languages that offer no direct translation for coming out, and so for some individuals, the act of coming out itself becomes enmeshed in dominant practices and ethnocentric cultural values. In "A Lecture on Woman-woman Love and Sexuality in the Arabo-Islamic Middle East," Samar Habib describes the contested nature of similar claims about the cultural specificity of coming out: "I also know that some Arab lesbians see coming out as a Western strategy and we don't have to come out in order to be free because our com- 
munities differ from those in the West," and she adds, "I cannot say I agree with this strategy of duality" (13). The subtext of Habib's observation may be that coming out is not a holistically desired or singularly identifiable concept but has been packaged and branded in dogmatic ways.

Lies Xhonneux agrees that coming out narratives make a significant contribution "to the construction of non-heterosexual identities." She argues that writers such as Audre Lorde, who "shows the limits of privileging visibility" (98), demonstrate, also, that one can "use non-linear structures that play around with chronology" (99) in their autobiographical narratives. Xhonneux analyzes diverse and nuanced ways in which coming out can take shape, and points to instances in which these narratives go beyond merely reporting on one's already formed sexual identity (96). I would argue for the likely existence of adjacent or counter-coming out narratives in which the writer's messages may defamiliarize the act of disclosure: You can't know the space of my closet. You don't see it and you are not invited to see it, and thus, you can't know what 'closet' means to me. Because classic versions of coming out stories are affirmed as the default script for self-love and validation, they displace other possibilities from a more public gaze. But research that investigates the abstract space of the closet as a site of active rather than passive occurrences offers insight into the literacy narratives that circulate in our field.

While literacy narratives are often said to provide writers with opportunities for self-exploration and discovery, I have pointed to instances in which they may take a pedagogical twist in that they (problematically) enable the teacher-audience to explore and discover facets of "difference" and Otherness. In a parallel manner, coming out narratives are commonly described as a site from which storytellers explain or articulate what they have explored and discovered before an audience. Prior to reading her letter in the video, Sabrina describes the order in which she comes out to her immediate family, telling her mother first because she is concerned that her father may not be as accepting. Sabrina then explains the sadness she feels while keeping her sexuality a secret from extended family members. After the letter is sent, she describes responses from relatives expressing displeasure and rejection, but at the end of the video, Sabrina recounts the story of one cousin who apologizes for having reacted so adversely. It turns out that this cousin is later able to support a friend who has also come out, and Sabrina has "taught him something that no one else in the family could have taught him" (Jalees).

There is a moral imperative in this video; by coming out, Sabrina fulfills (or performs fulfillment of) a social responsibility, which positively affects 
the lives of her cousin and his friend. Within broader discussions, the topic of coming out to oneself does exist, but this is typically regarded as a step taken toward coming out more publicly, that is, coming out to others as a way to complete the task more meaningfully. Bishop's research promotes literacy narratives as opportunities for writers to engage in critique, exploration, understanding, and self-reflective study, which may serve an end goal. Writers can work toward this goal, accomplish it, and set it to rest. In contrast, Tony E. Adams explains that, "If coming out of the closet is predicated on disclosing . . . attraction and/or . . . identity, then a person who does not know what this attraction is or what these identities are cannot come out [emphasis in the original]" (44). To clarify, Adams adds: "A person must thus be aware of and have the ability to describe attraction ... and, consequently, to understand what the closet and coming out might mean" (44). ${ }^{1}$ This is not to say that authors of coming out narratives are not making personal discoveries as they write. It is the extension of this idea, that coming out invariably makes a social impact, that is worth examining, for it positions the audience or consumer as an important consideration to the storyteller. There is a pedagogical twist implicitly taking place here, too, which in and of itself might not be problematic. The question lies in how the act of coming out becomes singularized and prescribed as a moral imperative within a broader social context.

Coming out stories also raise questions about consent, disclosure, and revelation. In his book, Narrating the Closet, Adams explains that "in order to 'come out' one must first somehow 'go in'” (21). He brings attention to the temporality of this movement or transaction, and as Eve Sedgwick points out, the closet, or more specifically, the perceived silence of the closet is worth examining: "'Closetedness' itself is a performance” and it exists in "a silence that accrues particularity by fits and starts" (3). Closetedness functions in contrast to the cacophony around it, and thus, is an active space where a complex set of choices and reflections might be taking place. These choices include whether or when to come out, stay in, or examine how one arrived there to begin with. For Steven Seidman, the closet is not a space in which "passive victims" are created, but instead, "closeted individuals remain active, deliberate agents" who "make decisions about their lives" and "forge meaningful social ties," among other things (30-31). The closet often conjures a symbolic space of silence and darkness, but activity can take place in dark silence, even if it is indiscernible to an outside spectator or audience. A fundamental question I would add here is who determines and defines darkness/silence. Seidman suggests that "it 
is perhaps more correct to speak of multiple closets" considering that the experience of closetedness "may vary considerably depending on factors such as age, class, gender, race, ability, region, religion, and nationality" (31). Referring to the closet as a singular object reifies an already limited view of what it means to come out. The closet is not merely some "neutral" vessel from and to which bodies move, for as Sedgwick explains, "in the vicinity of the closet, even what counts as a speech act is problematized on a perfectly routine basis" (3).

More literally, the closet can be a site of storage for artifacts intended to costume or cloak one's body, which can further disrupt perceptions of closetedness and disclosure as singular or universal experiences. Cloaking, masquerade, silence, and darkness have vexed feminist debates on the practices of veiling and cloistering, debates that have also hinged upon colonial images of dark, oppressed subjects and enlightened, liberated saviors. These images have been contested within postcolonial feminist theories, and not unlike the closet, veiling (and cloistering) practices require a close consideration about issues of agency and choice. Homa Hoodfar's work describes the veil's dual resistance for Iranian women: When it was outlawed "many women...put on the veil and symbolically rejected the state-sponsored gender ideology," but later under Islamic law "compulsory veiling" was met with "stiff resistance from women (including some veiled women) on the grounds that such a law compromised their democratic rights" (265). Hoodfar's analysis underscores tendencies to dichotomize agency and victimization. Along similar lines, Trinh T. Minh-ha writes, "if the act of unveiling has a liberating potential, so does the act of veiling" (216). These points can be applied to images of the dark closet, and perhaps more pointedly, to broadstroke discussions of literacy acquisition, coming out, and coming to a place of reflection, retrospection, and critical consciousness.

To be clear, I am not suggesting that any version of closetedness is preferable to any version of coming out. I am, firstly, arguing that multiple versions of both closetedness and coming out do exist, and secondly, cautioning against privileging certain practices at the expense or exclusion of others. Coming out stories also contain layered narratives that are worth analyzing. According to Pamela Caughie's work from over a decade ago: "Coming out is only the latest in a series of metaphors for the disclosure of the self. Getting personal, breaking silence, speaking up, coming out-these are the moral imperatives of our postmodern age" (246). Literacy narratives, then, share with coming out stories a sense of movement or progression from darkness and silence toward enlightenment and insight, but they can 
also work to dismantle the notion that this brand or version of movement is the only marker of progress.

\section{The Storyteller-Subject as Object}

The "progression" from darkness to enlightenment and closeted to out manifests in the broader discussions of literacy and coming out narratives, and I argue that this concept of progression is not necessarily germane to storyteller-subjects' experiences. It is a construction that is imposed upon and internalized by the subject, but in the broader discussions of these texts, the process of internalization can become distorted by projections of life events as distinct objects of study. Popularized ideas of what makes or marks iconic life events often overwrite and obscure how these events are actually being experienced, which enables inaccurate determinations about progress. Indeed, perceiving literacy narratives as holistically transformative and emancipatory to the lives of students (as well as teachers) is markedly different from critically considering what students can learn and transfer from working with these texts. The trouble lies in holding unexamined and predetermined images of life-altering events, situations, and circumstances then either expecting or explicitly demanding that these images shape the narrative structure in question. Such expectations and demands can be observed whenever prominent public figures come out but also within assignments that ask students to compose their own literacy narratives.

Some research paints a detailed and calculated picture of how students can and do meet the objectives of literacy narrative assignments. The objectives are spelled out, giving readers a clearer sense of what is being measured, how, and why. This research posits literacy narratives as artifacts that reveal complex, nuanced sub-narratives while telling a seemingly unidirectional story about the processes involved in acquiring language. Beth Daniell identifies these nuances as "little narratives" that exist within the larger scope of the text, and Kara Poe Alexander categorizes and names more specific little narratives in her qualitative analysis of student writing.

Daniell's work distinguishes between what she calls the "grand" and "little" narratives of literacy. Grand narratives reflect the overarching parables that tell us reading and writing are good, important skills that lead to personal betterment. There is an expectation (both tacit and explicit) that the grand narrative will construct a happy ending, a feel good lesson about the transformative power of literacy. What has shifted in our research over time is a willingness to acknowledge (and even endorse) little narratives that 
complicate this feel-good lesson. According to Daniell, little narratives are useful for examining the specific ways in which literacy plays out: "Taken as a whole, the little narratives argue ... that the relationship between literacy and oppression or freedom is rarely as simple as we have thought" (403). Daniell's point is exemplified in Narrative of the Life of Frederick Douglass. The slave's reading lessons posed a profound threat to Mr. Auld, who upon discovering what was taking place "forbade" further instruction on the premises stating "that it was unlawful, as well as unsafe, to teach a slave to read" (28-9). This moment in Douglass' account can be read as a little narrative within a much larger arc, and it is a rich site of exploration, revealing an arduous, conflicted, even painful journey toward the acquisition of reading and writing practices.

What Daniell's separation of grand and little narratives demonstrates is that by focusing primarily on the overarching benefits of literacy, readers risk overlooking or silencing underlying stories that are also important. I believe this has created a heightened consideration within discussions of literacy narratives especially in the basic writing context, one that allows and advocates closer attention to what students, who are underrepresented and already politicized as basic writers in the classroom space, might be complicating or resisting in their work. The presence of little narratives poses a challenge (within both assigned student writing and published texts) at two access points: First, that momentous, life-changing instances are recognizable, and second, that recognizable instances are the only or most important markers of the story being told. These little narratives can also make critical interventions in basic writing as a classification and basic writers as an institutionally sanctioned label.

More recently, Kara Poe Alexander's qualitative study presented a coded analysis of the more artful, critical, and nuanced little narratives students produce: the Success, Hero, Child Prodigy, Literacy Winner, Victim, Outsider, and Rebel narratives (608). Alexander confirms that the "literacy-equalssuccess" story operates as a common master (or grand) narrative, but these complex little narratives play an unmistakably important role within this larger framework. This is not to say that little narratives always or inherently complicate the glossy, romantic ideals of grand narratives, but literacy narratives can and are being read "for" a more complicated set of end goals within the scope of our broader discussions. Eldred and Mortensen originally propose "reading for" literacy narratives as a means of "studying the ways they interact and compete with other generic forms" (530). It is possible to examine a text that does not focus primarily on a character's experiences 
with literacy, schooling, and language acquisition and "read for" the literacy narrative threads woven into the fabric of the larger story. "Reading for" literacy narratives enables audiences to see how these threads form a subplot of their own. Eldred and Mortensen posit "reading for" as a useful strategy given the ubiquitous presence of literacy narratives within other kinds of texts: "For example, literacy narratives play an important part in coming of age fictions that chronicle, among other things, a character's movement into multiple literacies" (530).

I would argue that this practice of "reading for" has (inadvertently) been applied to the assessment of literacy narratives in the context of basic writing. For instance, after carefully considering and reading for the applications and outcomes of literacy narrative assignments in their basic writing program, Anne-Marie Hall and Christopher Minnix test, with successful outcomes, a revised pedagogical approach to using literacy narratives that emphasizes attention to sequence, recursivity, and continuity throughout the duration of the course. They conclude that this revised approach is helpful to students in "bridging the gap between the different rhetorical contexts," "enhancing transfer" and "meta-awareness" of the writing practices they have undertaken throughout the semester (74-76). Hall and Minnix advocate and model using these assignments to achieve clear goals that promote recursive and reflective writing; they read their students' writing samples for the ways in which they meet these broader course and programmatic objectives.

Discussions of literacy narratives that emphasize reflection on iconic life events as the primary object of study raise questions about agency, consent, and the extent to which a storyteller-subject's life becomes objectified by readers. These questions are manifested in direct or indirect references to home and culture. For example, Corkery, citing Clark and Medina, writes: "Reading a text as a literacy narrative, the reader engages in the character's process of developing an identity and becoming literate" (52). I question if and how discussions of literacy narratives might unintentionally "read for" clues about the storyteller-subject's identity, in ways that enable generalizations about home and its relationship to school. According to Corkery, "Narrative genres in general offer students channels by which to import the meanings of their home cultures into the classroom" (50). The question lies in how home is being read and discussed; can readers be too cautious of exoticizing underrepresented students or their constructions of life experiences in public and private spheres? I would argue that there are unknowable performances taking place, which may muddy the goals 
storyteller-subjects appear to have internalized, but within theoretical discussions, the values expressed in the narratives can become conflated with those the storytellers hold.

This conflated perception of storyteller as object drives discussions of coming out narratives, and we bear witness to it whenever celebrities' stories circulate in the media. The agency within a public coming out is presented as the storyteller's although it seems to lie with the audience. This is to say that when a celebrity discusses a detail about their life that identifies them on an LGBTQ spectrum, the detail or moment gets constructed as a public coming out, even if they were not in to begin with. In other words, it is possible that the individual has not been harboring an identity in secret, but through a casual remark, the public becomes suddenly privy to this aspect of the subject's life and marks it as a coming out act. What often ensues is an oversimplified discussion that typifies the individual as ambassador for pride, living "in truth," an example-setter for those who are living in the closet. The in versus out binary, as I have already pointed out, is in many cases more complex than a set of two states of being. One can occupy and move between inness and outness, for these are not rigid, fixed or innately dichotomous experiences. It often takes effort to depolarize these terms given the ubiquitous desire to pathologize the former and celebrate the latter. Nevertheless, it is possible to hold multiple positions at once, as a response to material, circumstantial realities or to satisfy other pressures, demands, conveniences, and rebellious or even pleasurable yearnings. Thus, the broader discussions about public coming out narratives can afford to reflect these complexities rather than overgeneralizing them, particularly in terms of how these acts of coming out become affixed as moral declarations.

The pressure to make declarative statements (moral or otherwise) in the context of literacy narratives may result, in part, from the conventions assigned in narrative-composing exercises. For instance, the Norton Field Guide to Writing offers a list of instructions that circulates online: "You need to make clear the ways in which any event you are writing about is significant for you now ... How did it change or otherwise affect you?" ("Writing a Literacy Narrative"). Images of a transformative literacy that gets attached to specific life events can reflect a context in which literacy alters or affixes itself to one's identity; a person becomes literate or is literate. Literacy is constructed as an aspect of one's very being.

The Norton Field Guide's emphasis on change and effects may exemplify what Eldred and Mortensen have cautioned with regards to "the cultural literacy movement": That it "is a conspiracy to co-opt the students for the 
purpose of training them to reproduce efficiently and unquestioningly the dominant ideology" (516). Encouraging students to identify pivotal life events may not be the problem itself, but holding predetermined ideas of what counts as pivotal or iconic, then affixing these images to the writer closes down unanticipated possibilities and erases a lived diversity of experience. In place of these practices, I argue that a rhetorical shift toward reading literacy narratives as or "for" texts in which the subject-storyteller performs little narratives (such as prodigy, hero, victim and the like) may lead to enriching responses to grand or master narratives.

\section{Reading Performance to Rethink Perspective}

Alexander's study illustrates that students are equipped with various sets of choices as they write. The extent to which students are conscious of these choices may be unknowable to readers, but that there are various possibilities is itself significant. I propose that these unknowable choices form "uncodable" narratives, little narratives that might operate within or beyond the category, "Other," included in Alexander's coding schema (608). There may be an important link between what is uncodable and the performative functions of literacy narratives.

Discussions that endorse literacy narratives as pedagogically transformative tend to imagine the classroom as a space in which underrepresented students are invited and encouraged to tell their stories (Soliday, Bishop Dunbar-Odom). It is, of course, possible that for some students, writing a literacy narrative may be an act of insurrection or a chance to control their own story, perhaps to dispel assumptions or to join an academic conversation and participate in a meaningful way. Pedagogues can and have certainly read students' narratives in this way, particularly in basic writing courses where students are institutionally positioned in the margins of such academic conversations. So, perhaps, these interpretations can open to additional possibilities in which, for example, students perform uncodable choices.

One such performance might involve students taking literacy narratives as an opportunity to invoke sympathy, an exercise in crafting pathos in which they are pleased to have a captive audience of peers and instructors. In this instance, what is taking place is a "consensual outing" of sorts, where students consider their audience and make strategic choices about what to say and how to say it to readers who are poised to listen. For Corkery, "assigning literacy narratives requires revealing only those aspects of their students' lives that are relevant to the course" (50). Students perform consent; thus, 
reading personal "revelations" as a performance might more easily elicit a scenario in which the performance (rather than the storyteller) becomes the object of study.

Readers may also invite a slightly more nuanced approach, one in which some students use the narrative as an occasion to downplay so-called difference. The goal here would be to disrupt assumptions that underrepresented students inevitably struggle with language acquisition. Students may seize the narrative an opportunity for savvy intervention, performing a literacy-equals-success story that assimilates their experience into more dominant images of schooling and education. They might employ master narratives of darkness to enlightenment as a performative strategy in order to coast under the radar or "pass" as upholding a belief in the romance of literacy.

Additionally, students with complex understandings of how marginalized status operates may appropriate tropes of darkness to enlightenment as a cunning, satirical act. In class discussions, my students sometimes admit to accomplishing versions of this: A former student once confessed to having written an assignment for a previous class in which he talked elaborately of his experiences in prison. These experiences were fictional, and he justified passing them off as "true" by explaining he knew the professor assumed Black men were criminals, so "why not give him the story he would expect-something he could tell his wife over dinner behind locked doors." The student was not only aware of his audience in this situation but was able to respond with what he took to be subtle ridicule directed at a racist insult. He expressed a sense of reprisal, and what made his action even sweeter was that this intervention could go unnoticed and therefore unpunished if it were to be (unfairly) ill-perceived.

The choice this student made functions as a rhetorical masquerade; it demonstrates a critical awareness of status quo attitudes and perceptions. ${ }^{2}$ When students perform satire like this, they consent to a sometimes farcical, absurd, fictional, perhaps even humiliating account. After all, the joke is theoretically on the audience not the author. On the other hand, some students feel that it is insincere to approach writing with satire so they choose not to employ this tactic themselves. But to consider these behind-the-scenes narrative choices as performative acts can redirect broader discussions that characterize the storyteller-subject as object of analysis and place greater emphasis on the performance itself.

What I am describing is merely an abbreviated list of choices students have at their disposal when writing. The pedagogical goal is neither to con- 
struct students as hapless victims nor fetishize their sense of agency. Nor do I think it is productive to engage in a guessing game, for we cannot know what we do not know about students' behind-the-scenes intentions, particularly since a common outcome of literacy narratives is to "treat the acquisition of school literacy as a goal, if not a triumph" (Corkery 60). We are working within an educational framework that inevitably sets certain parameters around student agency, so a literacy narrative writing assignment may not be as emancipatory or even as enlightening as is often discussed. But one useful approach might be to acknowledge, more deliberately, the uncodable choices that shape the text as a whole and address pedagogical expectations. Pedagogues can use students' sample narratives to gain insight into the ways in which the assignment guidelines are composed and presented.

\section{Performance in a Basic Writing Context}

Reconsidering the usefulness of literacy narrative assignments in basic writing curricula can redefine perceptions of student agency. More precisely, emphasis on performance, whether through costuming, masquerade, or any calculated expression, can bolster students' choices. Basic writing students composing literacy narratives might seize the opportunity to perform a response to the grand and little narratives often expected from them as well as predetermined attitudes and perceptions of basic writing status itself. This may sound more ambitious than it actually is, for students are already making strategic calculations as they write. According to Mary Louise BuleyMeissner, student writers may rely on "popular wisdom and generalizations" not necessarily from a place of insincerity but rather as a way to craft an argument that will be convincing to their audience. In this pursuit, student writers “are likely to be more concerned with affirming their readers' beliefs than with presenting their own" (49). Playing to an audience's desires can be a profoundly useful skill. And without doubt, a student's ability to do this may be their key to success in a system where they are earning a grade.

Reflection is not only a private or closeted matter. For instance, Sommers identifies the ways in which reflection is a "public act," that there is a chance students are communicating what they think the instructor would "want to hear" (100 and 117). Sommers acknowledges this as a reality that can still enable productive engagement in composition practices. Considering writing decisions as performative acts might offer insights into the imperatives of assignment guidelines and, in particular, how these guidelines intersect and shape the student writing we read, assess, and discuss. 
It is important to note that performance does not imply artifice or dishonesty, but it allows for both as strategic tools. I would argue that literacy narratives (like other forms of autobiographical writing) can emerge as or create a fiction. Dorothy Allison describes the production of autobiographical fiction stating, "I'm a storyteller. I'll work to make you believe me ... I know the use of fiction in a world of hard truth, the way fiction can be a harder piece of truth" (3). The "harder truth" has a least two implications: It invites and challenges writers to embroider life events as a narrative craft, but just as importantly, it challenges readers to (re)consider any impulse to conflate, and then make essentialist determinations about, the story as it is performed and the reality as it is lived. A productive goal might be to reconsider distinctions between truth and fiction and examine how literacy narratives occupy a space where such distinctions are indeed blurred. Challenging truth versus fiction binaries and considering how one crafts or performs fictions might intervene in discussions that characterize storytellers as objects of study by demanding attention on the narrative itself. At present, there is little if any theory that regards and analyzes the literacy narratives students produce as a kind of fiction. But if students are being given narrative prompts and parameters, such as those listed in the Norton Field Guide, then it would be a valuable practice to interrogate the ways in which writers can and will bend, adjust, and manipulate stories to fill the narrative mold.

It might also be valuable to pair the literacy narrative assignments we give students (be it analyzing published texts or requiring students to write their own) with a theoretical framework for understanding performance. One possible starting point might be Judith Butler's work on performativity, in which she claims that

acts, gestures, and desire produce the effect of an internal core or substance, but produce this on the surface of the body, through the play of signifying absences that suggest, but never reveal, the organizing principle of identity as a cause. Such acts, gestures, enactments, generally construed, are performative in the sense that the essence or identity that they otherwise purport to express are fabrications manufactured and sustained through corporeal signs and other discursive means. (173, emphasis in the original)

This work may be useful for untangling what students writers choose to (re) present in their narratives from a perceived "core" identity or "authentic" experience. By emphasizing and interrogating narratives as performative acts, students and teachers can consider the conditions under which writers choose to (re)present certain experiences over others. It provides more 
opportunities to reflect upon the impulse to read these (re)presentations as enmeshed with one's "essence"; it demands that we get more comfortable with fictions and the unknowable circumstances basic writers may face.

\section{Conclusion}

There are several implications for placing literacy narratives and coming out narratives in conversation: First, this work illuminates how audience expectations, desires, and demands drive perceptions of literacy narratives as transformative texts. It also reveals the ways in which these perceptions rely on dichotomizing tropes. Identifying these tropes helps us call into question the function and purpose of assigning literacy narratives, asking more specifically, whether (and which) teachers and students truly benefit in learning about "difference," Otherness, and experiences of underrepresented individuals. The value in interrogating beliefs about what these narratives can do invites opportunities to reflect on the influence audiences have on the genre itself: The sometimes problematic, exoticizing, and unidirectional ways in which literacy narratives are read. Such interrogation is necessary. It clarifies that literacy narratives are not divorced from social, ideological, and epistemological realities. It also encourages audiences to engage with these texts while sustaining self-reflective awareness of the parameter and molds through which we read.

Likewise, a close examination of disclosure and coming out magnifies a collective impulse to prescribe and privilege familiar demonstrations of progress over other possibilities. Analyzing the arcs that dominate coming out stories poses a challenge to storytellers and audiences; it necessitates considerations of the unfamiliar, uncodable, little but equally important narratives being shared. By considering the performative functions of literacy narratives, students and teachers have additional choices for how to read and write these texts. Students may feel more adept at playing to pressures of convention if and when they make direct choices about how to intervene, resist, satisfy, satirize, or evade such demands. Of equal importance, performance becomes a tool for leveling or renegotiating an uneven playing field - one in which readers cannot gloss over the multiple or intersecting identities present on the pages of a narrative and in the unknowable, uncodable, behind-the-scenes space. 


\section{Acknowledgements}

This article received support from the Research Foundation of CUNY/ PSC-CUNY Research Award Program.

\section{Notes}

1. The ideas presented in this book are focused on the terms "same-sex attraction" and "LGBQ" identity, an acronym that appears to exclude discussions of transgender and gender-nonconforming experiences and identities.

2. This point is also raised in Pratt's "Arts of the Contact Zone"; autoethnography offers a way to respond critically to constructions of oneself in mainstream culture.

\section{Works Cited}

Adams, Tony E. Narrating the Closet. Walnut Creek: Left Coast Press, 2011. Print.

Alexander, Kara Poe. "Successes, Victims, and Prodigies: 'Master' and 'Little' Cultural Narratives in the Literacy Narrative Genre." College Composition and Communication 62.4 (2011): 608-33. Print.

Allison, Dorothy. Two Or Three Things I Know For Sure. New York: Plume, 1995. Print.

Anzaldúa, Gloria. "Beyond Traditional Notions of Identity." Readings in Feminist Rhetorical Theory. Eds. Karen A. Foss, Sonja K. Foss, and Cindy L. Griffin. Thousand Oaks: Sage Publications, 2004. 100-104. Print.

-----. Borderlands La Frontera: The New Mestiza. San Francisco: Aunt Lute Books, 1999. Print.

-----. "Speaking in Tongues: A Letter to 3rd World Women Writers." Readings in Feminist Rhetorical Theory. Eds. Karen A. Foss, Sonja K. Foss, and Cindy L. Griffin. Thousand Oaks: Sage Publications, 2004. 75-84. Print. Bishop, Wendy. "The (Reading) Literacy Narrative." The Subject is Reading. Portsmouth: Boynton/Cook, 2000. 65-76. Print.

Buley-Meissner, Mary Louise. "Rhetorics of the Self." Journal of Education 172.1 (1990): 47-64. Print.

Butler, Judith. Gender Trouble. London: Routlege, 1990. Print.

Caughie, Pamela L. Passing and Pedagogy. Urbana: University of Illinois Press, 1999. Print.

Clarke, Caroline, and Carmen Medina. "How Reading and Writing Literacy Narratives Affect Preservice Teachers' Understandings of Literacy, Pedagogy, and Multiculturalism." Journal of Teacher Education 51.1 (2000): 
63-76. Web. 9 Sept. 2013.

Corkery, Caleb. “Literacy Narratives and Confidence Building in the Writing Classroom." Journal of Basic Writing 24.1 (2005): 48-67. Print.

Daniell, Beth. "Narratives of Literacy: Connecting Composition to Culture." College Composition and Communication 50.3 (1999): 393-410. Print.

Douglass, Frederick. Narrative of the Life of Frederick Douglass, an American Slave. New York: Penguin Books, 1988. Print.

Dunbar-Odom, Donna. Defying the Odds. Albany: State University of New York Press, 2007. Print.

Eldred, Janet Carey, and Peter Mortensen. "Reading Literacy Narratives." College English 54.5 (1992): 512-39. Print.

Habib, Samar. Arabo-Islamic Texts on Female Homosexuality 850-1780 A.D. Youngstown: Teneo, 2009. Print.

Hall, Anne-Marie, and Christopher Minnix. "Beyond the Bridge Metaphor: Rethinking the Place of the Literacy Narrative in the Basic Writing Curriculum." Journal of Basic Writing 31.2 (2012): 57-82. Print.

Hoodfar, Homa. "The Veil in Their Minds and on Our Heads: Veiling Practices and Muslim Women." The Politics of Culture in the Shadow of Capital. Eds. Lisa Lowe and David Lloyd. Durham, NC: Duke UP, 1997. 248-79. Print. Jalees, Sabrina. "I came out and my Muslim dad stood by me." Moral Courage Channel. YouTube, 18 Nov. 2014. Web. 17 Jan. 2015.

Karls, Nancy Linh. "Pilgrims' progress: The circulation of literacy narratives in composition studies." Diss. The University of Wisconsin - Milwaukee, 2001. Dissertations \& Theses @ University of Wisconsin Milwaukee. ProQuest. UWM Golda Meir Library. Web. 9 Jun. 2009.

Pratt, Mary Louise. “Arts of the Contact Zone." Profession 9.1 New York: MLA, 1991. 33-40. Print.

Rodriguez, Richard. Hunger of Memory: The Education of Richard Rodriguez. New York: Bantam, 1982. Print.

Scott, J. Blake. "The Literacy Narrative as Production Pedagogy in the Composition Classroom." Teaching English in the Two Year College 24.2 (1997): 108-17. Web. 9 Sept. 2013.

Sedgwick, Eve Kosofsky. "Epistemology of the Closet." The Lesbian and Gay Studies Reader. Eds. Henry Abelove, Michele Aina Barale, and David M. Halperin. New York: Routledge, 1993. 45-61. Print.

Seidman, Steven. Beyond the Closet. London: Routledge, 2002. Print.

Soliday, Mary. "Translating Self and Difference through Literacy Narratives.” College English 56.5 (1994): 511-26. Print.

Sommers, Jeff. "Reflection Revisited: The Class Collage." Journal of Basic 
Writing 30.1 (2011): 99-129. Print.

Sycamore, Mattilda Bernstein. That's Revolting: Queer Strategies for Resisting Assimilation. Brooklyn: Soft Skull Press, 2004. Print.

Trinh T, Minh-ha. "Not You/Like You." Readings in Feminist Rhetorical Theory. Eds. Karen A. Foss, Sonja K. Foss, and Cindy L. Griffin. Thousand Oaks: Sage Publications, 2004. 215-19. Print.

"Writing a Literacy Narrative." The Norton Field Guide to Writing. W. W. Norton and Company, 2005-2013. Web. 12 Apr. 2013.

Xhonneux, Lies. "The Classic Coming Out Novel: Unacknowledged Challenges to the Heterosexual Mainstream." College Literature 39.1 (2012): 94-118. Print.

Young, Morris. Minor Re/Visions: Asian American Literacy Narratives as a Rhetoric of Citizenship. Carbondale: Southern Illinois University Press, 2004. Print. 


\title{
iBooks Portfolios: Interface,
}

\section{Audiences, and the Making of Online Identities}

\author{
Thomas Peele and Melissa Antinori
}

\begin{abstract}
In this article, we describe a pilot ePortfolio initiative in which we asked students to turn their end-of-semester writing portfolios into iBooks, a project that grew out of our university's policy of giving an iPad to every incoming student. A template-based software for creating digital books, iBooks affords students the opportunity to personalize their portfolios using the same tools available to them on social networking sites (SNSs). We conclude that while templates are limiting, the kinds of templates that students use matter a great deal. When they make their iBooks portfolios, which use the same tools as those used at social networking sites, including images, videos, and hyperlinks, students have a much greater sense of audience awareness than is evident in print-based portfolios or portfolios that are housed on learning management systems. And, just as students create and curate their identities at social networking sites, they are able to use iBooks to create one version of an academic online identity.
\end{abstract}

KEYWORDS: ePortfolios; iBooks; digital rhetoric; basic writing; identity; social networking

Working in groups over a two-week period, students share their knowledge as they build digital iBooks for their final course portfolios. They learn page layout and graphic design and make choices about fonts, complementary colors, and background images. Some students learn how to apply cascading style sheets to make sweeping changes to their books; others embed videos that are designed to play at strategic moments. Images (both original and found) complement the texts, and hyperlinks connect the portfolio to and situate it within a web of knowledge. When their iBooks are complete, students submit their portfolios by email and share their work with their classmates by syncing their iPads to the class laptops. ${ }^{1}$ These students are basic writers in their first or second semester college composition courses.

Thomas Peele is Director of First-Year Writing at the City College of New York. His research interests include digital technology in the composition classroom, faculty development, and service-learning. He is currently working to introduce blended learning classes to the curriculum at CCNY and collecting 10,000 first and second drafts of student essays that will be scanned for evidence of revision. He is former WPA at Long Island University Brooklyn. Melissa Antinori is an Assistant Professor of English and the Associate Director of the LIU Brooklyn Honors College, where she is coordinating an ePortfolio initiative. Her areas of interest include technology in the composition classroom and assessment of general education. She is former Assistant Director of the Writing Program at Long Island University Brooklyn.

(C) Journal of Basic Writing, Vol. 32, No.2, 2013 
Through iBooks, the students are engaging in the literate practices of Web authoring, judiciously arranging text, image, and video to create academic online identities. ${ }^{2}$ When students make iBooks, they use the same digital literacy skills that they use on social networking sites (SNSs). Perhaps because the iBooks interface is in many ways similar to the interfaces of Facebook, Tumblr, and WordPress, students mimicked the arrangement and delivery choices that they often make on these SNSs. We also suggest that this is one reason that, in addition to collecting and reflecting on their work, students often combine the media available to them on the Web and in iBooks to develop a controlling metaphor, frequently of a journey, connected to their interests and experiences. While iBooks do not force students to choose a metaphor, the interface-chapters, introductory pages, and preformatted, adjustable spaces for pictures or videos-allows for its creation in much the same way that SNSs allow students to create online identities.

Composition scholars such as Anne Ruggles Gere, Shirley Brice Heath, and Glynda Hull have argued that we should look for connections between students' academic and home literacies. And in their work on multimodality in basic writing, Thomas Henry, Joshua Hilst, and Regina Clemens Fox emphasize the importance of building on existing knowledge for basic writing students: "Most of our digital native students will respond more favorably to our teaching strategies if we help them build on what they already know, which includes multiple ways of composing in multiple modes of communication." Multimodal composing not only builds upon already existing skills, experiences, and contexts for communication, but it also helps level the playing field between mainstream and basic writing students and among basic writing students whose print literacy skills vary widely. For students who have been placed into basic writing classes and who often feel academically marginalized as a result of this placement, the opportunity to make a digital book that draws on their knowledge of audience, technology, and social networking is very powerful.

\section{THE IPAD INITIATIVE AT LONG ISLAND UNIVERSITY, BROOKLYN: INSTITUTIONAL CONTEXT}

In 2010, Long Island University began supplying every incoming student in good financial standing with an iPad free of charge. It was at the time the largest deployment of iPads at an educational institution in the United States (Lai). This program could potentially have had an enormous impact at an institution whose mission to provide an outstanding education 
to students from all ethnicities, socioeconomic backgrounds, and levels of preparedness is often at odds with the fiscal challenges faced by both the University and its students. Part recruitment strategy, part retention effort, the iPad initiative was intended to help prepare students for $21^{\text {st }}$-century technologies and literacies.

Long Island University Brooklyn, located in Downtown Brooklyn, is one of LIU's two residential campuses (the other, LIU Post, is located in Brookville in suburban Long Island). The Brooklyn campus, which serves a population of ethnically and economically diverse, urban, mostly firstgeneration students, enrolls 7000 students annually (4200 undergraduates); the average adjusted gross family income is $\$ 45,000$; annual (2014-2015) tuition for undergraduates is $\$ 33,018$; and $88 \%$ of undergraduates receive some form of financial aid ("Long Island University" 131-32). Approximately $74 \%$ of incoming freshmen place into the basic writing sequence ("Long Island University" 42). ${ }^{3}$

Unlike those at many other institutions, the basic writing courses at LIU Brooklyn —nominally a two-semester sequence, although only about $15 \%$ are required to take the first course-carry three credits that apply towards the 128 required for graduation. As the courses meet for six hours each week (students pay an additional lab fee to cover the extra time), and instructors are credited with six workload hours, these courses are somewhat more in demand than they might be otherwise, although the classes are still largely staffed by part-time or non-tenure-track faculty. Classes are capped at 22, and, as there is no imperative from the administration that classes be full, some classes run with as few as nine or ten students.

While the University's efforts to help faculty and students integrate technology into their classes were well-intended, the administration did not secure faculty buy-in before they launched the iPad initiative. To our knowledge, no faculty were invited to participate in this decision-making process. No members of the English department faculty were asked to discuss how they might use the iPads or if they would be used at all. When the iPads arrived, faculty who received them were generally eager to put them to personal use-a valuable and necessary first step towards learning their functionality-but they were skeptical about using them in the classroom, and the lack of available training or support only increased the skepticismand resistance.

As Director and Assistant Director of our Writing Program, we launched the iBooks Portfolio Project not because we were uneasy with the print portfolios that students were writing and that we had begun to collect for 
assessment purposes, but because, relatively speaking, the University was awash in technology - and almost no one was using it. A year and a half after the start of the iPad initiative, we did not see the uptick in technology use that the University had hoped to create. Very few instructors in the English department showed students how the iPads could be used to access the library's databases or to submit work to the Writing Center for virtual conferences with tutors. No one was using any of the apps that had the potential to engage students visually in the creation of mind-maps or visual outlines. Faculty did not use them to better integrate Blackboard as a mobile learning device or to exchange essays for peer review. In other words, the list of ways in which the iPads were not being used was extensive.

There were some structural reasons for this gap. For one thing, as mentioned above, the administration that created the iPad initiative did not implement any faculty development or training programs, and instructors, many of whom held part-time appointments, were left to their own resources when it came to understanding how to use the devices in their classrooms. In addition, faculty lagged behind students in getting iPads for their own use; most full-time faculty had to wait until their computers were due to be replaced (generally once every three or four years), and most part-time faculty did not get iPads at all. Thus, early on, many of the instructors concluded that this technology was an add-on, something that the students could teach themselves how to use on their own time-or that would be one more thing to add to the list of devices, along with cell phones and laptops, that were banned from the classroom.

Students, for their part, told us that they had sold or given away their devices, or bartered them in exchange for baby-sitting services, or used them for some other purpose that provided immediate benefit. Since students were so freely disposing of their iPads, we can only assume that they were not required by faculty in any discipline, or, that if they were required, the failure to meet the requirement was inconsequential. Thus, we felt an urgent need to act, especially since our students were certainly, through some means, paying for the "free" technology and, statistically unlikely to graduate from our university, should be in a position to present their writing to other institutions in the hope of earning transfer credit. ${ }^{4}$

Our urgency also stemmed from what we were seeing in our writing classrooms. As Pamela Takayoshi and Cynthia Selfe point out, "while time marches on outside of U.S. secondary and college classrooms, while people on the Internet are exchanging texts composed of still and moving images, animations, sounds, graphics, words, and colors, inside many of 
these classrooms, students are producing essays that look much the same as those produced by their parents and grandparents" (1-2). Even in our highly unusual context in which students and some instructors were handed state-of-the-art technology for use in the classroom, almost no one was taking advantage of the opportunity. We discovered in the iPad Portfolio project that the limitations and affordances of the devices and the software provided a context in which students could, if given the chance, make use of the rhetorical skills they'd honed voluntarily on SNSs and apply those skills to their academic writing.

Writing Program Administrators' willingness to take advantage of existing technologies to support students in the face of faculty antipathy and administrative blundering might well be a hallmark of our times. In our case, the almost complete absence of faculty and student support allowed us to craft our own methods for incorporating the iPads into the curriculum. We asked ourselves how we could make the technology central to the curriculum rather than an afterthought; we wanted to use the technology in ways that would help students see its educational value. Students were already required to create end-of-term portfolios, but for a variety of reasons-including concerns about cost, access, and privacy-few of these portfolios were housed on digital platforms. The Google sites that students could create through their University accounts protected their privacy almost too well-instructors were outside the firewall and often could not easily view the portfolios-and in many ways they replicated too directly the format of the paper. As we discuss later, the Blackboard portfolio application offered so few design choices that it was little different from submitting a folder of essays via email and calling it an electronic portfolio.

The iBooks platform would provide a solution to these problems. It is free, and it could easily be loaded onto students' iPads. It requires the use of Web literacies_image, video, sound, hyperlink, and visual design—but unlike widely available Web 2.0 applications for building online portfolios, such as Google Sites, Wix and Weebly, the iBooks platform does a better job of protecting students' privacy because it does not have to be housed online to be fully functional. ${ }^{5}$ Thus, iBooks offer an intermediate space between the fully closed-off world of Blackboard and the potentially fully exposed world of other Web 2.0 applications, a space in which students can make use of the identity-building practices common to SNSs while being protected from wider scrutiny. Perhaps most importantly, iBooks Author could make the technology a central feature of the course. Since iBooks have no print cognate, the iPad could no longer be seen as an add-on. Instead, it was es- 
iBooks Portfolios: Interface, Audiences, and the Making of Online Identities

sential to completing the required portfolio. Without exception, students expanded their skill base in the service of making a portfolio for an audience that it was easy to imagine could-and sometimes did-extend beyond their instructors and their classmates.

\section{The iBooks Initiative Pilot Portfolio Project: Start Up and Early Success}

For three semesters (Spring 2013 through Spring 2014), a group of three instructors worked with us on the iBooks project, for a total of five project participants. Students were introduced to the portfolio goals early in the semester, but individual instructors were able to approach the project in a manner that suited their interests and teaching styles. The first semester, two members of the cohort required iBooks, while the other three members made them optional. In the classes in which the iBooks were optional, no more than three students in any class took on the project, leading us to conclude that while students generally found this to be a rewarding and engaging process, they were unlikely to take it on unless it was required of them and more importantly they were given ample time and support for completing their projects.

Because the templates left a space for a photograph on the cover of the book and at the beginning of each chapter, students were asked to supply a photograph, either original or from the Web. Since these were books, they also required a title. No specific instructions were provided on the kinds of titles and images that students had to provide, but students were asked to think about how these elements would complement their texts. Because the platform allowed for it, students were given the option of including videos and/or hyperlinks in their text. Most of the students in classes that required iBooks completed the portfolios with a very high level of success, as we describe later in the article.

In our assessment of the iBooks Portfolio Project, which coincided with our general Writing Program assessment in the spring of 2014, we noted two major trends. We learned in our faculty meetings and in our assessment of print-, iBook-, and Blackboard-based portfolios that students were using the iBooks portfolios not only to collect their academic work but also to add a narrative element in order to build an online academic identity. This identity was evident in the books' titles, almost all of which relied on a metaphor of students' movement through physical space, as well as chapter headings, image selection, and students' reflections on their writing. In most cases, 
the titles included references to a journey or to a climb. While some students used these metaphors to visually and textually guide their readers through their portfolios, others made explicit connections between the work they did in the class and journeys they had taken in their lives. In these examples, students equated their essays with various stages of these journeys, thereby personalizing their portfolios in ways that we did not see in Blackboard or print portfolios. In our review of portfolios from all sections of compositionboth those that were a part of the iBook Portfolio project and conventional courses-we learned that students who made iBooks used the same strategies for constructing identities that we all do on SNSs. Through combined images and text, students told stories about themselves and their work-that is, they framed their academic work, here their text-based essays, within a personal narrative in order to engage and enlighten their readers, both real and potential. Students who made print- or Blackboard-based portfolios, on the other hand, very rarely used a controlling metaphor or even a simple title to frame their collected work; they seemed unconcerned with guiding their readers through their portfolios, telling a coherent story about their work, or building their identities as students.

While the technology to create these digital books is beyond the means of many basic writing students and the budgets of many writing programs, we offer our example of the iBooks portfolio as one way to achieve the positive outcomes associated with ePortfolios. When students create iBooks, they participate in an economy of writing that broadens the range of semiotic resources available to them and that builds on the textual arrangement, audience awareness, and identity construction that they have developed on SNSs.

\section{Digital Portfolios, Templates, and the Construction of Online Identities}

In many ways, our experience is in keeping with substantial research that demonstrates the value of digital portfolios in mainstream composition courses, particularly as it relates to student learning, engagement, and retention (see Cambridge, Cambridge, and Yancey; Enyon; Knight, Hakel and Gromko; Enyon, Gambino, and Török). Though this work does not always specifically address basic writing students, scholarship in the field shows that the student engagement made possible through ePortfolios is evident in increased rates of student persistence and success.

The digital portfolios that these scholars describe take a variety of forms. Some of the portfolios rely heavily on templates: students have little 
to no choice at all in how their portfolios look. In other cases, students have more control over the portfolios' final presentation. In the case of iBooks, students do have considerable control over how their portfolios appear, but that control is mediated by the available templates. Those templates shape the appearance of the individual chapters - the arrangement of text, image, sound, and video-as well as the overarching idea of a book as a container. The issue of the template - the interface between the writer and the text-has been addressed by Kathleen Yancey, who has expressed concern about students' reliance on templates. Yancey argues that if students rely on templates, they "learn only to fill up those templates and fill in those electric boxes," which, she writes, in terms of intellectual work, is the "moral equivalent of the dots on a multiple choice text." Yancey is rightly concerned that if students rely on templates they "will not compose and create, making use of all the means of persuasion and all the possible resources thereto; rather, they will complete someone else's software package; they will be the invention of that package" ("Made" 320).

Given this concern about students' reliance on templates, how do we decide how much of the design responsibility lies with students and how much lies with the package itself? Although we share these concerns about the potentially coercive effects of templates, we also recognize that, pragmatically, for all but a very few students, building an online identity means creating it within the confines of templates and adapting already-existing designs to suit their purposes. Most SNSs, for example, allow minimal control over design- "Facebook blue" has become identified as a palette color-and sites like Tumblr (or even the free versions of WordPress and Google sites) have users selecting from a variety of templates that are more-or-less instantly recognizable.

We agree with Yancey that students do need to learn the technology, and they need it to learn it as a part of the broader curricular aims of the composition course. The technological aspect of the assignment cannot be added on as an after-thought but should be a central concern of the rhetorical aims of any assignment. To make the claim that the technology is unimportant to the assignment is to make the argument that the method of delivering the message is inconsequential. However, we also can think of no practical alternative to the kinds of templates that are familiar to students. From our experiences in the classroom, we have learned that students are intimidated when faced with having to manipulate templates that are more complex than the drag-and-drop interfaces of Facebook. As danah boyd has shown, millennial students are not "digital natives," and, like everyone 
else, they must learn how to manipulate complex interfaces. While we developed strategies over the three-semester project to teach students, in forty-five minutes, the basics of how to use iBooks templates, we cannot imagine having the time, in an introductory class, to teach students how to build their digital projects without relying on any pre-formatted templates. While iBooks does provide ready-made templates, we argue below that it also allows users to alter the templates much more comprehensively than the Blackboard portfolio platform (which, during this pilot program, was available as an alternative to iBooks as a digital portfolio option). Students can build significantly more nuanced, informative, and visually interesting identities on the iBooks platform.

To some extent, students are already aware of the limitations of the templates and the possibilities they afford for design and rhetorical choice. One student wrote a rhetorical analysis of her own Facebook page, which she discusses in her iBook portfolio cover letter:

My Facebook page has the same format as everyone else page, because we don't really have control of our fonts and the colors of our Facebook page. But we do however have control over our default pictures as well as our cover page. My modeling Facebook page I would have to say is because as many of you all know Facebook doesn't really give us all that freedom of changing the fonts, formats, and sizes of the page. But I however consider my page to be unique due to the reasons that I don't just only use it to communicate with my friends, families, and other modeling business. But I feel like I really do portray a lot of stuff on it.

In her reflection, the student tells us that she understands the very limited range of formatting options that Facebook makes available, but that what makes her page unique is that it is aimed at multiple audiences. Although the writer does not say who those audiences are, she makes clear that she does not use it just to communicate with her friends or family (though this audience does not seem to be excluded) but to portray an image of herself. The student demonstrates a high level of audience awareness and an understanding that she can reach that audience through the formatting available through the SNS.

Furthermore, even as Web design results more and more from preformatted templates, there are a variety of features that students do have control over in iBooks. Tiani Kennedy, a graduate teaching assistant who 
participated in the iBooks project, identified in the instructions she wrote for her students a number of choices they had to make: creating chapters, sections and pages; changing background color; adding a text box and changing the font; adding images (the students' own and from the Internet); creating hyperlinks; and adding video. Some students were able to make changes to the code. Even working within a template, then, students do have considerable control over the look and feel of their texts. A glance at images of iBook libraries on the Web shows the variety of possibilities that this platform affords students.

Templates, as interfaces that make composing possible for students with little experience with computer science, also have their defenders. Daniel Anderson, in his early work on multimedia composition, does not explicitly advocate for students' use of templates in their multimedia projects, but he does argue that a technology's simplicity is not a marker of its value: "these entry-level composers are able to create viable new media projects so it can't be argued that less functionality and more ease of use necessarily limit literacy. In fact, the relationship between complexity and literacy is fraught with tensions." He advocates teaching students how to produce entry-level new media as a method both for engaging critical thought and for demystifying, through practice, the technologies they use to receive information.

James Porter makes a similar point about "mechanical procedures" in this discussion of techne.

Rhetoric, as techne, is the art of creating discourse . . to achieve a desired end for some audience. . . . It becomes degraded when it is taught or practiced as a set of mechanical procedures, rules or formulas to be followed or patterns to be copied. It achieves status as a true art when it is taught and practiced as a form of knowledge involving a critical understanding of the purposes and effects of the art on audiences and the practical know-how to achieve those effects in new discursive situations. (210)

Like Yancey, Porter is not specific about the procedures that he references, perhaps because a too-specific definition of these procedures would limit the uses of the conceptual work he provides. For our purposes, we believe that these procedures might include teaching students to use templates, as we have done in our iBooks project, in order to the help them gain the tools to both understand the rhetorical effects of their design decisions and to conceptualize and reach their audiences. He makes the point more forcefully a 
few lines later: "I often see humanist academics committing a different kind of fallacy: dismissing technical knowledge too readily as mindless mechanics or robotic functions, failing to see the importance of technical know-how to rhetorical competency. One cannot be an effective digital writer without knowing both technical procedures and how to deploy them to achieve the desired end" (211). Porter, then, is not talking about merely teaching students how to complete templates, but rather pointing out the importance of asking them to achieve significantly more.

Part of that achievement is creating an online academic identity in addition to the social one they already have. In his study of identity formation on SNSs, José van Dijck analyzes "how the struggle between users and platforms to control online identities is played out at the level of the interface" (200). van Dijck argues that the recent changes to the Facebook interface have changed it from a database of "personal information" to a tool for "(personal) storytelling and narrative self-presentation" (200). Students use the same strategies in their constructions of iBooks. The most successful of the iBooks-those that are both most engaging to their audiences and effectively present their academic work-rely on a personal, narrative structure that was neither required nor taught. One student, an artist, created an original background image from a photograph of herself and included in her text pictures of food she ate. This background image, far from being distracting, presented the reader with multiple images of the text superimposed on an image of her face, and the food images helped her make her argument about the potential health risks a vegetarian diet might pose for women, an argument that was partially rooted in her own story of becoming a vegetarian. No attentive reader could fail to notice that this writer had taken a bold step to personalize her academic work.

Describing the timeline feature of Facebook that was introduced in 2011 and is currently still the main organizing principle of data on the site, van Dijck writes that the "most significant ordering principle of the new interface layout is a vertical bar on the right indicating a chronological order from the present to the past" (204). The timeline feature also orders previously posted material so that it's presented sequentially. The result, as van Dijck writes, is "a construction in hindsight, a retroactive ordering of life events at one moment in time" (205). Furthermore, van Dijck writes that "transforming a database into a narrative requires not only adding new data to already existing content, it also triggers a new awareness of how you want your life story told, to whom and for what purpose" (205). This audience awareness, van Dijck argues, is in part a result of Facebook users 
having to make multiple decisions about what material to make available to which audiences. Scholars such as boyd have also demonstrated the ways in which SNS users have become increasingly aware of audience concerns, but what is most compelling to us about van Dijck's work is its analysis of the Facebook's timeline feature. That the portfolios students create bear a striking resemblance to the narrative features of Facebook that van Djik describes is not entirely surprising. While the personal narrative as well as the more academically-focused literacy narrative have long been staples of basic writing classes, the added affordances of a digital platform allow students to achieve significantly more as they simultaneously develop rhetorical and technical skills in order to reflect on their progress as they tell their stories to a wider audience.

Although we did not ask these groups of students about connections between their iBooks and Facebook's arrangement, the similarity is striking. While students have always been likely to use a chronological structure in a portfolio cover letter, they were not likely to pin that chronology to a narrative structure and to use an over-arching metaphor as a framing device. In contrast to the print portfolios, which tend to have much more generic titles such as "My Portfolio," students' iBooks titles include "Many Roads," "Work in Progress," "The Sky Is the Limit," and "How I Went from Lost in Space to Forming a New Ground," to frame their portfolios. Other titles reflect on the students' self-discovery: "I Am Dedication," "You're Braver than You Believe," and "The Epiphanies of an Amateur Writer." These titles suggest that in the iBooks Portfolio Pilot project the students made use of the sense of audience that they developed on their SNSs and applied it with great success to the organization of their portfolios. One participant reports that of her 48 students, 32 had original titles, seven used the journey motif we will discuss below, and seven did not include titles on the cover page but had original titles on the internal pages (including the motif of the journey); only two used the "Name + Portfolio" formula.

As the iBook Portfolio Pilot continued, we realized that as students learned to operate the iBooks program they were using the tools familiar to them from SNS templates-design, graphics, video, sound-as a means of creating an academic online identity. In the same way that SNS users create a persona to present and interpret the events we decide are important enough to share with our social networks, students create an online identity to interpret and present their academic work to audiences that could extend beyond their instructors and their classmates.

That the template suggests or even forces a particular narrative struc- 
ture is, surely, one of the challenges to creating an online identity that concerns Yancey. While there are many concerns that we could raise in regard to this kind of identity formation, we remain aware that other templates encourage students to produce other identities. Given the same assignment in the Blackboard environment, the students do not personalize their portfolios with a narrative, and the titles revert to "Melissa's Portfolio" and the like. Students completing a Blackboard portfolio do not personalize their portfolios beyond choosing from one of the color schemes (the only real design option available) and do not include visuals, even on their landing pages, and even when instructed (how) to do so. These portfolios are virtually interchangeable; it would be almost impossible to identify the student by the design. As Yancey notes, then, the template does have an impact on the identity that the students is able to produce, but the identity that students create through a limiting application such as Blackboard is not that same as that created when faced with the challenges and opportunities available in a more comprehensive platform such as iBooks Author.

The creation of an iBook is a significant accomplishment for students. They are writing their own book and exercising substantial control of its content and appearance. They are taking what the New London Group has called the "Available Design," or the book form, and reshaping it in accordance with their own goals. The New London Group asserts that making use of the Available Design in the act of redesigning it "is never simply a repetition of the Available Designs. ... Any semiotic activity—any Designing-simultaneously works on and with these facets of Available Designs. Designing will more or less normatively reproduce, or more or less radically transform, given knowledges, social relations, and identities, depending upon the social conditions under which Designing occurs" (195-96). While students in our classes are not radically transforming the world, they are able to create new identities for themselves as students, an act that is potentially transformative for them.

\section{Close-Reading of Two Students' Portfolios}

In many ways, the two portfolios discussed here are representative of the kind of work all the project participants received from our students. The narrative theme of the journey, as we have noted, was a common one, and many students chose images that connected to one another, although most did not do so to the degree Mark and Tiffany did. ${ }^{6}$ The students appropriated the form of the chapter book to weave the texts into a meta-narrative of their 
personal journeys through composition. Their iBooks have a high degree of what Mary Hocks describes as transparency: the "ways in which online documents relate to established conventions like those of print, graphic design, film, and Web pages. The more the online document borrows from familiar conventions, the more transparent it is to the audience" (632). Mark, Tiffany and all of the other students appropriated and redesigned the book form for their own purposes (Kress). They wanted their books to look like books, and neither did anything to disrupt their readers' expectations. At the same time, the use of carefully chosen found images to create an identity, the hybridity of text and image, the textual annotations, and the links to external sites, were familiar to Mark and Tiffany, and their readers, from SNSs. As readers of SNSs, we understand that Mark and Tiffany are the subjects of the images they have chosen, even though they are not pictured in them. This, too, is a lesson gleaned from SNSs, where the found images and videos are often carefully chosen to cultivate a public image for a perceived audience.

In fact, in his response to our question about his reasons for using these images, Mark articulates his interest in representing himself to his audience. Mark notes that he "wanted to be clear about what I wanted to show the readers of this. I wanted them to be able to know that I came a long way. Then it just hit me to kind of show it in a kind of physical way. I started with the idea of that and went from there. I'm from the Middle East so I thought it would somewhat fit my personality having a desert there." Clearly, Mark is interested in making sure his audience understands both his identity and the value of the work he has accomplished. 


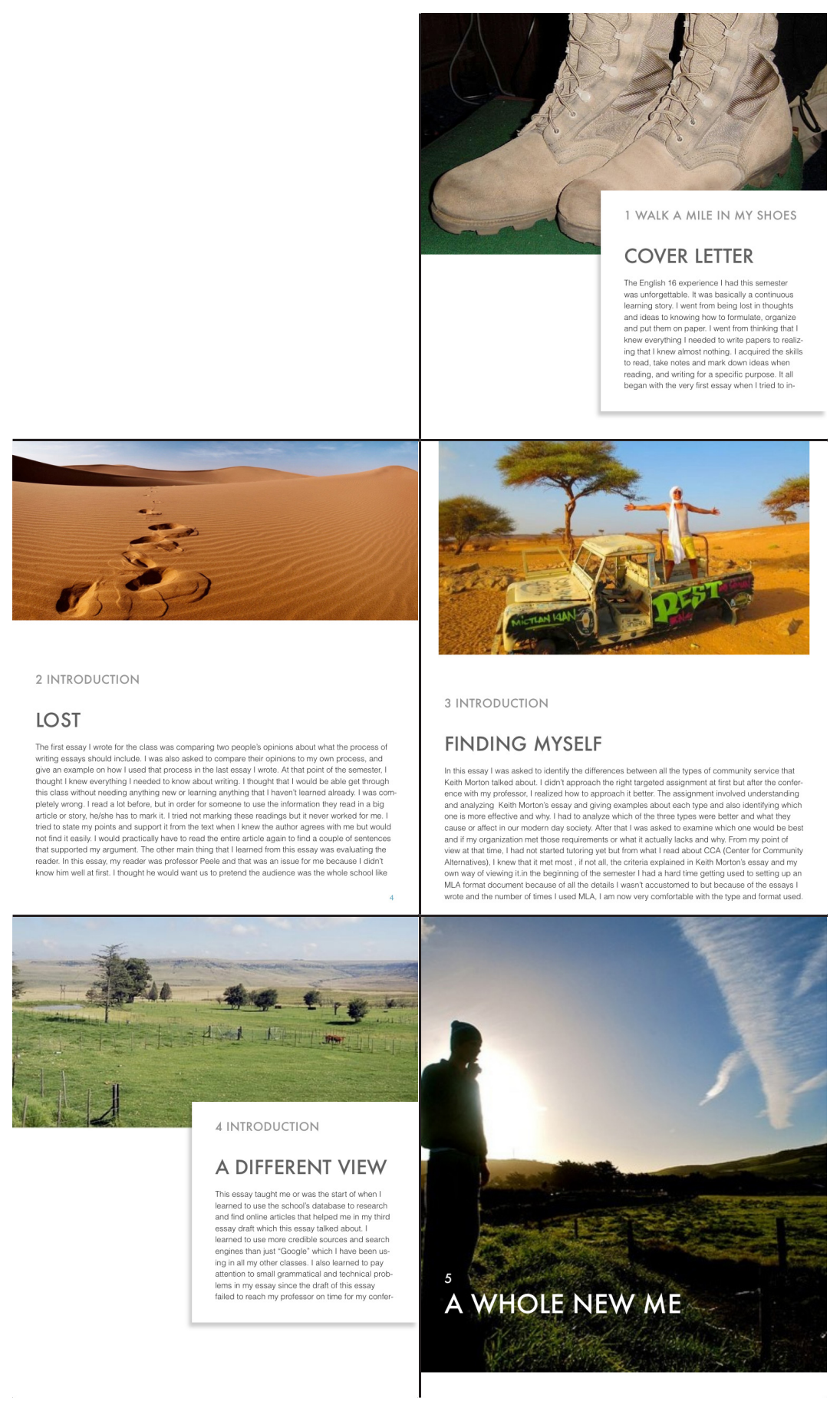


The book is entitled The Narrow Opening. On the top half of the cover, there is a photograph of what appears to be a desert with a fairly imposing rock formation. There is a hole in its center (the "narrow opening") that appears to have been created by blowing sand. The sky behind the rock formation is an almost perfectly clear blue. On the cover of his book, Mark presents an image of something that seems impossible to achieve: the carving, into intricate shapes, of rock by sand. While Mark might be suggesting that he has accomplished this task by random, repeated acts, our reading of this image is that he intends to convey to his audience that he has achieved something difficult, perhaps something that he thought was impossible. As he notes in the first paragraph of his introduction, "I acquired the skills to read, take notes and mark down ideas when reading, and writing for a specific purpose." We do not comment here on Mark's fluency with these abilities, but we do note that in his cover letter he presents himself as someone who has worked very hard. Thus, Mark sets the stage for the reader to correlate the text and the images, to see the writer in both. By using a series of images to illustrate each chapter of his book, Mark both invites the reader into the text and builds an identity using tools that are germane to SNSs.

In the first chapter, the image of a pair of well worn, military boots are juxtaposed with the phrase "Walk a Mile in My Shoes." Here, Mark invites the reader to imagine that these are the shoes that he has worn, metaphorically, through the various challenges of his composition course. Mark has made excellent use of the hybridity afforded by the digital medium. He uses the text and image to inform each other, and he uses the image to invite the reader to imagine Mark himself on a journey through the semester and to see him as the struggling author of these texts. In fact, without the image, we wonder if Mark would have used the "walk a mile" metaphor at all; as noted, certainly very few of the students submitting print or Blackboard portfolios attempted to engage their readers by establishing an identity or personal narrative in this way, as the vast majority of reflective letters in the print portfolios are eponymously titled.

Similarly, the footprints in an empty, sand-filled landscape that illustrate the next chapter, "Lost," can appear to the reader as a metaphor for Mark as he worked his way though the course. The color scheme is consistent with the opening image: sand and deep blue sky. As Mark notes in the text, "At that point of the semester [during the first assignment sequence] I thought I knew everything I needed to know about writing. I thought that I would be able get through this class without needing anything new or learning anything that I haven't learned already. I was completely wrong." Mark suc- 
cessfully combines text and image to help the reader visualize his struggle as a writer. Mark continues the visual metaphor throughout the book as the footprints lead us, in the final two chapters, to a more fertile landscape and a fully-realized figure-as Mark puts it, "a whole new me."

The images also suggest a larger narrative. Knowing that Mark is a recent immigrant from Egypt, we begin to read these images on a global level. In the "Finding Myself" image that follows the footprints in the sand, a man stands with his arms outstretched. He is wearing what appears to be a combination of Western and Middle Eastern clothing_-shorts, a tank top, and a long scarf that is wrapped around his head and neck and flows to below the cuff of his shorts. The image for the final chapter, entitled "A Whole New Me," completes the visual metaphor. In this image, the figure of a man stands at the left side the frame while the sun rises behind him. His attire is not clearly visible, but he's wearing the kind of watch-cap that's currently associated with the urban hipster. He also appears to be wearing a backpack of the kind usually worn by hikers, which is what this individual appears to be. The "narrow opening" of the cover image suggests not just the difficulties of getting through composition, but the larger difficulties of immigration.

This level of meaning is made available, at least in part, because of the affordances of iBooks. The non-iBooks academic portfolios available to our students in this pilot project called for a narrative of composition, not of one's self. SNSs, on the other hand, give us the tools to cerate an identity and to tell our personal stories-tools that students readily adapted to their basic writing portfolios. In his portfolio, Mark has superimposed a layer of meaning on top of the story that he created with his academic work. That is, he provides the reader with additional information about who he is-a struggling student, a recent immigrant-as well as specific information about the essays.

Another example illustrates the way iBooks allow students both to personalize their portfolios and demonstrate fairly sophisticated audience awareness skills. Like Mark, Tiffany personalizes her portfolio with an extended metaphor. She explains the illustrations she chose to introduce each chapter: "I decided to name my portfolio 'English Blossom'," she writes, "because of my growth. According to thefreedictionary.com blossom is a period or condition of maximum development. I feel like that describes my work perfectly because throughout the semester I've developed into a better reader and writer." While Tiffany's illustrations, like Mark's, show her growth through the course, unlike Mark's, they represent an attempt to connect the student's personal story to the content of the chapters they 
introduce. The reflective letter pictures a water lily in bloom-and reflected in the water. The photo accompanying the rhetorical analysis assignment pictures the subject of the analysis, in this case the Web site of Perez Hilton, with a carefully-selected photo showing Hilton sporting both a bright yellow flower on his lapel and a flowered handkerchief in his breast pocket and-it takes a good eye to notice it-standing against flowered wallpaper. The essay on social psychology and media shows a cartoon bird watering a flower, a somewhat more incongruous choice, although in keeping with her overall theme. The book's final image-following the last essay-is another cartoon, this one of children playing happily in a field full of flowers and perhaps representing Tiffany's joy (and relief) at having successfully completed both the course and the portfolio.

In addition to this controlling metaphor of growth, Tiffany chose to intersperse images through the essays themselves. For her rhetorical analysis of Perez Hilton's website, for example, she methodically illustrated each paragraph with the tab for the section of the site under discussion so that her reader's experience mirrored the experience of reading the site she was analyzing. The social psychology essay, an interdisciplinary paper based on a class lunch during which students were allowed to communicate only through social media, is illustrated with the corporate logos of the restaurant where we ate (the Applebee's across the street from campus) and the social media sites they used to communicate. While the discussion of the use of corporate logos is beyond the scope of this essay, we want to point out how Tiffany mimicked Facebook, where the advertisements in the sidebars bombard us with such images, making it likely that if she used Facebook to post or chat about the lunch, she had an ad for Applebee's in her newsfeed before we left the restaurant. In this case, too, the audience was invited to share her experience, including a picture of the food she ate, through techniques Tiffany learned at least in part from her experience with SNSs.

The work that students create here is a variation on the kind of work that Ben Lauren and Rich Rice describe when they write that the "photo essay can employ images to represent evocative associations or ideas students are having difficulty putting into words." In this case, as we saw above, Mark and Tiffany were able to articulate their intentions. They used images to create an identity and a personal narrative that, without digital affordances, they would not have had the means to express. Like Mark and Tiffany, the other students made use of these affordances to achieve their own rhetorical ends and to guide readers through their portfolios. While they did not ultimately write about this process, the text that they were creating-the 
portfolio-was itself a meta text. They successfully appropriated the form of the book, redesigned it for their own purposes, and brought to bear skills they learned on SNSs to reach their audiences.

\section{iBooks, Networked Writing, and Audience Awareness}

On a practical level, our project taught us several things. First, as discussed earlier, students successfully completed their iBooks when they were required-that is, when they were built into the fabric of the course. Second, access to the technology is key; our students, whose home access to hardware and the Internet is often unreliable, would not have been able to complete the project if we had not dedicated class time to it. Third, some students will be much more adept with the technology than we are. This is okay. In fact, having students discover new functionalities and then teach them to each other-and to us-increases the ownership students feel for their finished portfolios.

Our assessments of our students' iBooks led to several observations. Every student who completed this project chose a unique series of images to illustrate their texts. Similarly, students chose a wide variety of fonts, page layouts (full-page, two- and three-column layouts) and color schemes. Students who submitted Blackboard-based portfolios did not make these same choices; they arranged their portfolios following MLA format and provided them with generic titles such as "My Portfolio." In these portfolios, awareness of an audience beyond the instructor seemed non-existent. Of all of the affordances that iBooks and these other, locked platforms allow, the sense of audience that students demonstrate is perhaps the most dramatic. iBooks Author encourages students to play with their writing using a wide range of tools and to think about presentation to an audience in ways that text-only essays do not. Through the templated space of their iBooks portfolios, they create an online academic identity-an avatar of sorts-through which to present their work. This self-presentation aligns with the creation of identity experienced by users of SNSs. In this digital context, they are able to use the audience awareness that SNSs provide and apply it to their academic work.

The reasons that students have a heightened sense of audience are no doubt multiple and varied. Perhaps for basic writers, the opportunities to use images and videos to convey meaning enhances academic communication and makes them more interested in reaching an audience that is easier for them to imagine. Perhaps the change in audience awareness results in 
part from students' knowledge that documents produced to circulate on the Web function differently than texts designed to be handed to an instructor. In their study of writing in the freshman year, Nancy Sommers and Laura Saltz note that the idea "that a student might 'get something' other than a grade and that there might be a 'greater purpose in writing than completing an assignment,' represents the most significant paradigm shift of the freshman year. ... When students begin to see writing as a transaction, an exchange in which they can 'get and give,' they begin to see a larger purpose for their writing. They have their first glimmerings of audience. . ." (139). And this is true whether or not the texts actually do circulate. Abby Dubisar and Jason Palmeri, in writing about a political video remix project, argue that the students' projects need not be public, which suggests that much of the value of the project lies in the design process itself (79). And in an essay about the difficulties associated with copyright, Steven Westbrook writes about his student's multimodal production that her "text may not change the world overnight, but it has at least more potential to disrupt distributions of power within this larger publication context precisely because it can be easily circulated among masses of people" (472).

The iBooks that our students create are not intended to be subversive, nor are they necessarily intended to critique the broader culture. The similarity between these projects and those described by Dubisar, Palmeri and Westbrook is that the iBooks, though they are distributed in only limited ways to their instructors, to other students, and perhaps to friends and family, still contain the potential for much wider distribution. The texts invoke the canon of delivery and enliven the idea of audience. For these students, creating and distributing a book that looks and feels like a book challenges them, and the readers of their texts, to think differently about their identities as students and as basic writers. iBooks ask students to think more carefully about delivery and design as they move students to see writing as having value beyond the grade and classroom. iBooks offer students the opportunity to see themselves as successful writers pursuing their own goals by adapting the tools they have at hand.

\section{Notes}

1. As of 2015, the Apple operating system makes it possible for iBooks to be viewed on all Apple computers, a development that should make a project such as this one more widely accessible. 
2. We are indebted to Mary Louise Pratt for her concept of the "pedagogical arts of the contact zone," which she describes in "The Arts of the Contact Zone." Pratt argues for heterogeneous approaches to composition practices, including "exercises in storytelling and in identifying with the ideas, interests, histories, and attitudes of others; experiments in transculturation and collaborative work and in the arts of critique, parody, and comparison" (40). Pratt makes the case for a diverse, inclusive composition practice. We hope there are echoes of these values in our approaches to ePortfolios.

3. Students are placed into our remedial sequence in one of three ways: through a combination of SAT and high school GPA scores, through a pen-and-paper placement test in which students respond to an editorial, or through an online exam, called iMOAT, in which, over the course of two days, students read several editorials/articles on a topic and write a response. Students unhappy with their SAT placement may challenge it by taking the exam. Most students are placed by SAT scores; very few opt to take the iMOAT as issues of home computer access seem to make them favor the pen-and-paper option.

4. According to the Chronicle of Higher Education study on college completion, in 2013, the six-year graduation rate for LIU Brooklyn was 24.0\%; four-year rate was $8.0 \%$.

5. J.S. Dunn, Carrie Luke, and David Nassar, comparing off-the-shelf technology with the platforms they chose to use, Google Sites and Google Docs, note that although the systems they "developed may not be as comprehensive or nearly as tailored as those built from scratch, it is arguably more customized than many of the current off-the-shelf eportfolio software packages-and with minimal front-end costs, it is much more sustainable" (69).

6. Students' names have been changed; their work is used with permission and has been deemed by the institution as exempt from IRB regulations.

\section{Works Cited}

Anderson, Daniel. "Prosumer Approaches to New Media Composition: 
iBooks Portfolios: Interface, Audiences, and the Making of Online Identities

Consumption and Production in Continuum." Kairos 8.1 (2003): n. pag. Web. 6 Nov. 2013.

Bezemer, Jeff, and Gunther Kress. "Writing in Multimodal Texts: A Social Semiotic Account of Designs for Learning." Multimodal Composition: A Critical Sourcebook. Ed. Claire Lutkewitte. Boston: Bedford (2014). 233-57. Print.

boyd, danah. It's Complicated: The Social Lives of Networked Teens. Yale UP. 2014. Print.

Cambridge, Darren, Barbara Cambridge and Kathleen Yancey, eds. Electronic Portfolios 2.0: Emergent Research on Implementation and Impact. Sterling, VA: Stylus (2009). Print.

Clark, Elizabeth. "The Digital Imperative: Making the Case for a $21^{\text {st }}$-Century Pedagogy." Computers and Composition 27 (2010): 27-35. Print.

“College Completion: Who Graduates from College, Who Doesn't, and Why it Matters." Chronicle of Higher Education. Web. 23 April 2015.

Dubisar, Abby, and Jason Palmeri. "Palin/Pathos/Peter Griffin: Political Video Remix and Composition Pedagogy." Computers and Composition 27 (2010): 77-93. Print.

Dunn, J.S., Carrie Luke, and David Nassar. "Valuing the Resources of Infrastructure: Beyond From-Scratch and Off-the-Shelf Technology Options for Electronic Portfolio Assessment in First-Year Writing." Computers and Composition 30 (2013): 61-73. Print.

“English 16/16X." LIU Brooklyn. Long Island University, 2013. Web. 16 May 2014.

Enyon, Bret. "Making Connections: The LaGuardia ePortfolio.” Electronic Portfolios 2.0: Emergent Research on Implementation and Impact. Ed. Darren Cambridge et al. Sterling, VA: Stylus, 2009. 59-68. Print.

Enyon, Bret, Laura Gambino, and Judit Török. "What Difference Can ePortfolio Make? A Field Report from the Connect to Learning Project." International Journal of ePortfolio 4.1 (2014): 95-114.

Gere, Anne Ruggles. "Kitchen Tables and Rented Rooms: The Extracurriculum of Composition." College Composition and Communication 45.1 (1994): 75-92. Print.

Heath, Shirley Brice. Ways with Words: Language, Life, and Work in Communities and Classrooms. New York: Cambridge UP (1983). Print.

Henry, Thomas, Joshua Hilst, and Regina Clemens Fox. "Remembering Basic Composition: The Emergence of Multimodality in Basic Writing Studies." BWe 10.1-11.1 (2011-2012): n.pag. Web. 6 Nov. 2013.

Hocks, Mary. "Understanding Visual Rhetoric in Digital Writing Environ- 
ments." College Composition and Communication 54.4 (2003): 629-56. Print. Hull, Glynda, and Katherine Schultz, eds. School's Out:Bridging Out-of-School Literacies with Classroom Practice. New York: Teacher's College P (2002). Print.

Knight, William. E., Milton Hakel, and Mark Gromko. "The Relationship between Electronic Portfolio Participation and Student Success." Professional File 107 (2008): 1-13. Tallahassee, FL: Association for Institutional Research. Web. 2 Dec. 2013.

Lai, Eric. "Long Island University Deploys 6,000 iPads, May Double that Next Year." ZDNet. CBS Interactive. 1 December 2010. Web. 16 January 2015. Lauren, Ben, and Rich Rice. "Teaching Style in Basic Writing through Remediating Photo Essays.” BWe 10.1-11.1 (2011-2012): n.pag. Web. 6 Nov. 2013. "Long Island University Self-Study Report 2013, Submitted to the Middle States Commission on Higher Education." 2013. Print.

New London Group. "A Pedagogy of Multiliteracies: Designing Social Futures." Multimodal Composition: A Critical Sourcebook. Ed. Claire Lutkewitte. Boston: Bedford (2014): 193-217. Print.

Porter, James. "Recovering Delivery for Digital Rhetoric." Computers and Composition 26 (2009): 207-24. Print.

Pratt, Mary Louise. "The Arts of the Contact Zone." Profession 91 (1991): 33-40.

Sommers, Nancy, and Laura Saltz. "The Novice as Expert: Writing the Freshman Year.” CCC 56.1 (2004): 124-49. Print.

Takayoshi, Pamela, and Cynthia Selfe. "Thinking About Multimodality." Multimodal Composition: Resources for Teachers. Ed. Cynthia Selfe. Cresskill, NJ: Hampton: 2007. 1-12. Print.

van Dijck, José. “'You Have One Identity': Performing the Self on Facebook and LinkedIn." Media, Culture and Society 35.2 (2013): 199-215. Print.

Westbrook, Steven. "Visual Rhetoric in a Culture of Fear: Impediments to a Multimedia Production.” College English 68.5 (2006): 457-80. Print.

Yancey, Kathleen. "Electronic Portfolios a Decade into the Twenty-First Century: What We Know, What We Need to Know." Peer Review 11.1 (2009): 28-32. Print.

Yancey, Kathleen. "Made Not Only in Words: Composition in a New Key." College Composition and Communication 52.2 (2004): 297-328. Print. 


\title{
'Me/We': Building an Embodied Writing Classroom for Socially Networked, Socially Distracted Basic Writers
}

\author{
Kendra N. Bryant
}

\begin{abstract}
This article addresses the premise that twenty-first century millennial students have difficulty forming personal relationship with teachers, classmates, and within learning communities partly because their attachments to online social networking sites distract them from being present to physical classroom spaces. As a result, academic proficiencies may suffer as engagement with peers and others is curtailed. The author discusses an approach to a writing classroom that seeks to bridge students' attraction to online social networking with more relational, face-to-face classroom encounters, building a pedagogy of the embodied classroom that, as Janet Emig argues, ensures students' personal development and community-building.
\end{abstract}

KEYWORDS: embodied learning; blogging; collaboration; online social networking communities; accountability groups; millennial learners

"The embodied classroom invites students to know themselves in ways only interaction with others can provide."

Janet Emig, "Embodied Learning” (2001)

In the past ten years, our students have been thrust toward membership in online social networks such as Facebook, Twitter, and Instagram. According to Maeve Duggan and Aaron Smith from the PewResearch Internet Project, users 18-29 years old make up $87 \%$ of the Facebook population, 37\% of the Twitter population, and 53\% of the Instagram population. While these social media spaces have created platforms for boundless networking opportunities, creative musings, and fellowshipping, they are also changing how people who occupy the same physical space interact with one another. More specifically, online networks are challenging classroom teachers to rethink how learning environments work for our networked students.

Kendra N. Bryant is a poet, painter, and blogger and Assistant Professor of English at Florida A\&M University, Tallahassee. Her scholarly interests include rhetoric and composition, Black woman writers, and writing with technology. 
According to Janet Emig, who predicted “technology's inevitable dooming" fourteen years ago, composition teachers need to rethink how they will engage twenty-first century learners in a technology age that confuses the acquisition of information with the acquisition of knowledge. Although online social networks are attractive to many of us, students may have the tendency to "associate [their] computer screens and email accounts with [their] most profound experiences of community and connection" (Rushkoff 48), thus curtailing the opportunity to be in communion with real life others, which encourages a different kind of knowledge acquisition.

As critics have variably noted, participation in social media platforms may limit students' social skills, decrease their (academic) writing ability, challenge their aptitude for concentration, and shrink their knowledge base-all the while broadening their social networks, increasing their writing habits, improving their ability to multitask, and expanding their information bank. Clearly, this technology age, which has tossed us into both a social networking frenzy and an information overload, has contributed to a smorgasbord of students who "know" everything and everybody and nothing and nobody at all. Exactly what are teachers to do but meet millennial students where they are, while providing them with a classroom community that invites them to fellowship with actual others-in human interaction where, says Emig, knowing happens?

In her 2001 essay, "Embodied Learning," Emig claims that technology_particularly online distance learning communities-has the potential to prohibit twenty-first century learners from experiencing a traditional classroom environment where learning develops from interpersonal relationships. She argues that online distance learning communities will disrupt "our grounded, subtle, and complex knowledge, [because] the seductive simplicities of technological models [may] confuse the acquisition of information with the comprehension and creation of concepts" (273). In other words, similar to critics Douglas Rushkoff, Nicholas Carr, and Joseph Moxley, Emig suggests that the influx of information that the Internet and distanced communities provide users may be confused with knowledge, therefore creating a generation of students who mirror subjects of Paulo Freire's banking model of education. Basically, says Freire in his 1970 Pedagogy of the Oppressed, students engaged in a banking model of education are reduced to deposit boxes that merely receive information; they know very little about the information they have received (71-86). "Knowledge emerges only through . . . the restless, impatient, continuing, hopeful inquiry human beings pursue in the world, with the world, and with each other," says 
Freire (72). In an effort to curtail the dire consequences of distance learning that Emig anticipated, she argues for an embodied learning environment.

Emig's embodied learning environment does not necessarily reflect the embodied learning pedagogies and/or environments discussed in the more recent literature, which include social activism (Ollis); physical disabilities (Gustafson; Standal); moving bodies (Barndt; Bresler; Crawford; Maivorsdotter and Lundvall); ecocomposition (Dobrin and Weisser); and present awareness (Fleckenstein; Stolz). While both Kristie S. Fleckenstein (1999) and Steven A. Stolz (whose 2014 article is also titled "Embodied Learning") argue, like Emig, a case for "organic anchoring in the material reality of flesh" (Fleckenstein 281), neither of the two directly responds to the millennial student whose knowledge about self and others is being altered as a result of online activities. Likewise, not much of the current discourse regarding embodied learning, which ranges from discussions of physical abilities and social activism to ecocomposition and the somatic mind, specifically explores the embodied classroom as possibly "one of the last sites for socialization available in our [techno-driven] society" (279, my inclusion) - which makes Emig's embodied classroom so vital to the humanity of our current students.

According to Emig, the embodied classroom is a space where actual bodies collaborate with one another "to acknowledge human complexity, situational ambiguity, vexed, even unanswerable questions about self and society" (279). It is a space, says Emig, that "reintroduces students to the joys and inevitability of human pace [where] learning ... cannot be rushed or decreed" (280). In other words, Emig's embodied learning community, more or less, reflects a traditional learning environment where learning happens as a result of discoursing human agents, who are not online, but are sitting amongst one another, in a physical classroom. It is an educational philosophy grounded in theories as old as Socrates, Parker Palmer, and John Dewey and, indeed, supported by recent notions regarding ecocomposition, social activism, and the permeable mind and body.

Fortunately, while since 2001 there has been a surge in internet use, an increase in online games, applications, and communities, and an augmented demand for online courses and university programs, most students are still enrolled in physical classrooms that bear the potential for the Platonic Academy that Emig is apparently trying to salvage. In most universities, students still "transact with literal others in authentic communities of inquiry" (273), where learning happens. This is especially evident amongst historically Black colleges and universities (HBCUs), as Steve Lamos has noted, as well 
as liberal arts schools, whose missions, customs, and/or funding discourage a technology takeover.

While most university courses still function within the physical classroom model, the popularity of social media networks threatens the integrity of the classroom that Emig claims "asks us to introduce the customs and mores of collaboration and community" (279). Surely, Emig could not have predicted the invasion of online social networks. Yet when she contends, "[O]ne of the great ironies here is that to work in seeming isolation within a technological universe requires ultimately working collectively" (27980), and asks, "What can we offer learners who live in a technological era?" (277) the answer emerges: "an embodied classroom," but one supported by an online social community. For, says Stephanie Vie, "[I]nstructors and institutions in the late age of print need to rise to the challenge presented by students' increased participation in online spaces” (10).

In “Digital Divide 2.0 'Generation M' and Online Social Networking Sites in the Composition Classroom" (2008), Vie argues that while students are heavily engaged in online social media, their critical digital literacy is not advancing. Just as Emig concludes in her essay, Vie claims that twenty-first century teachers should reexamine their pedagogical practices, rethink their classroom materials, and revise their learning environments to meet the current needs and demands of our tech-savvy, millennial students. While inviting resources and materials with which millennial students are already familiar into a traditional classroom setting may promote student engagement and increase student comprehension, teachers, too, must be careful not to simply replace one new pedagogical method for another. Simply creating an online distanced learning environment within a traditional classroom setting, however, would be counterproductive to ensuring our students are developing knowledge versus simply receiving information-both teachers and students would benefit from reinventing, if you will, the traditional embodied learning environment that is supported by an online community with which students are already familiar.

The reasons that many of our millennial students struggle with initiating and engaging the classroom community are complex. However, I am inclined to believe that much of their angst about forging relationships with "real life" others in the classroom is a result of their online participation. According to Emig, "Perhaps, because of the time spent in cyber rather than embodied space, users like our students may begin to prefer the virtual over the actual ... or they may suffer from the ultimate confusion: not being able to discern the difference between the two" (277). Academically, most of our 
students surf the Net for information; socially, they send friend requests in order to build their circles. Both activities-which make up a large part of their human behavior-require they engage a distanced community. More often than not, student communities exist amongst the hundreds and thousands of "friends" with whom they share Facebook, Twitter, and Instagram. But because students' active membership to online communities requires their clinging to the technologies through which these distant communities are accessed, students are more likely to carry computer tablets than textbooks, reach for smartphones rather than pen and paper, and wear headphones instead of "thinking caps." The popularity of the Internet and its social media networks has encouraged a generation of students whose immediate community seldom exists amongst their peers and teachers with whom they share actual classroom space. Thus, teachers often enter into silent spaces in their classrooms, where students are not discussing the latest reading, reviewing last night's homework, or even gossiping about the latest reality television program, but are sitting there, "alone" - distracted and reaching for a sense of belonging via texts, tweets, selfies and Facebook updates.

Inevitably, with digital devices in hand, ear, or face, many students disconnect themselves, perhaps unintentionally, from real-world (or real time) experiences-accessible in the embodied classroom-as they stay joined to online communities. Unfortunately, says Douglas Rushkoff, "By using a dislocating technology for local connection, [students] lose [their] sense of place, as well as [their] home field advantage" (41). In other words, many millennial students use dislocating technologies that prohibit them from being fully present to the now that grounds people to the reality that fosters relationships. "Digitized" students become decentralized students. As a result, students' classroom proficiencies stand to suffer, for, as Emig maintains and other researchers have echoed (Gottschalk and Hjortshoj; McKeachie and Svinicki; Palmer; and Schoeberlein), classroom collaborations with real-life others are essential to ensuring meaningful learning experiences.

If our classrooms are to reflect the real world experiences we'd like our students to have, we must create a learning environment that supports their mind-body-soul selves-while inviting in the best of what online writing and social opportunities have to offer. Therefore, since fostering classroom relationships is vital to student learning, and students more readily engage the learning process when its practices are supported by resources with which they are familiar and interested, I believed creating an embodied classroom supported by an online social network would benefit the Improving Writing 
2300 course I teach at Florida A\&M University, a public historically black university. Even more, such pedagogy would be especially apt because Improving Writing 2300 is a writing course for students who earn a C or better in Freshman Communicative Skills I and II but still need extra time to work on their writing. Most of these sophomore and junior students major in the social sciences; however, English majors are required to take the course as a measure of additional support before taking Advanced Composition 3320.

\section{SOME BASICS OF THE EMBODIED LEARNING CLASSROOM}

In 1975, Muhammad Ali delivered a Harvard Graduation Commencement Address in which he recited what is considered the shortest poem in American history. "Me, We," he said. Like Ali, I don't believe there is a greater commitment human beings have to themselves and other sentient beings, human and non-human, than to foster relationships that ensure compassion, understanding, and love-all of which are grounded in truth. For a community of truth-often advocated for by civil rights leaders, educational philosophers, and politicians-requires a shared vulnerability that makes possible the peace we imagine. Therefore, as a classroom teacher who believes that students' classroom experiences should mimic the "real world" experiences I would like them to have, I endeavor to "create a space where the community of truth is practiced" (Palmer xiii). I particularly believe that the liberal arts, such as the writing classes I teach, are especially responsible for ensuring our students are reminded of their humanity via reading and writing practices.

According to Parker Palmer, whose philosophies support Emig's notion of embodied learning, "Knowing is a profoundly communal act, [and] ... [n]othing could possibly be known by the solitary self, since the self is inherently communal in nature" (xv). In To Know As We Are Known: Education as a Spiritual Journey, Palmer claims, "the pain that permeates education [is] "the pain of disconnection"” (x). He suggests that creating a classroom "“community of truth"” where students and teachers collaborate with one another-where they "must speak and listen, make claims on others, and make [one another] accountable" (xii)—is a practice in "knowing, teaching, and learning" (xii, emphasis in the original). It, too, becomes a practice in loving, for "to know as we are known" requires both students and teachers to form relationships with one another in a vulnerable fashion that conjures self-reflection, compassion, inquiry, and creativity. Therefore, in order to situate my Improving Writing students in an embodied learning environment 
that I thought would help them to develop meaningful relationships, I took two measures: I decided to personally engage with my students and form accountability groups among them.

\section{Engaging Students and Teacher Self-Revelation}

During a teacher training I attended some years ago, my director suggested that novice teachers should enter the classroom sternly. She actually claimed that my peers and I would be able to manage the classroom more effectively if we began the semester with a no-nonsense attitude. Don't smile, don't share personal information, and don't become friends with your students, she said. In other words, maintain a safe distance from our students, and we will be fine. Be objective. However, most good teachers do not build such thick walls between students and themselves. Teaching practitioners and theorists, including bell hooks, Paulo Freire, and Palmer, have revealed how important building relationships with students is to their learning development. According to hooks, who borrows much from both Freire and Palmer to undergird her own pedagogical theories, "[T]he professor must genuinely value everyone's presence. There must be an ongoing recognition that everyone influences the classroom dynamic, that everyone contributes. These contributions are resources," she says. "Used constructively they enhance the capacity of any class to create an open learning community" (emphasis in the original, 8). In essence, as teachers engage their students as actual human beings, they illustrate a love that invites them all into community.

Although Freire, hooks, and Palmer do not use the term "embodied learning" in their pedagogical theories, they each advocate for an embodied classroom where student relationships among themselves and others ground their learning experiences both in and outside of the classroom. "[T]he way we relate to each other and our subject reflects and shapes the way we conduct our relationships in the world," says Palmer (89). Therefore, if one of my teacherly goals is to position the classroom in the real life situation that it actually is, thus allowing students a mind-body-soul learning experience, then I must engage students in a relationship that transcends the traditional teacher-student hierarchy.

And so, I have not held on to my director's advice, for not only has research taught me differently, but my own experience as both a former high school teacher and a student myself has taught me that the best teachers do smile and share some personal information with their students in an effort 
to create relationships with them. Additionally, says Deborah Schoeberlein, "Academic performance improves when students feel safe and connected-in short, when they are supported by a strong relationship with their teacher" (71). How can I expect students to trust my directions and engage in classroom discussion if they don't see me as a human being who thinks and feels and who cares about their personhood? According to hooks, "Professors who expect students to share confessional narratives but who are themselves unwilling to share, are exercising power in a manner that could be coercive" (21). I know that because I have a doctorate degree, am responsible for accessing students, and am some years older than they, my students may feel that these hierarchies obligate them to share themselves with me; they must do what the "all-knowing, all-powerful" professor tells them. Therefore, because the hierarchical nature of higher education tends to promote exercises of coercive power, I shared just as much of myself with my Improving Writing students as I asked them to share; I began on the first day of class.

Student introductions are standard during the first week of classes. Therefore, the first day that I met with my Improving Writing students, I asked them to stand up and give one another brief introductions of themselves including their majors, hometown, and desired careers. However, instead of leaving students to recite their demographics, I led each of them into a dialogue with me and their peers. At any point that students shared information that I had in common with them, I noted the commonality, asked questions about their experiences, and laughed with them. Eventually other students participated in the banter and we ultimately were engaged in a lively discussion based on these introductions.

Participating in classroom introductions laid the foundation for the embodied classroom. During first day class introductions, I discovered that some of my students lived in the neighborhood where I grew up, a few attended the same high school as I did, and others enjoyed the same music I did. As I actively listened to each student, which included welcoming each student by name after he or she provided it, I offered students an attentiveness that assured them that they mattered. "Names can serve as proxies for flesh-and-blood students . . . or they can convey respect and recognition by acknowledging another facet of a person's identity," says Schoeberlein. "The way you say a student's name can confer welcome and attention or dismissal-literally and figuratively" (55). These class introductions alone grounded students and me in mutual respect. Since understanding and compassion come directly from respect, a foundation for truth was immediately being cultivated during class introductions. 
In other words, when one practices understanding and compassion, she exhibits respect for others that promotes love. In loving spaces, students are able to embody a truth free of judgment and criticism. In truth, human beings are given permission to be themselves, wholeheartedly. When teachers give students permission to be themselves, they assist students in reclaiming their humanity. Calling students by their names and remembering them foster the respect that invites students into truth with their professors. Such agency cultivates an awareness that acknowledges-as Maya Angelou claims in her poem "Human Family" — "we are more alike ... than we are unalike." Eventually, introductions segued into a classroom dialogue that further allowed us to know one another. My students and I connected, for we "embodied" similar at-home situations that were reflected in our regional vernacular, attire, and body language.

During these informal dialogues, I also spoke to my students-who are predominantly Black-in what James Baldwin calls "Black English," because I believed it would reinforce our connections with one another. People find community — a sense of belonging — in the shared languages that they embody. Since I aimed to forge a classroom community, I had to speak in a language that invited students into the community. As a rhetoric and composition scholar, I also draw on my style of dress, my body language, and my demeanor as an aspect of my language and communication with students. Undoubtedly, being a (young) Black professor helped me create community in my class, for my Black students and I encountered little to no problems connecting because we shared similar cultural (popular, religious, and Black) experiences.

Talking with students in a common language definitely enhanced my relationship with them. Speaking in a language that is ordinary and innate to my Black students seemingly relaxed them into an academic space that often excludes those who do not speak the language-a notion that hooks examines in her 1990 essay, "Postmodern Blackness." I discovered, for instance, that engaging in conversations about hometowns-or what my students call "crib" - in a way that reflected their personhood allowed them to further trust the classroom community, because they felt akin to me, their professor. As a result, they talked more openly and honestly about their personal experiences, because they believed I related to them; I cared. And truthfully, while I helped students to comply with the standards of American English via their writing skills, I spoke in Black English the majority of class time. My students are Black, and I wanted them to thoroughly comprehend classroom objectives and expectations. Therefore, my job as professor is to speak in a language that promotes understanding. 
In addition to sharing personal information by way of class introductions, I shared myself with my students through the same writing assignments that I required of them. While I did not write weekly with them, I did engage in freewriting and blogging exercises with them that required personal reflections, as I will discuss later. Engaging with students promoted the embodied classroom, for it encouraged me to become more of an engaged classroom member versus classroom teacher.

During one class meeting, for instance, I was able to secure a computer lab for student use. In the short time we were allotted (50 minutes), I required students to free write online on the topic, "Describe Your God." This subject evolved from a previous discussion the class had had on religion-a discussion, I have realized, that always concludes with my Black students believing I am atheist. Nevertheless, instead of watching students free write, which distances me from the classroom experience, I situated myself into the classroom body and freely wrote with students. It was such a riveting experience!

As I wrote with them, I found myself eyeing the clock, because I didn't want to run out of time. I was anxious about my sentence structure and use of mechanics, spelling, and punctuation. I wanted to sound profound-like a philosopher. And I wanted to tell (via blogging) my student readers that I wasn't an atheist. I cared about their judgments of me. Additionally (and perhaps sadly), I wanted to show off. I wanted to integrate literature that supported my ideas, and I wanted to write poetically. As I was writing, and simultaneously thinking about all of my writing desires, I imagined my students experiencing similar anxieties. What a stressful way to be. Placing myself in the students' position awakened my compassion and patience for them, which, of course, reinforced the classroom community. By situating myself as member of the class, I identified with students, which developed the "relationshipping" that anchors community.

Moreover, during a few class meetings, students watched me perform the same writing tasks that were required of them, heard me read through my expressed insecurities, and observed the edits, revisions, and proofreading marks I made on my own work. As an engaged teacher, I removed myself from the head of the class into the classroom body and students watched me embody their role as student; as their "peer," students were more inclined to comment on my writing, and they did.

And while students respected my role as professor, they absolutely appreciated the opportunity to "school" me. For instance, students freely commented on my blog post about God, which was a humbling experience. Receiving feedback for any writing that I share with others is absolutely 
daunting, for my work is a reflection of my personhood. Reading criticisms always feels like a spiritual assault. So imagine the fear I felt about receiving feedback from students (who also use Rate My Professor). Allowing them to access my thoughts via the blogs I wrote with them made me just as vulnerable to my students as they have been to me. Such vulnerability, which can be practiced only in a compassionate space, grounded us in a community of truth, where we each were fully present to one another. Experiencing that kind of vulnerability and anxiety regarding my students' comments reminded me of the fear and upset that my students often experience when I return their papers to them. Nevertheless, with a courage that my students muster every week, I read each student's comments.

One of my students found my ideas humorous. His entire blog response is worth quoting here. ${ }^{1}$ He wrote:

I find it comical that you think that the class believes God is some sort of fairy-like creature that sings with the doves and dances with the cherubs. As comical as it is, I think that you would be hard-pressed to find an individual (at least in our class) that thinks this way. Reflecting on my peers, I honestly can't see the majority of them believing that he is white either. It's interesting that you believe that "Our God" and "Your God" are two completely separate entities. God is the universe. God is love. God is a being. He does live outside of us. However, He also lives within the hearts of all who believe. However, God also gave us free will. We can believe in whatever we want and I respect your beliefs. So, now that the sermon's over, how was your Thanksgiving? I hope all is well with you and your loved ones. God Bless.

This particular student's comment to my blog is courageous. Not often do students challenge their professor's ideas the way this student challenges mine. He not only labels my thoughts "comical," but he affirms his right to believe what he wants. He also claims to know his classmates well enough to speak on their behalves. Finally, he concludes his response sarcastically"God Bless." Undoubtedly, the relationships that our embodied classroom helped to create encouraged this student's agency. Usually a quiet student, he trusted that he could boldly respond to my thoughts without reprimand. Blogging allowed him the space to speak so freely. The embodied classroom cultivated the trust he needed to do so, and invited his peers to do the same. Once students entered into relationship with me, I reinforced their relationships with each other in what I call "accountability groups." 


\section{Forming Accountability Groups}

At about the second week of class-at which time student class schedules are fixed-I assembled students in groups of three to four. I organized the accountability groups myself for two reasons: First, I organized students by alphabetical order of their last names, because doing so helped me to quickly memorize student names. Knowing and calling students by their names reinforced the sense of belonging that I want students to feel; it also grounded them into the classroom experience (Schoeberlien 55). Second, I organized the accountability groups myself in order to curtail the unintentional "othering" that often occurs when students choose their own groups. In other words, when left to their own devices, some students gravitate to those who look cool, while others link to their same genders, and the few students who are already familiar with one another stay connected-prohibiting their opportunity to meet new students. As a result of students' self grouping, more often than not, two to four students are left un-chosen, which encourages inferiority and fragmentation. Although those "othered" students usually form their own group, collectively_albeit unintentionally—they become "outsiders."

I called these student clusters "accountability groups" because, unlike other class collaborations that require students to complete group projects together, accountability groups require students to simply be responsible to one another. In other words, students used their accountability groups to keep one another informed about class assignments, to submit assignments on behalf of absent students, to help one another complete assignments, and to participate in peer review exercises; however, they did not have to rely on one another for grades.

While earning grades based on group projects has the potential to prepare students for the collaborations that they will confront outside of school, I have encountered classrooms that become fragmented because of group grading. In fact, in previous writing courses I have taught, some students actually withdrew from the course when they discovered some of their grades would rely on peer collaborations. Unfortunately, many students fall susceptible to the notion of a dog-eat-dog world and would rather fend for themselves than collaborate with others. But accountability groups relaxed students into a classroom community, for students did not have to perform the tasks of disciplining teacher-which many of them are neither confident nor mature enough to do. Accountability groups detached students from the stigma that is often placed on group work, and as a result, they didn't enter their groups defensively. 
Moreover, after Improving Writing students were placed in their accountability groups, I still had to encourage them to physically move into intimate clusters to talk with one another and retrieve each other's contact information. Surprisingly, and unfortunately, although I initiated student grouping, students moved into a group, but they just sat there in each other's faces staring into space, waiting for me to tell them what to do next. Machines. So, I actually facilitated their peer discussions by offering them questions (What did you do this weekend? What other classes are you taking?) to pose to one another. Additionally, I moved around the room, often sitting on students' desks and chit chatting with individual groups, which reinforced the relationship I continued to forge with students. (Although I do not care for icebreakers, in an effort to assist students in their getting acquainted with one another as well as with the teacher, an icebreaking activity may prove helpful here.) Finally, before class ended, I reminded students to use their smartphone apps (Google Hangouts, GroupMe, Skype) as spaces for touching base with one another. Surprisingly, more often than not, while students carry smartphones, many of them fail to connect their mobile devices and their capabilities to academic settings.

Many students used Group Me, a smartphone application that allows users to form group text messaging forums to keep in contact with one another. In these forums, students informed each other of their absences and possible tardiness, which were relayed to me when I took attendance. They also scheduled out of class study groups with one another. I discovered, too, that these accountability groups encouraged students to share their text books, by way of scanning or photocopying chapter pages, with students who did not have the finances to purchase their text books in a timely fashion. Some students even shared their access codes to their e-books in order to ensure their classmates were prepared.

Student accountability groups undoubtedly developed the embodied classroom community I endeavored to help students foster, which in turn made learning more meaningful and accessible. With accountability group members, students engaged in peer review tasks. They also helped one another to understand and accomplish the course's technology requirements. Although I required students to move into their accountability groups to accomplish these tasks, I observed the classroom community that these groups helped to develop. While students were in their accountability groups, none of them were distracted or displaced by their cell phones where they seek access to their distant online communities. Instead, they were engaged in their local classroom community, where they collaborated with one another other. 
Students were totally present to the classroom situation-an attentiveness and desire that accountability groups absolutely helped to foster. Members of the class talked, laughed, and listened to one another. We were able to have heated discussions without becoming angry with each other and without any one person dominating the conversation. Additionally, students deferred to their group members if they needed support during class discussions. Sometimes, students would even take up for slacking classmates claiming I should consider students' out-side-of-class situations. I remember a student, riffing on our university name, professing to me and her classmates, "We are a FAMUly."

I know had I not created accountability groups, students would not have forged the classroom community we were currently engaging. The classroom would have been a fragmented one where the same two or three students freely participate in class discussions, where the majority of students do not know their classmates well enough to seek their assistance, and where the general classroom would be void of the enthusiasm (spirit) needed to cultivate a meaningful learning experience. Because many students belong to social network communities, they do not have to commit themselves to belonging to a classroom community. They can (and often do) distract themselves from their feelings of loneliness and isolation by absorbing themselves in a distant community of "friends" and "followers." Unfortunately, an unbalanced belonging to these distant communities can distract students from collaborating with classmates and teachers in real time. If students do not feel connected to a community, what would encourage them to participate in that community? Eventually, teachers will experience increased student tardiness and absenteeism, for student disconnection leads to a lack of care and commitment.

Moreover, student accountability groups helped to create student friendships. As students became situated into their accountability groups, many of them rearranged their classroom seats to sit near group members. Their classroom togetherness also transferred outside of class, as members claimed to have formed local study groups as well as attended Universitysponsored events together. Additionally, many of the students collaborated with one another to attend the required semester's off-campus film viewing. Surely, the relationships that students forged in the classroom informed how they responded to one another outside of class. Although my using the term "friendship" may be presumptuous, there is no doubt that students trusted and respected one another enough to engage in a sense of community outside of the structured classroom community. 
As the semester progressed and my students and I continued to practice classroom community by working together in a physical space where we engaged traditional writing tasks, peer review exercises, class discussions, and student presentations, I eventually integrated WordPress into our weekly tasks. I did this for two reasons: 1) WordPress is an online content management system whose inclusion in the course syllabus modernizes required departmental course objectives that do not oblige students to integrate social media into their writing practices; and 2) it is an online social community network that I believed would support the embodied classroom to which my millennial students belonged. Integrating such technology into the traditional embodied learning community responded to Emig's question: "What can we offer learners who live in a technological era?" (277); fulfilled Palmer's request to: “[B]ring students into living communion with the subjects [teachers] teach" (xvii); and considered Vie's challenge to address students' increased participation in online writing spaces (10). The discussion that follows details how I integrated WordPress-particularly blogging practice-into the Improving Writing course and how it supported the embodied classroom.

\section{SUPPORTING THE EMBODIED CLASSROOM WITH AN ONLINE SOCIAL COMMUNITY}

Although computer technologies may distract both students and teachers from being present to the physical bodies that populate the classroom, we also know their potential to actuate the new, interactive twentyfirst century classroom (Ferdig and Trammell; Goodwin-Jones; Krause; and Miller and Shepherd). Surely, students can engage in online "whole group peer-review sessions" that encourage collaboration (Bush), and they can participate in other learning communities via online tutoring sessions (Coogan). Further, they can develop their embodied relationships by way of online learning communities they share with one another. However, students still need practice in transferring and balancing their online collaborations with "real-life" actualized spaces. After all, say both Emig and Palmer, the classroom should reflect the "real" world experiences our students (will) engage. And, in this current technological era, the "real" world includes student participation in both cyber and physical spaces.

While technology use in composition classrooms dates back to the early 1960s (Daigon; Engstrom and Whittaker; Fisher and Kaess; and Page and Paulus), our current technological age in particular encourages distance 
and dislocation. If the contemporary classroom teaches students how to balance their online engagements with the significance of local communities, then students will have more meaningful classroom experiences-ones that are grounded in intimate collaborations where creativity, inquiry, and compassion are practiced with real life human beings. With hope, what students learn in their classrooms will eventually transfer into their out of class experiences. And so, whether we want to or not, teachers must tend to students' attachment to communication technologies to ensure that students have meaningful classroom experiences that they can carry with them beyond the classroom, thus bringing us closer to the peace we imagine.

As a child, I often wrote letters to my teachers and parents that expressed emotions, posed inquiries, and exposed insecurities. I was often afraid to verbally render my frailties, but writing them down on paper offered me the courage to speak-particularly of those thoughts and ideas that affirmed my personhood and allowed me to (safely) practice agency. Fortunately, my parents and teachers either wrote me back, or they verbally responded to my letters gently and compassionately. Those written exchanges, unbeknownst to me then, supported the embodied relationship that we were already engaging. Their responses to my letters made me aware that they were listening - that my thoughts and ideas mattered. In turn, as I got older, I became more confident in myself, and I felt more situated-courageous and secure-in the embodied relationship we already shared. With the advent of technology, however, computers and smartphones have replaced pen and paper, and as a result of these technologies' ability to provide its users instantaneous gratification, some researchers (Angelone; Scruton; and Warrell) argue that communicating via technological devices is "hiding behind the wall of technology." "Our digital tools play to our vanity and vulnerability," says Forbes columnist Margie Warrell. "We can easily become seduced by them, relying on them for affirmation, validation and a sense of belonging" (Warrell, Margie).

I absolutely believe, as Warrell writes in her blog post, "Is Facebook Making Us Lonely?: Why We Mustn't Hide Behind Technology," “[A]s we have built expansive social networks online, the depth and breadth of our networks offline has diminished." However, I also know, as research suggests (Bryant; Eyman; Miller and Shepherd; and Stefanone and Jang), that online communities can support real-life relationships. Surely, just as traditional "pen palling" supported the intimate relationships I was already having with my parents and teachers, writing in online spaces could offer students the provisions (courage, safety, agency) they need to forge intimate relation- 
ships with actual others. If teachers like myself understand writing practice as an exercise in developing student agency, then the twenty-first century technology-driven student can find relief in using computer technologies as tools for embodied community building. The distance that technology forges creates a safe space for student self-exposure. Onliners are usually more courageous risk-takers in virtual spaces than they are in actualized real-life environments. And despite some of the oppositions regarding online communities, not all online users are using computer screens to be confrontational, violent, and/or fraudulent. Many are simply products of their time and have become more comfortable participating in online social networks than face to face.

Because our students are using Facebook and Twitter as platforms for written confession, self-expression, and community building, as well as for marketing and professional networking, it is vital that composition classrooms teach students how to use these technologies to support and develop the embodied relationships that are often neglected as a result of users' attachments to technology. With that said, I figured blogging-which is a practice that many composition scholars and teachers (Santos and Leahy; Tougaw; and Zhang) have integrated into their writing classrooms in order to engage twenty-first century students in current writing practices-would be a significant addition to the traditional embodied classroom. It would especially be beneficial to the African American students to whom I teach Improving Writing.

African American students statistically belong to more social networks than their White counterparts; they also lead their White counterparts in smartphone usage (Duggan and Brenner). Unfortunately, however, African American students continue to trail White students in their ability to use technology for academic and professional growth (Blackmon 153-66). Their disadvantages can be contributed to several forces, including the fact that HBCU classrooms rarely have the computer technologies (Roach; Snipes, Ellis, and Thomas; Stewart; and Stuart) that enable students and teachers to approach writing practice beyond the traditional computer requirements (Blackboard, Word Processing, and e-mail).

To an extent, this is true at my campus: although my HBCU has several computer labs across campus, the Department of English doesn't have its own. Limited access to computer technologies therefore encourages a traditional classroom approach, void of pedagogies that include technology instruction. And so, for many of the Black students I encounter, computer technologies are a fashionable accessory that promotes "swag." Therefore, in 
an effort to assist Black students in doing more than consuming technology, integrating it into the traditional Improving Writing course I teach assisted them in being producers of the technology they use, while enhancing the embodied classroom in which they were already engaged.

\section{“Improving Writing” with WordPress}

The Improving Writing course I teach is one of three elective writing courses from which students can choose to fulfill their curriculum requirements; the other two are Creative Writing and Advanced Composition. Most non-English majoring students (Criminal Justice, Sociology, and Education) opt to take the Improving Writing course, which has garnered the reputation of being the most remedial writing class of the three elective writing courses. However, students must have earned a $\mathrm{C}$ or better in their first year composition courses before taking the class and are expected to write business/professional documents, write film reviews, and read and respond to contemporary texts/issues-writing activities that are advanced even for many successful freshman writers.

Because the course has been stigmatized, many students enter Improving Writing believing it is a less demanding course than the other writing courses the University offers. However, the WordPress component that I included in the course challenged writing students to pay careful attention to voice, structure, audience, and mechanics — an endeavor that caused writing to "get real." Since WordPress publicizes student work to an audience beyond the classroom, students were often encouraged to be more mindful writers.

WordPress, which is a content management system, is perhaps the most practical computer technology to use in my Improving Writing course, for it allowed my students to create a website, which I called their "online employment portfolio." Essentially, the online content that made up student e-portfolios came from the required course units. Students created four web pages: "About Me" (elevator speech assignment); "Personal Philosophy" (personal statement assignment); "Resume"; and "Blogs" (reader response assignments, including required film review). Students practiced grammar and mechanics via their editing, proofreading, and revising tasks. Unless students were majoring in computer science, the majority of them created a website for the first time when they took Improving Writing with me. Likewise, the majority of them blogged (beyond microblogs) for the first time, too. 


\section{Belonging to an Online Social Community}

In addition to serving as a content management system that allowed students to maintain an e-portfolio, WordPress includes a blogging feature that invited students into an online social community with which they were already familiar. WordPress users can comment on other blogs, follow each other, and re-blog other posts. Additionally, like most social media networks, WordPress allows users to add tags to their posts and to link their WordPress accounts to their other social media networks in order to increase their visibility amongst their followers and their followers' followers. And so, once students created and added required content to their "About Me," "Personal Philosophy," and "Resume" pages, they were tasked to engage in blogging exercises that reinforced their embodied learning environment; those writing tasks were posted to their "Blog" page.

I provided students their blog topics. Topics included: "Describe Your FAMU Experience"; "What/Who Interested You in Your Current Career Choice?"; "Describe The Person You Admire in Your Career Field"; "What Does Your Name Mean?"; and the previously discussed topic, "Describe Your God." Students also composed and voted on three other topics, which included "Describe Your Favorite Song," "Freewrite on Anything," and "Evaluate Your Semester." Their film review was also written as a blog post, and it required students to see and examine George Tillman's The Inevitable Defeat of Mister and Pete (2013).

Instead of engaging contemporary readings, which the Improving Writing course requires, I encouraged students to engage themselves, which I believe is vital to building relationships with other people. As composition research has already showcased for years (Brand; Elbow; and Macrorie), personal writing assignments provide basic writing students a sense of agency that more formal academic writing does not. As a result, students often write more, and they write more truthfully. Therefore, since blogging is a form of online journaling, students were allowed and encouraged to approach the blogging situation as a practice in journaling. They had the freedom to relax in their own voices, which encouraged an authenticity in student composition that was easier for students to write and often times more pleasurable for their peers and me to read. Moreover, although students were encouraged to blog in their authentic voices, they were also reminded that their WordPress audience included a hypothetical employer, as well as their classmates and other social media followers. 
Students blogged once a week on Fridays. Since our class was not housed in a computer lab, students did not convene for class during blogging days. Instead, they were given the opportunity to use class time to blog and the weekend to proofread, revise, and comment on each other's blog posts. All blogs were both posted on WordPress and hand submitted to me so that students could receive comments that would help them to improve their writing. They also were required to comment on their group members' posts via WordPress's commenting options, and occasionally, students were required to read their blogs out loud to their classmates.

Blogging with WordPress encouraged the embodied classroom community, which then influenced students' class participation. Out of the twenty students who populated the class (and were surveyed about their semester experiences), only one student noted not feeling like he/she belonged to a classroom community as a result of blogging exercises. According to this student, "[Blogging] still felt as if it was a class assignment." In other words, blogging did not inspire this student to participate in classroom happenings more than any other traditional writing assignment. This student's sentiment supports Jill Walker's notion that forcing students to blog may not be empowering at all (jilltxt.net).

On the contrary, much research (Brindley; Hrastinski and Naghmeh; Solimeno; and Tharp) supports the notion that online communities do provide students with a sense of embodied classroom community. According to Galloway, Greaves, and Castan, "While the internet and its tools are not a panacea for the woes of the academy, they do afford a range of opportunities for a more engaged scholarly community" (187). In their "Interconnectedness, Multiplexity and the Global Student: The Role of Blogging and Micro Blogging in Opening Students' Horizons," the authors claim, "[S]ocial media platforms can be used creatively to supplement conventional educational practice to generate collaborative communications beyond the limitations of physical classes or traditional printed media" (187-88). My Improving Writing students agreed, concluding that blogging did encourage classroom community, for they were able to deeply engage their classmates online, which promoted their in-class engagement with one another other.

WordPress's commenting feature further inspired the embodied classroom, for it encouraged student agency. Once students obtained a sense of agency, the act of writing and sharing became more desirable. Student users freely commented on their peers' blog submissions, further developing their online collaborations and eventually enhancing their classroom community. 
WordPress's commenting feature offered students feedback that transcended teacher responses.

More specifically, as part of their writing requirements, students had to read and give written feedback on more than two of their classmates' blogs-a practice that is not accessible in the traditional pen and paper classroom. Students were not permitted to comment on each other's spelling, sentence structure, and the like. Allowing them to do that would have placed them in a teacherly role, which could have possibly created a wedge in the peer relationships they were forging. Instead, students responded to each other's sentiments, which validated their feelings, ideas, and personhood, and eventually connected them to one another as human beings. Writing (blogging), then, became a practice in securing one's place in the classroom and understanding one's self in relationship to others. It provided students with a sense of agency.

One student claimed that the ability to comment and respond to peers made him or her "feel connected to them as a whole." Another student agreed, noting student responses to blogs allowed him or her to see the commonalities that students shared. "Knowing your classmates can relate to you is an amazing thing," said this participant. A different student added, "I think that [blogging] did make me feel [connected]. It was cool to see other students that I hadn't previously interacted with in class comment on my posts." "[Blogging] provided an atmosphere that connected our ideas and thoughts," said one more student. ${ }^{2}$

While students verbalized their belonging to a classroom community, their belonging was illustrated in their interaction with one another as well as with me. At the start of the semester students did not know each other and had not independently attempted to relate to one another-which contributed to a lonely, fragmented classroom. My teaching experiences have taught me that classrooms void of student and student-teacher relationships often result in boredom, low participation, and decreased attendance. However, by mid semester, each student came to class prepared mind, body, and soul, and most students were already seated in the classroom engaged in various discourses once I entered the space.

Because blogging supported classroom community, I found that most students also became more inclined to successfully complete their writing tasks-perhaps because they were interested in receiving their classmates' comments. In addition, occasionally I would ask students to read their posts out loud to their classmates, which also ensured completed writing tasks, for a student who failed to complete her assignment would inadvertently 
disappoint her peers with whom she was fostering a sense of belonging. "Knowing that your teammates are depending on you increases the likelihood of your doing your work," says McKeachie and Svinicki (218). And so, as the embodied classroom developed, so did students' sense of academic responsibility.

I have realized that blogging exercises-although an online practicesecured an embodied classroom, and if the semester lasted longer than 14 weeks, could very well have further situated students in the embodied classroom and assisted them in seriously improving their writing skills. For instance, in a high school classroom, where students and teachers meet for thirty-six weeks, classroom members have almost triple the additional time to practice both community building and writing skills. I imagine as high school students continue to blog weekly, their writing agility will increase and their writing skills will improve, for not only does regular writing practice improve one's writing skills, but the demands of weekly writing exercises might encourage undirected peer editing, reading, and collaboration-exercised both in and outside of class. Eventually, writing collaborations could possibly become second nature to these high school students, and hopefully, encourage their collaborating in other academic spaces and local communities.

However, because our semester is only fourteen weeks long, and less than seven of them were spent blogging, my college students received an introduction, if you will, to blogging practices. Yet those seven weekscoupled with the weeks spent engaging them via my personal self and their organized accountability groups-were enough to reawaken them to their natural, communal sensibilities. As students became more comfortable with their writerly selves, as well as with their classmates and teachers, they became more open to participating in other writing activities intended to improve writing, such as peer review exercises, writing collaborations, and class discussions and presentations.

Finally, according to the students surveyed, reading and commenting on their peers' blogs made them aware of their worth, provided shy students courage, and provided others comfort. "Responding to my classmates' blog posts enhanced the classroom community 'cause we got the opportunity to get up close and personal with each other [by] learning things we never knew before about one another," said one student. Other students claimed that engaging in blog exercises allowed them the time to connect with students in a way the allotted fifty-minute class time didn't allow, while others said blog comments allowed them to connect with students outside of their 
accountability groups. "We learn more about each other and that turns us into a small family who wants to see each other succeed" (emphasis mine), said another student.

Sometimes, I meet students who embody the characteristics of the technology they carry: unthinking, unfeeling, isolated machines that only do as commanded. Because so many of them are distracted by their communications technologies, they are not engaged in the real-life collaborations that support student learning. Many of them, therefore, perform poorly on their assignments; some fail the course. Likewise, many of my writing students are just as disconnected from other academic service communities-such as the Writing Resource Center, the Library, and the Career Center-as they are their scheduled classes with me. Although these free services are available to students, unless I require them (via extra credit, scheduled presentations, or final grade percentages) to physically go to these learning environments, most students will not seek these services. Neither do most of my students freely attend my office for face-to-face conferences.

Because students' current attachment to their computer technologies often prohibits them from physically and presently engaging with their peers, their teacher, and their learning tasks—thus barring students from engaging in the kinds of collaboration that conjure knowledge of the self and others-I knew I had to meet millennial students where they are, which most teachers are always trying to do. Therefore, to remedy students' disconnection from their classroom community so that they can practice belonging to a "real-life" local community intended to increase both their interpersonal and writing skills, I integrated an online writing community into our traditional embodied classroom setting.

Incorporating a distant online community into an embodied learning environment appears counterintuitive to ensuring that students develop knowledge versus merely receive information. However, not integrating technology-specifically online social networks to which most of our students belong-into a twenty-first century writing classroom would be a disservice to students who can benefit from learning how to use their current technologies to enhance their mind-body-soul connection. Clearly, as sentient beings with an innate desire for belonging, the twenty-first century learner's attachment to online social communities is not simply a trend, but a concerted effort at being in relationship with people. Our students were born into the Google, Facebook, Match.com age, and therefore, engaging them in a community of truth when many of them are committed to online social communities that invite fabrication, anonymity, depersonalization, 
violence, and arrogance is vital to their humanity. It is vital to our humanity, and really, all there ever is, is us. After all, "[r]elationships-not facts and reasons-are the key to reality" (Palmer 53).

Embodied classrooms foster truth through connection and community; therefore, developing the embodied classroom within this current technological era ensures our millennial learners receive meaningful lessons that transcend the classroom environment. Embodied classrooms promise whole people who make up a whole world where love is all there is. As teachers, we are responsible for helping our students make sense of themselves and the world around them via the subjects they are assigned to take. A traditional approach to classroom writing practices such as those Emig offers is necessary to an academy concerned with the whole student; it is just as necessary as the cutting-edge practices that academies hope will ensure our students' interest and marketability. Simply, embodied learning is to heart as distanced learning is to brain. They both equal a balanced education, which our millennial students deserve.

\section{Acknowledgements}

Thank you Deborah Plant, Ceron Bryant, and Kimberly Harding for your encouraging words and Gurleen Grewal for teaching me about contemplative learning spaces. Thank you Veronica Yon and the Florida A\&M University Writing Resource Center staff for providing me a space to write, fret, and feel the sun. And a very special thank you to my FAMU students.

\section{Endnotes}

1. All student work is used with permission.

2. Student comments, which are used with permission, were gathered at the semester's end via an anonymous online questionnaire.

\section{Works Cited}

Angelone, Frank. "Does Generation Y Hide Behind Technology When It Comes to Relationships?" Social Tech Zone. Web. 28 July 2014. Print. Angelou, Maya. "The Human Family." The Complete Collected Poems of Maya Angelou. New York: Random House, 1994. 224-25. Print.

Anzaldúa, Gloria. "How To Tame a Wild Tongue." Borderlands/La Frontera:

The New Mestiza. San Francisco: Aunt Lute Books, 1987. 75-91. Print.

Baldwin, James. "If Black English Isn't a Language, Then Tell Me, What Is?" 
New York Times. (1979). Print.

Brandt, Deborah, Zabe MacEachren, and Heather Rigby. "Reflections from the Neck Down: Embodied Learning in the Classroom." The Ontario Journal of Outdoor Education. 11:2 (1999): 11-14. Print.

Blackmon, Samantha. "(Cyber)conspiracy Theories? African American Students in the Computerized Writing Environment." Labor, Writing Technologies, and the Shaping of Composition in the Academy: New Directions in Computers and Composition. Eds. P. Takayoshi and P. Sullivan. New York: Hampton Press, 2007. 153-66. Print.

Bock, Mike. “On Interactive Platform, Students Use Mind and Body." Education Week 32:7 (2012): 8. Print.

Brand, Alice Glarden. "The Why of Cognition: Emotion and the Writing Process." The Norton Book of Composition Studies. Ed. Susan Miller. New York: W.W. Norton \& Company, 2009. 706-14. Print.

Bresler, Liora, Ed. Knowing Bodies, Moving Minds: Towards Embodied Teaching and Learning. Dordecht, Netherlands: Kluwer Academic Publishers, 2004. Print.

Bryant, Kendra N. “Composing Online: Integrating Blogging into a Contemplative Classroom." Exploring Technology for Writing and Writing Instruction. Eds. K. Pytash and R. Ferdig. Hershey, PA: IGI Global, 2014. 77-99. Print.

Bush, Laura L. "Class Peer Review in a Computer-Mediated Classroom: Using Classroom Projection Capabilities and E-mail Messages." Strategies for Teaching First Year Composition. Eds. Duane Roen, Lauren Yena, Veronica Pantoja, Eric Waggoner, and Susan K. Miller. Urbana: NTCE, 2002. 453-57. Print.

Carr, Nicholas. “Is Google Making Us Stupid?” The Atlantic. theatlantic.com. July 2008. Web. 3 April 2015.

Coogan, David. "Email Tutoring, A New Way to Do Network." Computers and Composition 12:2 (1995): 171-81. Print.

Crawford, L. "Including the Body in Learning Processes." Proceedings of the 17th Annual Conference of the Canadian Association for the Study of Adult Education. Ed. M. Taylor. Ottawa, Ontario: University of Ottawa, 1998. 29-30. Print.

Dixon, Mary, and Kim Senior. “Appearing Pedagogy: From Embodied Learning and Teaching to Embodied Pedagogy." Pedagogy, Culture and Society 19:3 (2011): 473-84. Print.

Dobrin, Sidney, and Christian R. Weisser. "Breaking Ground in Ecocomposition: Exploring Relationships between Discourse and Environment." 
College English 64:5 (2002): 566-89. Print.

Driver, Paul. "Pervasive Games and Mobile Technologies for Embodied Language Learning." International Journal of Computer-Assisted Language Learning and Teaching 2:4 (2012): 50-63. Print.

Duggan, Maeve, and Aaron Smith. "Demographics of Key Social Networking Platforms.” PewResearch Internet Project. Web. 9 January 2015.

Duggan, Maeve, and Joanna Brenner. "Social Networking Site Users." Pewinternet.com. 14 February 2013 Web. 5 May 2014.

Dwyer, Bernadette, and Lotta Larson. "The Writer in the Reader: Building Communities of Response in Digital Environments." Exploring Technology for Writing and Writing Instruction. Eds. Kristine Pytash and Rick Ferdig. Hershey, PA: IGI Global, 2014. 202-20. Print.

Elbow, Peter. "Some Thoughts on Expressive Discourse: A Review Essay." The Norton Book of Composition Studies. Ed. Susan Miller. New York: W.W. Norton \& Company, 2009. 933-42. Print.

Emig, Janet. “Embodied Learning.” English Education 33.4 (2001): 271-80. Print.

Eyman, Douglas. "Computers and Composition 20/20: A Conversation Piece, Or What Some Very Smart People Have To Say about The Future." Computers and Composition 28.4 (2011): 327-46. Print.

Ferdig, Richard E., and Kaye D. Trammell. "Content Delivery in the 'Blogosphere."” T.H.E. Journal Online 13 February 2004. Web. 18 December 2013. Fleckenstein, Kristie S. "Writing Bodies: Somatic Mind in Composition Studies." College English 61:3 (1999): 281-306. Print.

Freire, Paulo. Pedagogy of the Oppressed. New York: Herder and Herder, 1970. Print.

Galloway, Kate, Kristoffer Greaves, and Melissa Castan. "Interconnectedness, Multiplexity and the Global Student: The Role of Blogging and Micro Blogging in Opening Students' Horizons." Journal of the Australasian Law Teachers Association 20 (2013): 177-88. Print.

Goodwin-Jones, Bob. "Blogs and Wikis: Environments for On-Line Collaboration." Language Learning and Technology 7.2 (2003): 12-16. Print.

Gottschalk, Katherine, and Keith Hjortshoj. The Elements of Teaching Writing: A Resource for Instructors in All Disciplines. Boston: Bedford/St. Martin's, 2004. Print.

Gustafson, Diana L. "Embodied Learning about Health and Healing: Involving the Body as Content and Pedagogy." Canadian Woman Studies. 17.4 (1997): 52-54. Print.

Hrastinski, Stefan, and Naghmeh M. Aghaee. "How Are Campus Students 
Using Social Media to Support Their Studies?: An Explorative Interview Study." Education and Information Technologies 17.4 (2012): 451-64. Print. hooks, bell. Teaching to Transgress: Education as the Practice of Freedom. New York: Routledge, 1994. Print.

Jensen, Camilla, Winslow Burleson, and John Sadauskas. "Fostering Early Literacy Skills in Children's Libraries: Opportunities for Embodied Cognition and Tangible Technologies." Interaction Design and Children: Proceedings of the 11th International Conference (2012): 50-59. Print.

Johnson-Glenberg, Mina, David Birchfield, Lisa Tolentino, and Tatyana Koziupa. "Collaborative Embodied Learning in Mixed Reality MotionCapture Environments: Two Science Studies." Journal of Education Psychology 106:1 (2013): 86-104. Print.

Krause, Steven D. "When Blogging Goes Bad: A Cautionary Tale about Blogs, Email Lists, Discussion, and Interaction.” Teaching Composition. Ed. T.R. Johnson. Boston: Bedford/St. Martin's, 2008. 325-36. Print.

Lamos, Steve. "Minority-Serving institutions, Race-Conscious 'Dwelling,' and Possible Futures for Basic Writing at Predominantly White Institutions." Journal of Basic Writing 31.1 (2012): 4-35. Print.

Macrorie, Ken. "From Telling Writing." The Norton Book of Composition Studies. Ed. Susan Miller. New York: W.W. Norton \& Company, 2009. 297-313. Print.

Maivorsdotter, Ninitha, and Suzanne Lundvall. "Aesthetic Experience As An Aspect of Embodied Learning: Stories from Physical Education Student Teachers." Sport, Education, and Society 14:3 (2009): 265-79. Print.

McKeachie, Wilbert, and Marilla Svinicki. Teaching Tips: Strategies, Research, and Theory for College and University Teachers. New York: Houghton Mifflin Company, 2006. Print.

Miller, Carolyn D., and Dawn Shepherd. "Blogging as Social Action: A Genre Analysis of the Weblog." The Norton Book of Composition Studies. Ed. Susan Miller. New York: W.W. Norton \& Company, 2009. 1450-73. Print.

Moxley, Jospeh. "Datagogies, Writing Spaces, and the Age of Peer Production." Computers and Composition 25 (2008): 182-202. Print.

Ollis, Tracey. A Critical Pedagogy of Embodied Education: Learning to Become an Activist. United Kingdom: Palgrave Macmillan, 2012. Print.

O’Malley, Claire. "Design Considerations for Tangible and Embodied Learning." Cognitive Ergonomics Proceeding of the 31st European Conference (2013): 1. Print.

Palmer, Parker. To Know As We Are Known: Education As A Spiritual Journey. New York: Harper One, 1983. Print. 
Roach, Ronald. "HBCUs Strategize on Ways to Close Digital Divide on Their Campuses: Slow Adoption of Technology by Faculty Seen as Barrier." TECH TALK. Black Issues in Higher Education (2000): 42-43. Print.

Rushkoff, Douglas. Program Or Be Programmed: Ten Commands for a Digital Age. Berkeley: Soft Skull Press, 2010. Print.

Santos, Marc, and Mark H. Leahy. "Postpedagogy and Web Writing." Computers and Composition 32 (2014): 84-95. Print.

Schoeberlein, Deborah. Mindful Teaching and Teaching Mindfulness: A Guide for Anyone Who Teaches Anything. Boston: Wisdom Publications, 2009. Print.

Scruton, Roger. "Hiding Behind the Screen." The New Atlantis: A Journal of Technology \& Society 28 (2010): 48-60. Print.

Snipes, Vincent, Walter Ellis, and Joy Thomas. "Are HBCUs Up To Speed Technologically? One Case Study." Journal of Black Studies 36.3 (2003): 382-95. Print.

Solimeno, Andrea, Minou E. Mebane, Manuela Tomai, and Donata Francescato. "The Influence of Students and Teachers Characteristics on the Efficacy of Face-to-Face and Computer Supported Collaborative Learning." Computers and Education 51.1 (2008): 109-28. Print.

Standal, Oyvind F. "Re-embodiment: Incorporation through Embodied Learning of Wheelchair Skills." Medicine, Health Care, and Philosophy 14:2 (2011): 177-184. Print.

Stefanone, M., and C. Jang. "Writing for Friends and Family: The Interpersonal Nature of Blogs." Journal of Computer-Mediated Communication 13 (2008): 123-40. Print.

Stewart, Pearl. "Unparalleled Challenges: From Keeping Pace with Technology to Helping Students Finance Their Educations, Four Presidents Discuss Meeting Head-on the Multitude of Challenges that HBCUs Face in the 21st Century." Diverse Issues in Higher Education. 26.9 (2009): 55-58. Print.

Stolz, Steven A. "Embodied Learning." Educational Philosophy and Theory (2014): 1-14. Print.

Stuart, Reginald. "Getting Connected: Closing the So-called Digital Divide is Becoming Less of a Possibility for Many HBCUs." Diverse Issues in Higher Education 27.3 (2010): 13-15. Print.

Tharp, Tara Leigh. "Wiki, Wiki, Wiki, What?” Assessing Online Collaborative Writing." English Journal 99.5 (2010): 40-46. Print.

Tougaw, Jason. "Dream Bloggers Invent the University." Computers and Composition 26:4 (2009): 251-68. Print.

Vie, Stephanie. "Digital Divide 2.0: "Generation M" and Online Social Net- 
working Sites in the Composition Classroom." Computers and Composition 25:1 (2008): 9-23. Print.

Walker, Jill. "Talk at Brown." Jilltxt/net. 3 December 2003. Web. 18 December 2013.

Warrell, Margie. "Is Facebook Making Us Lonely?: Why We Mustn't Hide Behind Technology.” margiewarrel!.com. Web. 28 July 2014.

Yancher, Stephen, Jonathan S. Spackman, and James E. Faulconer. "Learning as Embodied Familiarization." Journal of Theoretical and Philosophical Psychology. 33:4 (2013): 216-32. Print.

Zhang, Wei. "Blogging for Doing English Digital: Student Evaluations." Computers and Composition 27:4 (2010): 266-83. Print.

Zickhur, K., and Smith A. "Digital Differences." Pew Internet and American Life Project 13 April 2013. Web. 18 December 2013. 


\title{
Seeking Texts in All Available Forms: Invisible Writing and a New Reading Rhetoric of Sight and Sound
}

\author{
Kati Fargo Ahern
}

ABSTRACT: Basic writing students are faced with challenges as readers who must understand a variety of texts that fit into traditional notions of academic genres, but also negotiate selfsponsored, digital, and multimodal writing. Rather than focusing on specific acts or sequences for how to read, I argue for the metaphor of invisible writing as a new reading rhetoric to help student readers negotiate various types of texts and what makes those texts "invisible." Invisibility is discussed in connection to definitions of writing, value, and productive potential. Finally, the metaphor of invisible writing is considered in concert with ear training. This use of sight and sound to reframe the process of reading is meant to offer basic writing teachers new approaches for the challenges of helping students understand multimodal and varied texts.

KEYWORDS: basic writing; composition theory; pedagogy; invisibility; reading; listening

In a recent article in $J B W$, Cheryl Hogue Smith notes the ways in which basic writers may suffer from "inattentional blindness" when reading. She recounts a classic study from the field of psychology where viewers could not see a person in a gorilla suit run across a basketball court because they were trying to count the correct number of passes made by players on the court (59-60). Smith uses this example to frame her discussion of basic writers as basic readers, unable to "see" elements in the text due to their focus on finding the "correct" answers. In so doing, she also notes that there is a long history of concern for basic writers as basic readers. For example, Marilyn Sternglass in 1976 called for composition instructors to focus more intentionally on reading (60), and more recently, Sheridan Blau found that students are most reluctant to engage in practices of rereading (emphasis mine, 61). "Behind all these arguments is the recognition that college students' ability to write is limited by their ability to read" (60). Instead, students need to be taught to overcome their reluctance to reread, and resist deferring to "answers" within a text, by becoming producers of their own interpretations (65-68).

Kati Fargo Ahern is an Assistant Professor in the English Department at Long Island University, Post campus. She conducts her research primarily in writing theory, sound studies, and multimodal and digital composing. Currently she serves as Chair for the Campus Committee on Student Writing, working closely with first year writing and writing across the curriculum faculty. 
In other words, different reading practices could help students overcome their "inattentional blindness."

What strikes me in this discussion is the way that blindness and sight are involved in metaphors of reading. On the one hand, this is not unexpected. We have a long tradition of visual-centrism in language connecting seeing to knowing. Phenomenologist Don Ihde cites Theodor Thass-Thienemann in translating the ancient Greek present form of the verb eidomai, meaning to "appear" and "shine," and in the past tense, "I know" and "I saw" (6-7). Ihde reminds us that common contemporary English words such as "enlighten" and "insight" further demonstrate our relationship between seeing and knowing (8). Not only is the link between seeing and knowing strong, but Scott Consigny argues it has limited our possible interpretations. He is particularly concerned with contemporary translations of Aristotle's definition of clarity (saphes). While we typically think of clarity as being visibly clear, like a window pane, Consigny offers another interpretation. Consigny suggests that saphes could be understood quite differently, where clarity refers to a bell, or a distinct sound, rather than a visibly transparent meaning (415).

Consigny's rereading of saphes should serve as a reminder that while we do live in a world rife with visual-centrism, we could choose alternative auditory metaphors for knowing over visual ones. For example, the concept of clarity as distinct rather than clear could also be linked to another common auditory concept in writing - voice. Perhaps student readers and writers could be asked to listen for the distinct qualities of voice in a text rather than being told that their writing or interpretations must appear clearer. By linking voice to clarity as distinct, students may be better able to form connections between the voices they read and the goals they may have for their own writing. Furthermore, asking students to recognize the ways in which a text is distinct or distinguishes itself from other texts opens a range of possibilities beyond the idea of "seeing" an answer or position in a text. (I will return to this notion later with the metaphor of ear training.)

Still, we cannot deny the ways in which seeing has become metaphorically synonymous with knowing. When we use "clarity" in the classroom, we typically mean the students' ability to work transparently with language or to "see" an author's meaning effortlessly, not to distinguish original (or distinct) voices, moves, or symbolic choices. Yet, I am arguing here that this visual-centrism in metaphors of reading and knowing is something that could be both questioned and used productively with student readers.

As a teacher and researcher who typically does her work in sound studies, I am very much "attuned" to how students literally use different auditory 
and visual practices to compose, as well as how sight and sound play out in our own ideas of reading and writing. In fact, my interest in auditory and visual metaphors is what led me to use the concept of "invisible writing" in my own composition courses to encourage student readers to find new ways to "see" forms of writing as writing. Invisibility still plays on many of the traditional and problematic notions of knowledge and sight, of which I have just noted, but what "invisibility" does as opposed to Smith's "inattentional blindness" is reconfigure and shift the idea of a lack of sight or lack of perception from the reader to the text. Instead of a reader who suffers from "inattentional blindness," not seeing a text, there might be a text that seems to possess (by virtue of authorial choice) some complex quality that allows that text to be undetected or unperceived as academic or legitimate. This shift is one of my main goals in working with student readers-to have students understand texts as possessing contingent, complex qualities that they as readers must seek out, perceive, name, listen for, and explore in their analysis, rather than to see themselves as so named, basic readers. Because metaphors are powerful ways of understanding ourselves in the world, the metaphor of invisible writing must first be explored theoretically, pedagogically, and politically, as well as in relation to actual responses from students reflecting on their experience with the metaphor in a course. Finally, alternative, auditory metaphors need to be considered, such as "bell-sound" and listening for writing and "ear-training" for reading, in order to further interrogate our epistemological possibilities and counteract exclusionary practices.

\section{SEEKING ALL AVAILABLE FORMS}

For a text to be invisible, it must simply exist in a way that we do not "see" it. While it might not literally be invisible, any text or genre may become neglected or be devalued in a particular setting. Additionally, invisibility is not necessarily a fixed quality. Something is not always invisible to all audiences or for all situations or at all times. Thus, résumés, cereal boxes, or King Lear could all be considered "invisible writing" based on definitions of "writing," audience assumptions, or a community's values. However, just because a text begins as a piece of "invisible writing" does not mean that it should remain invisible. Student readers must learn to read academic texts regardless if they fit comfortable traditions of texts or seem to be of value. Additionally, students will need to understand self-sponsored forms of writing, like recipes, slam poetry, and blogs as legitimate and complex texts. Finally, students must recognize all different forms of writing as contingent, social, 
historical, and political. Only when students can appreciate all available forms of writing may they feel more comfortable negotiating unfamiliar reading situations, and potentially moving back and forth between different communities and practices of reading-from scholarly journal articles to social media or online, multimodal texts.

While contemporary students are sometimes given the label "digital natives," extremely comfortable with technology and social media, students may not define digital forms of writing as writing. Andrea Lunsford reminds us that students often hold narrow and conservative definitions of writing, even within typically alphanumeric, inscribed composing situations, such as creating digital presentations or webtexts. When asked about their experiences in a newly-redesigned Stanford University Writing and Rhetoric course, students were unsure of whether they were simply learning new ways and media for "delivering" their writing, or whether they were learning more about writing (174). "In other words, they knew they were learning something, but many of them wouldn't call it writing” (174). Lunsford's students held onto more traditional notions of what it means to truly write, and those notions did not include using new media to make arguments. Lunsford was concerned with studying students as writers in the midst of confronting shifting definitions. But not recognizing a form or text as writing goes beyond labeling; it may also result in students not reading those kinds of distinct and unfamiliarly mediated texts as the kind of writing that they may be able to produce. Or students may not read those kinds of texts at all.

Teaching students to question and understand texts with unfamiliar design and composing choices expands students' notions of what it means to compose and design their own texts. Not recognizing an opportunity to compose a text differently or a choice as a choice leads to what Ann Frances Wysocki calls an "unavailable design," where a student cannot recognize a combination of composing materials and design possibilities (59). Unavailable designs are dependent on socially situated and historical conventions. They are made "unavailable" based on "what is expected by a particular audience in a particular context but also what an audience or instructor might not be prepared to see" (emphasis mine, 59). Thus students are taught habits of composing which continue to limit choice and force student composers to acknowledge fewer than "all available means" of expression. An "unavailable design" for a reader might also make students unable to "see" the full range of an author's composing choices. J. Elizabeth Clark notes that counterintuitive as it might seem for a digitally raised generation, students do not always rush to the opportunity to create digital texts: "Far from embracing digital rheto- 
ric, many students reject it in favor of a more comfortable essayistic literacy" (32). I have also found this to be true. When giving students an opportunity to create distinctive texts in forms less familiar than an academic essay, often less than a third of the class will choose to do so. Some have even remarked during the presentation of such projects that "they didn't know they could do that" (for example, when seeing another student's video-essay or a piece of interactive fiction). In other words, there are a variety of different forms of writing that may appear invisible to student writers based on what is also unavailable in their reading from a range of sources.

While student readers must learn to negotiate academic texts in their reading and writing, there are other situations or even other university courses where students will be required to adapt information for an audience outside of the university-one that would not be reached effectively through an "academic essay." Reaching different audiences is not merely a consideration of delivering texts through different technology and new media, but also of teaching students familiarity with self-sponsored forms of writing. As Brian Street has noted, literacy is not and should not be viewed as a fixed, academic activity of reading and writing. Rather, studying literacy is "problematizing what counts as literacy at any time and place and asking 'whose literacies' are dominant and whose are marginalized or resistant" (77).

Other recent scholarship on self-sponsored literacies also emphasizes the need to offer students a more flexible idea of audience and writing as dynamic and adaptive. Shannon Carter discusses teaching students writing as a social practice of "rhetorical dexterity": "I argue, [rhetorical dexterity] is a new understanding of the way literacy actually lives-a metacognitive ability to negotiate multiple literacies" and the acknowledgement that literacy is not all one thing (119). Carter's approach recognizes that teaching students to write in one particular form or genre is not as productive as teaching students the ability to flexibly move between multiple, distinct literacy practices in their writing. These practices may also include writing experiences that take place outside of traditional university settings.

Kevin Roozen also recognizes the otherwise invisible nature of different forms of writing marginalized in university courses and why that invisibility can be detrimental. Through his study of his student Charles's extracurricular engagement with standup comedy, poetry, and sports journalism, Roozen explains why we must make these forms of writing "visible."

By not fully attending to basic writers' self-sponsored literacies and their potential contributions to students' academic writing, we reduce 
the scope of their literate lives and identities as literate persons to only what we see in their work for college courses.... By overlooking selfsponsored literacies, we also subtly but powerfully signal that such writing is not "real writing" and that such reading is not "real reading." (emphasis mine, 100)

Our pedagogical choices to overlook certain literacies, or forms of "invisible writing," serve as our own form of "inattentional blindness" to the variety of texts our students will be called upon to read and negotiate. By offering them a set of reading practices that encourage new ways of seeing a previously invisible form of writing, we enable students to recognize many distinct forms in the future-forms that include traditional texts, digital and new media texts, and students' own practiced forms of literacy like poetry slams or standup comedy. Foremost, our students must also learn to push beyond the bounds of a single modality.

Even though we often think of writing as silent and visual, the history of composition also includes a strong connection to aurality, as well as new opportunities for digital technology to make possible combinations of auditory, visual, and gestural choices. For Cynthia Selfe, the historical and pedagogical developments which have occasioned a loss of aurality in composition have consequently silenced particular voices (632-636). She argues that the need to incorporate multimodality within the teaching of composition is by no means trivial. In her work on oral histories and the Digital Archive of Literacy Narratives, she continues to advocate for what she sees as the importance of multimodality.

By broadening the choice of composing modalities, I argue, we expand the field of play for students with different learning styles and differing ways of reflecting on the world; we provide the opportunity for them to study, think critically about, and work with new communicative modes. Such a move not only offers us a chance to make instruction increasingly effective for those students from different cultural and linguistic backgrounds, but it also provides an opportunity to make our work increasingly relevant to a changing set of communicative needs in a globalized world. (Selfe 644)

Jody Shipka also argues that the relevance of multimodal composing is not based in merely adding different modes of expression (such as sounds or images) to "traditional" alphanumerical, print-based writing afterward, but 
to view composing as an inseparable incorporation of modes, including the aural. In her book, Toward a Composition Made Whole, Shipka's main goal is not to teach students a fixed set of multimodal composing processes but instead "to make the complex and highly distributed processes involved in the production, reception, circulation, and valuation of texts more visible" (emphasis mine, 38). Like Selfe, Shipka believes that authentic composing often crosses modal boundaries, and that multimodal composing allows student writers to draw on all available semiotic resources. Similarly, student readers must be taught to read multimodal texts as a whole, rather than trying to first isolate words from images, sounds, or gestures. The scholarship above affirms that students must learn to understand examples of digital, multimodal, self-sponsored, and academic writing, but introducing students to a single form of writing or how to recognize a single author's choices will not teach student readers the skills and experiences to be able to negotiate all available forms of reading in their futures.

While many of the scholars cited above rely on visuality as a metaphor for knowing (Wysocki-seeing, Roozen-looking, and Shipka-making visible), Jenn Fishman, Andrea Lunsford, Beth McGregor, and Mark Otuteye get even closer to the idea of invisibility by stating: "Likewise, school-centered studies that go beyond the classroom illuminate otherwise hidden or undocumented scenes, actors, or acts of composition" (emphasis mine, 225). Each of these authors has anticipated the importance of the visual in understanding "invisible writing" by drawing on common visual metaphors that suggest many forms of writing have traditionally been made invisible in the classroom. All make a case for illuminating or uncovering only a specific kind of invisible writing, though. In addition to advocating for reading based exclusively on examples of "self-initiated" (Brandt 171), self-sponsored, digital, or multimodal forms, I argue that students must learn all available means of reading to make visible the texts that they will encounter.

\section{INVISIBILITY AS A READING RHETORIC}

The term "invisible writing" was originally used in the field of composition studies by Sheridan Blau to describe a particular method of drafting. Blau tested Britton's argument that one must be able to see during the writing process, by having students write with empty ball-point pens and carbon paper to confirm whether writing without the ability to see, scan, and monitor one's drafting process truly hinders composing (298). Surprisingly counter to Britton's original results, Blau found that "According to the participants, 
the absence of visual feedback from the text they were producing actually sharpened their concentration on each of the writing tasks, enhanced their fluency, and yielded texts that were more rather than less cohesive" (298). In other words, far from preventing the writer from drafting, the "invisible writing" could in fact be more productive. "The invisibility of the words they were writing apparently forced the writers to give more concentrated and sustained attention to their emerging thoughts than they ordinarily gave when composing with a working pen or pencil"(299). Thus, Blau concludes that the process of "invisible writing" could be employed as a strategy for producing more confident writing (particularly for those suffering from writer's block) by temporarily making the drafting process invisible to the writer (309-310). Using the term "invisible writing" from a reader's perspective could also temporarily eliminate "reader's block." Smith discusses the reluctance for student readers to reread or form individual interpretations, but framing a text as "invisible writing" forces readers to approach the text as one that must be made visible through a form of active reading. Rather than assuming that other students can already "see" the text and understand its meaning, student readers are free to engage more confidently in the act of attempting to make what is invisible more visible or more understandable.

Essentially, the metaphor of invisible writing allows student readers to see themselves as seekers-people actively pursuing the task of making a form of writing visible to themselves. We have numerous cultural and childhood acts that draw on concrete, material memories of seeking such as peekaboo, Marco Polo, hide-and-seek, and Where's Waldo. Additionally, smartphone apps, QR codes, and locative metadata reaffirm our sense that writing and information exists beyond the naked eye, and can be made present through acts of seeking. Thus, the metaphor of invisibility ties into the idea of what analysis does-it brings attention to some function or consequence of a text.

Seeking also allows students to inhabit a different identity toward reading. In order to become confident readers, students must form an identity as readers. Barbara Bird discusses the importance of identity for student writers: "If we want basic writing students to participate authentically and not resort to sentence-level mimicry, then we will want them to understand the purpose for academic texts and to self-identify with the academic community"(66). Similarly, if we want student readers to authentically engage in the social identity of academic reading, then students must feel connected to actively seeking in their reading. Like sentence-level mimicry, we do not want student readers to simply uncover some truth or "answer" within a text, but instead to identify as connected to an academic community of readers performing acts of discovery. 
In addition to strengthening students' identities as readers and underscoring reading practices as acts of uncovering, the metaphor of invisible writing also emphasizes the ways an author employs choice in allowing a text to remain invisible or not to particular readers or communities. An author could choose to employ a new compositional means, blur the lines of a genre, or confront our traditional definitions of what it means to write. For example, an author of a video-essay or graphic novel may combine written words with multimodal and digital elements such as image, sound, and motion, which could necessitate new reading practices in order for us as readers to make that text "visible" to ourselves. These choices, while linked to an author's purpose, may shock, surprise, or unseat our expectations. On the other hand, an author might make choices that seem quite "visible" or clear to other readers, but we might not see ourselves in the intended audience for a text, and thus feel like readers whose needs were invisible to the author. These aspects of invisibility then are not a matter of student readers being unequal to the task of reading a text, but rather an acknowledgement that our reading processes must do some work in making a text visible.

Alternatively, invisibility could arise from a sense of implicit valuing or devaluing some forms of writing. Smith reminds us that "gorillas" are easy to miss and could elude any reader/viewer who is unable to notice them while preoccupied with counting basketball passes (59-60). Similarly, we as readers might not attend to reading or interpreting self-sponsored or extrainstitutional genres, such as resumes, checklists, or order forms because we are looking for forms of writing that seem to "count" as "correct" academic writing. Research in New Literacy Studies and scholarship on discourse communities also understand certain forms of writing to be more visible or valued in certain communities or among members. Within any given discourse community, the forms of writing that are most present are the ones valued by and valuable to that community.

However, what makes "invisible writing" powerful is precisely its use as a metaphor. Students have a context of "invisibility," drawing on popular culture examples, as well as experiences of "feeling invisible." Additionally, they have a basis for understanding how things (like germs) are only invisible in certain situations, to certain audiences, or in the absence of certain tools for "seeing." (Sometimes these tools are literally for seeing, like a microscope.) Invisible writing is a concept that is at once understandable, yet multifaceted. Finally, "invisible writing" as a metaphor allows many different types of writing to be categorized under the same term. Rather than introducing texts as examples of digital media, multimodal composition, 
business writing, or writing in/across various disciplines, I can say: "Here is another example of invisible writing. If this text is invisible to us, then why is it invisible?" As a class, by defining that type of invisible writing, we might also learn a bit more of how and why that form of writing became invisible to us; if it can be made more visible to us in our individual and institutional contexts, and even if we want it to be.

By framing each text as "invisible writing" and connected to our systems of value, I can both remove and simultaneously expose differing systems of valuation, not by placing more value on a text as self-sponsored or digital, but in making students aware of the weight or value we place, almost transparently, on some forms of writing versus others. Additionally, we can discuss how different forms of writing are given certain weight or value in different communities, situations, and settings.

\section{“INVISIBLE WRITING” IN PRACTICE}

In the fall of 2012, I first adapted the metaphor and theme of "invisible writing" in two sections of a beginning-level composition course on analysis, called English 1: Composition. Institutionally, the goals of this course are to teach students how to read various texts, engage in a process of analysis, and compose their interpretations of those texts. Because our institution does not offer a separate basic writing course, English 1 often meets the needs of students who might traditionally enroll in basic writing. The second course in our institutional sequence, English 2, teaches topics more traditionally found in a first-year writing course, such as research and argumentation. Every English 1 section at our institution includes the following three to four assignments: 1) one to two essays analyzing a single (verbal, visual, or multimodal) text, 2) a comparative analysis of two or more texts, and 3) an analysis of a text through the lens of the personal. Beyond these standard assignments, instructors are encouraged to select their own texts and approaches ranging from rhetorical analysis to cultural studies, literary analysis, and even quantitative reasoning.

I approached this course as an opportunity to truly expand my students' understanding of what constitutes a text as well as how multimodality, materiality, digital media, and extra-academic communities might influence our analysis of texts. I wanted students to encounter their own dorm room/ bedroom spaces as texts, see comic books and videogames situated within particular communities' reading practices, and compare online and physical memorials as forms of writing. My course theme was explicitly named "invisible writing" and offered the following course description: 
What "counts" as writing? For many of us, there are types of writing or writing practices that are "invisible." In this course we will proceed through four units: private/family writing, commercial/entertainment writing, memorialized writing, and digital writing. We will explore texts that may have previously been invisible to us such as recipes, photo albums, videogames, online memorials, and finally the writing that we do online and networked to one another. Along the way we will make these forms of writing "visible" to ourselves and each other by engaging in four analysis projects. . . . (Course Description for English 1, Fall 2012).

The course description relied heavily on the idea of value/what "counts," as well as some relationship or transition by which "invisible writing" as marginal or devalued could be "made visible" through our analytic acts of speaking, discussing, and writing.

The four formal assignments were as follows: 1) an analysis of a dorm room or bedroom (as an example of personal/private, self-sponsored, and multimodal writing); 2) an analysis of a videogame (as an example of commercial, digital, and multimodal writing); 3) an analysis comparing two online memorials (based on digital, multimodal, and public and commemorative writing); and 4) an analysis of a digital environment of the student's choice (as an example of digital, multimodal, and potentially self-sponsored writing if the digital environment included a student's own text, such as personal tweets on Twitter). Texts were chosen for the formal assignments based on the multiple ways in which they might cross divisions into unfamiliar or "invisible writing." For example, the dorm room was personal, multimodal, and self-sponsored.

In addition to the formal projects, students also spent in-class time informally discussing a variety of other texts within each unit. For instance, the first unit on the dorm room also introduced the "invisible writing" of personal, private, and self-sponsored writing such as recipes, grocery lists, to-do lists, and family photo albums before proceeding with the first essay. Whenever we explored a new form of writing, I posed introductory questions such as the following:

1) What is the form or identifying features of this invisible writing?

2) Who is it invisible to?

3) Why is it invisible? 
In the third question I pushed students to consider whether a form of writing was invisible simply because we don't regard it as fitting the definition of "writing," or if it had more to do with us as an audience in the context of our university course, or the sense of value that we attached to a form of writing. Given that our beginning composition course focuses on analysis, our discussion then led to the role that analysis plays in making things "more visible." We discussed how the written nature of our analysis of dorm rooms could be circulated to other potential audiences, and how each new text we discussed became more visible to $u s$ through granting it our attention.

For most students, the dorm room represents a very particular type of text, often romanticized in its depiction in films as eager college students move in and customize their shared spaces. While our institution is largely a commuter school, we do have many international and student athletes who live in dorm rooms, as well as a growing out-of-state student population. For the purposes of our first assignment, I specified that students could choose to analyze a dorm room of their own, another person's dorm room, or their bedroom at home. I learned from reading my students' analyses that for many commuter students, the rite of passage into college also involved the further design/re-design of childhood bedrooms into a "dorm room style" even if these were not technically "dorm spaces" on campus. For those who did have dorm rooms, the norm seemed to be the traditional two-person shared spaces, though some of the international students or athletes were housed in suite configurations. For all students, though, the dorm room or bedroom represented a very understandable, definable personal/private space, even if shared with another person, and even if students would never formerly have considered those spaces to be "writing."

During their analysis of a dorm room/bedroom, students encountered several new and fairly common ideas that applied to most of their spaces. First, a dorm room is composed in a way that is personal/private and is not often on display to others. Second, it is an example of a self-sponsored composition. Composing one's dorm room is not usually connected to any sort of academic writing, even though the scene of composing takes place within a university. Third, a dorm room as a text is necessarily multimodal in that it involves different materials, furniture, and objects that contribute images, written words, and sounds to the space. To "see" the dorm room as a piece of "invisible writing" also necessitates students becoming comfortable with how an author could make choices that are aural as well as visual. Specifically, aural choices might involve the inclusion of sounds from music, television, or videogames, but also the way seating arrangements and 
the spatial configuration of materials in the room encourage other sonic activities like talking, writing, typing, or silences. Fourth, a dorm room (like videogames and memorials) forces students to think about writing existing in different spaces and not merely on a page. In addition to the writing through sounds and images, traditional forms of writing might be found in scraps of paper stuck in notebooks, taped to walls, or called up on screens. Furthermore, the dorm room could also in theory be considered as a digital text in the way it is distributed to different audiences via FaceTime, Skype, or even still photographs.

The first essay asked students to take into account these multiple ways in which a dorm room (or bedroom) could be a composition that is private/ personal, self-sponsored, multimodal, and even perhaps digital. In their essays students constructed arguments based on what they thought were the primary considerations the author or authors had made while composing those rooms as texts linked to identity, memory, or social purposes.

In some cases, students responded with hesitation with statements like "I didn't think a dorm room could be writing, but I did 'compose' it. I guess I did author this space" or "I don't think this is writing at all." However, students did begin to appropriate words and ideas like composing and authorship, and began to take on an "academic reader" identity (Bird). Rather than trying to find "answers" in reading a dorm room, students began to identify as readers of texts who could make personal evaluations about whether a text counted as "writing." Also, the very act of questioning what could be defined as writing led us to other interesting avenues of discussion. Talking about a dorm room as a text being composed also led to discussions on institutional constraints of dorm rooms, co-authorship with parents or rooms with multiple sibling authors, and expectations of genre and purpose. We also arrived at the conclusion that it was not only multimodal aspects of the dorm room that could make it an invisible form of writing. Even though recipes and grocery lists traditionally fit a definition of writing as "words on a page," their self-sponsored quality could cause them to be invisible to us in a university setting as well.

After completing these formal projects, at the end of the semester students were asked to write informal reflections on a kind of writing that we did not discuss and that might still be invisible to them. I will now turn to these student reflections as they both echo and complicate some of the benefits of framing expanded views of writing as "invisible writing." 


\section{ANALYZING STUDENT RESPONSES TO “INVISIBLE WRITING”}

At the end of the course, as part of a series of reflection activities, students responded to a short reflection question about what forms of writing they thought were still invisible and why. I collected these responses because my interest in using "invisible writing" as a course theme was to expand students' notions of writing and emphasize the variety of texts and composing situations that could in fact be read. These responses reflect the variety of texts that students might now consider as "invisible writing," but also more importantly, their attitudes toward what makes certain forms invisible in the first place.

When setting up this study, I wanted to know more about student perceptions of the metaphor of "invisible writing," so I decided to work with a very simple, open-ended prompt. The prompt for reflection was just "What genres or forms of writing have remained invisible [despite this course] and why?" I hoped that this question would prompt students to identify some of the reasons they found particularly resonant for why forms of writing might be invisible and to draw on their experiences of what they now recognized and might find invisible to others. Students were asked to write a few sentences in response. Since I gave this question to students in the last week of classes, they had had ample time to reflect on some of our previous activities and review the forms of writing we had discussed over the semester. In one sense, I was asking them what they thought had been left out of the course, but in another sense, I was also asking what could not be made visible in a course like ours and why. I was very interested in the last part of the question - why or how students perceived forms of writing to still be invisible. I did not want to ask students "Why are certain forms of writing invisible?" because I did not want them to feel like I was looking for one specific answer. I believed that by asking students about further forms of writing they perceived as invisible, they would feel more freedom to interpret invisibility in connection to their example.

\section{Developing Codes for "Invisibility"}

Strauss and Corbin's "grounded theory" approach notes the importance and possibility for coding categories to be developed as they emerge within the data rather than necessarily being developed prior to data collection (274). "Grounded theory is a general methodology for developing theory that is grounded in data systematically gathered and analyzed. Theory 
evolves during actual research, and it does this through continuous interplay between analysis and data collection" (273). In order to study my students' responses about invisibility, I first developed a set of code categories such that each response could be assigned to a category. Cheryl Geisler discusses how coding schemes (or code categories) can be created in four different ways from 1) using a source (or framework), 2) using comparisons, 3) "intuition," or 4) letting the scheme develop from the data (Bird 75). Since I had not been working with an existing framework or a single source for what the metaphor of invisibility might mean for student readers, I began to develop my code categories, or coding scheme, from two categories I expected to see through "intuition," and remained open to any other coding categories that might emerge within the actual student responses I would receive.

I expected to see students respond to why a form of writing might still be invisible with either of the following: 1) because the form of writing did not fit people's (typical) definitions of "writing," or 2) because the form of writing might not be valued. I began a textual analysis with the assumption that most responses would fall into one of those two categories. I developed the two code categories as follows:

1) "Not defined as writing" - a response will fit into this code category if the reason given for a piece of writing being invisible suggests that people do not define "writing" to include that type of text: for example a text that would not be "defined as writing" could involve digital forms or sound, image, movement, and so forth.

2) "Not of value" - a response will fit into this code category if the reason given for a piece of writing being invisible is that people do not value this form of writing: for example people may not appreciate a given type of writing or see any reason to study it.

When reading through the data, though, it became clear that a third category was emerging from the responses. This third category of student responses focused more on the fact that a piece of writing could still be invisible because it was not meant for a public audience and/or it was somehow secret or intentionally hidden from particular audiences. By allowing the data to define this third category in the way that Strauss and Corbin suggest, I developed the following, third code:

3) "Not for audience, secret/hidden"-a response will fit into this code category if the reason given for a piece of writing being 
invisible suggests that the piece of writing is not intended for a general public or is secret and/or intentionally hidden: for example a piece of writing might be intended for specified audiences for some reason.

Having developed these code categories, I then proceeded to code the data and check my codes for reliability.

\section{Coding Student Response Data on “Invisibility”}

Twenty-three students signed a form giving consent for me to analyze their responses outside of our class. Although this is a fairly small number of students, my main goal in exploring these student responses as coded data was to find out what students found meaningful about the metaphor of invisible writing in relation to reading texts. While the genres and forms of writing that students found to be still invisible varied greatly from comic books to art, music, and Labanotation (a symbol system for notating dance choreography), their concepts of why texts were invisible fit into the three different code categories described above.

In order to code each response, I first isolated only the part of a response (typically one to three sentences) where a student discussed why a form of writing was still invisible rather than what form was still invisible. Then I began to assign each response to a code category. Once I had placed each student response into a code category, another coder used my code categories to independently assign responses to categories and we calculated our reliability scores. ${ }^{1}$

Table 1 shows the distribution of student responses within each code category. I was most interested in the existence and confirmation of three code categories rather than a particular pattern of responses. Additionally, since there was a fairly even distribution of student responses among all three code categories, the data did not suggest that students found any one category more meaningful or prevalent than the other two. 
Table 1: Code Categories and Number of Responses

\begin{tabular}{|c|c|c|c|}
\hline $\begin{array}{c}\text { Code } \\
\text { Category }\end{array}$ & Brief Description & Example & $\begin{array}{c}\text { \# of } \\
\text { Responses }\end{array}$ \\
\hline $\begin{array}{l}\text { "Not defined } \\
\text { as writing" }\end{array}$ & $\begin{array}{l}\text { The form of writing } \\
\text { is described as invis- } \\
\text { ible because it does } \\
\text { not fit a definition of } \\
\text { what it means to be } \\
\text { writing. }\end{array}$ & $\begin{array}{l}\text { "Music is invisible } \\
\text { because people do } \\
\text { not count it as writ- } \\
\text { ing" (response } 21 \text { ) }\end{array}$ & 10 \\
\hline $\begin{array}{l}\text { "Not of } \\
\text { value" }\end{array}$ & $\begin{array}{l}\text { The form of writ- } \\
\text { ing is described as } \\
\text { invisible because it } \\
\text { does not have value } \\
\text { (in the university) or } \\
\text { otherwise. }\end{array}$ & $\begin{array}{l}\text { "It is invisible } \\
\text { because a professor } \\
\text { would not accept a } \\
\text { flyer for a writing } \\
\text { assignment unless } \\
\text { one was taking an } \\
\text { advertising class" } \\
\text { (response 9) }\end{array}$ & 5 \\
\hline $\begin{array}{l}\text { "Not for } \\
\text { audience, } \\
\text { secret/hid- } \\
\text { den" }\end{array}$ & $\begin{array}{l}\text { The form of writ- } \\
\text { ing is described as } \\
\text { invisible only for } \\
\text { particular audiences } \\
\text { or people, and may } \\
\text { further be seen as } \\
\text { secret or hidden to } \\
\text { the general public. }\end{array}$ & $\begin{array}{l}\text { "I believe any for[m] } \\
\text { of writing can be } \\
\text { perceived as invisible } \\
\text { or visible, depending } \\
\text { on who the audience } \\
\text { is. I believe that art is } \\
\text { viewed as an invisible } \\
\text { form of writing to the } \\
\text { majority of the popu- } \\
\text { lation" (response 2) }\end{array}$ & 8 \\
\hline
\end{tabular}

Because it was unexpected and included a fairly even distribution of responses, the most interesting finding from this small data set was the very existence of the third category, where students suggested invisibility could be based on audience, secrecy, and opportunity. While my classes had discussed the importance of audience, we did not typically discuss the productive potential or affordances of invisibility before, and when we had discussed audience it was usually in the context of a general or academic audience not valuing a particular piece of writing. We had not raised the possibility before that specified audiences might be privy to forms of writing otherwise occluded from the view of the general public. This was a quality of invisibility that occurred to students apart from any class discussion. 


\section{“Not for the Audience, Secret/Hidden": Power in the Invisible}

Since the third category was both unexpected and arose from students' own interpretations beyond class discussion, I will focus briefly on that third code category here. Table 1 shows an anonymous student response that helped to define the third code category based on the idea that art may be hidden from a general audience. Another response offered the idea of how a piece of writing could remain invisible to all but a specified audience through the example of comic books: "The audience for these are teens, children, or maybe even adults who grew up with the type of series. These are considered invisible because they contain pictures and have graphics and the subject matter is usual[ly] about super heroes and other fictitious events" (response 1). Here the student points to aspects that might be inaccessible to or not intended for certain audiences. Another student wrote:

Advertisements have invisible aspects to them. If it is a commercial than the actors might be speaking about a product but the company will hide certain hints into the commercial that appeal to the audience. Magazines consist of words and pictures. They also include different appeals so that the readers become attached, but these appeals are not always obvious. It is a new way of secretly communicating with the audience to make them connect with material either written, through a picture, or acted out. (response 12)

Here is also the idea of secrecy or invisibility that is of some advantage to the author. It is not the case that the author would necessarily desire for advertising to become more visible to a reader. Finally, another response points to the opportunity, potential, or power involved in being able to "see" a form of "invisible writing" unintended for all but a very specific audience: "Laban Notation is invisible because it was meant to preserve dance history if something were to happen where early dance movements could not be remembered or utilized. It is invisible to people who cannot dance and who cannot express their feelings through movement" (response 3). Again, this response identifies that there is a power for the potential reader, who is able to understand and see Labanotation, but no desire on the part of an author to make these forms visible to a wider public. Also, because we had never discussed Labanotation in class, this last response demonstrates how a particular student (most likely one of the dance majors in my class) connected the discussions from our class to other symbolic systems of ex- 
pression she was aware of as invisible forms of writing. Unlike comic books or art, Labanotation was a form of writing completely invisible to any general public of non-dancers, and to me as well.

As a whole, the responses in the third code category revealed that students were thinking beyond the two reasons we had discussed for invisible forms of writing, based on definition or value. In fact, many of these responses confronted the "deficit model" of invisibility (as a lack in definition or value to be made visible) and instead returned "invisibility" to a quality involving possibilities or potentials. The tension between invisibility as a lack versus a potential was not only surprising, but also leads me to several points of caution for using the metaphor of "invisible writing."

\section{KNOWLEDGE, SIGHT, AND LISTENING IN “INVISIBLE WRITING”}

While I have found that "invisible writing" gives students an easy frame for rethinking their process of reading and analysis, it is still true as discussed in the beginning that the metaphor contains a potentially damaging assumption of sightedness. In reconfiguring Smith's use of "inattentional blindness," "invisible writing" still draws singularly on one mode of perception, which is a problematic metaphor and a harmful position. Although I still favor the use of "invisible writing," as a person who primarily studies sound in writing, I cannot ignore the ways in which even a metaphor of seeing is non-inclusive and may promote ableism. The same tension which makes an interplay of uncovering, seeing, and making visible productive, still encourages a reaffirmation of visual-centric notions of knowledge production that carries the risk of disenfranchising those with differing visual abilities or visual practices. Also, Ihde might argue that it is a rather post-positivist notion that assumes all of the ontological world could and should be made "clear" to us. Additionally, "invisible writing" may even lose its traction in a digital moment, which impels us to see forms of digital writing either through ubiquity or a materially visible instantiation, and hence do not feel invisible at all. (How invisible is a flashing street billboard, we might ask.) So, the question then becomes again, what is it that the metaphor excludes, and far more importantly, who may become excluded?

Another way to resolve this issue of visual-centrism could be to include listening as a metaphor when thinking about how to read "invisible writing." Krista Ratcliffe has proposed just that in her argument for "rhetorical listening," which asks a reader to suspend decisions, judgment, or "acts of saying" until having fully immersed oneself in a discourse and an ethics of listening 
(202). While Ratcliffe argues explicitly that rhetorical listening is not simply a different attitude toward reading, rhetorical listening accomplishes the same goal in moving students from reading for "correct answers" to suspending judgment or interpretation until exploration has taken place. Rhetorical listening offers the additional concept of an ethics of interpretation which would decenter the position of the reader.

Ratcliffe developed "rhetorical listening" in order to help students pause before forming interpretations borne from personal experience without properly remaining "open" to a text, and she has applied the term only as a metaphor for listening rather than literally involving listening. Beginning readers do not usually suffer from being too sure of their own interpretations, though. In fact, basic writers often defer too much to what they perceive as the "answers" or others' interpretations of a text (Smith 64). While the metaphor of "rhetorical listening" may help confident readers think about the presence of alternate discourses or decenter themselves from a text, student readers may only see "rhetorical listening" as synonymous with remaining open to a text, which is still a nebulous concept. Additionally, "rhetorical listening," like "seeing" or "inattentional blindness" still places the emphasis on the student reader as being able to engage in an (appropriate) activity with the text. Since even the term "reading" itself can promote a kind of anxiety and reader's block for students in basic writing courses, rhetorical listening may serve only to increase that anxiety. However, metaphors that tie sound to knowledge in the reading and understanding of texts are still a fruitful place for future exploration. For instance, in addition to Ratcliffe's "rhetorical listening," Hannah Ashley and Katy Lynn have argued that students learn to write in the university through a series of moves constituting ventriloquist writing or basic writing as ventriloquism. They suggest that students learn to "throw their voice(s)" such that "students recognize all utterances, even those that feel like 'our own' are a ventriloquist act" (24). While this still does not get to the idea of what would be entailed by "voice throwing" in reading or perhaps "voice recognition" as a reading metaphor, this is an area for further thought. Is there a way to teach reading as a practice of detecting voices that still feels concrete yet complex to students?

Another important critique for "invisible writing," which came out of the student responses analyzed above, is that forms of writing that may seem invisible do not merely exist for the benefit of a university course making them visible. Though I introduced invisibility originally as a condition by which we could encounter texts, and make them more visible through our analysis, it may be the case that what is invisible can also hold its own po- 
tential for being invisible. A text's invisibility is not necessarily evidence that it is being devalued. The very fact that the writing is invisible to us might actually leave open the possibility for certain transgressions, enactments of power, or opportunities for its intended audiences. We want to make basic writers comfortable in their acts of writing, but these may include choosing to make their writing "visible" to all readers sometimes, and withholding some forms of writing at other times. (How often have I said to myself that I'd like to "see," and by "see," I mean understand, my student's writing process? However, perhaps they are owed the dignity of not showing, exposing, or making that process visible at all times or under my conditions.) Perhaps some of what we do in introducing digital writing, multimodality, and selfsponsored forms to our students threatens for them the very authenticity of Instagram, bodily display, dress, or the construction of dorm rooms with a patronizing sense of privilege, as those forms are placed in a university context and so now are visible, or "valued." This is of course only a brief echo of what scholars of alterity, colonial literature, cultural studies, and indigenous rhetorics have been saying all along.

\section{TOWARD A READING RHETORIC OF EAR TRAINING}

Rather than abandon the concept of "invisible writing" altogether, I will conclude here with a possible addition. In response to Krista Ratcliffe's rhetorical listening, and Ashley and Lynn's ventriloquism, I would like to briefly propose a means of hearing what is "distinct" in "invisible writing" by returning to the auditory realm and the idea of "ear training." Ear training has the potential to be applied both metaphorically and in a multimodal sense, but is also a literal practice that comes from musicology and music theory. In ear training exercises, musicians learn (or train themselves) to hear particular intervals between pitches, chords, or other elements of a musical composition. A similar term was proposed by R. Murray Schafer in response to the issue of noise in natural environments. Schafer argues that "The first task of the acoustic designer is to learn how to listen. Ear cleaning is the expression we use here. Many exercises can be devised to help cleanse the ears, but the most important at first are those that teach the listener to respect silence" (emphasis original, Schafer 208). Ear training is similar to ear cleaning, except in being tied to the traditions of musicology and a process of learning to listen rather than purifying listening (through "cleaning" or "cleansing"), ear training remains more related to "reading" than associations with value. Additionally, similar to the student reader who learns to 
seek "invisible" forms of writing, ear training offers a concrete but extendable set of practices for learning to literally and metaphorically listen.

Ear training is analogous to the process of rereading. Ear training does not assume that we can listen to a text or hear the "invisible" aspects the first time. It is also tied to both an auditory experience and a visual notion of reading music. Reading a musical composition and seeing when a note is written flat outside the normal tonality of the key signature, or when a voice part has a suspension that resolves a chord, is also intimately involved in being able to listen for and hear that moment. So, ear training does not occur normally in isolation or in a singular, auditory mode, but in relation to the visual aspects of a musician reading music. Additionally, ear training is a metaphor and practice that works in concert with Consigny's notion of clarity as distinct-as bell sound. Ear training focuses on the reader's ability to listen for and decipher which "bell" is being rung (whether the "bell" is an oboe, an interval, or a chord). Metaphorically, ear training is also a concept that can help unite other auditory metaphors we have for writing such as identifying distinctions in voice, dissonances in writing, and structural, visual, and auditory concepts of point and counter-point. Like "invisible writing," teaching students to read as ear training emphasizes the process and practices by which students make texts, in this case, "audible" in a specific way. It does not assume that texts are heard in the same way for each audience or that authors make each text heard through the same choices. A reading pedagogy of ear training might entail any of the following: 1) listening to the diagetic and extradiagetic sounds composed in a videogame soundscape 2) charting words that indicate certain tones (or "emotional pitches") in a verbal text, or 3) constructing a map of spatial/visual features in a website that create a distinctive visual voice (whether those features owe to color, font, or image choices). Ear training could encompass activities of listening, rereading, re-looking, re-witnessing, and breaking down parts of a text in order to identify what we hear.

Of course, ear training as a metaphor is still susceptible to some of the same critiques of exclusion as invisibility. We as instructors must be careful not to reify any mode or experience of a text exclusively at the risk of limiting student experience or promoting ableism. However, ear training as both a metaphor and a literal practice does provide a possibility to intentionally offer a more multimodal attitude toward reading as an interplay among hearing, seeing, and sensing invisible forms. Sound scholars, such as Steph Ceraso, have proposed listening as not just connected to the ears, but as implicated in a larger multimodal and material array of bodies, spaces, and sonic 
experiences. In fact, Caraso proposes and theorizes the term "multimodal listening" to emphasize the integrated nature of sonic experience (103). As students begin to understand their experience of texts as more embodied, they are in turn able to build their social identities as academic readers based on the promise of subjective interpretation.

Perhaps by introducing students to ear training as a means for hearing the "invisible," we will begin to get closer to not only seeing the "gorillas" that Smith laments that our student readers often miss, but also to hearing, sensing, and feeling their subtle tread. As Smith says,

By shifting [student readers'] focus from their insecurities to the transaction they experience with difficult texts, they will learn to see through the mist to capture glimpses of the gorillas that appear before them-even if they see those gorillas as chimpanzees or orangutans or even if they, at first, mistake them for lions. (Smith 75)

Similarly, I am not so much concerned with ear training as a means for "correctly" identifying literal or metaphorical pitches, but as a new means and attitude toward hearing as another reading practice of attending, witnessing, and uncovering.

\section{REFLECTIONS FOR THE FUTURE-POST SCRIPT}

At the time of writing this article, I have taught English 1 using "invisible writing" for a third year. I have made some revisions in terms of the exact forms of writing we analyze, but I have also played intentionally with unseating the metaphor of invisible writing as the course progresses. For instance, during fall of 2013, one of the last formal projects involved students analyzing how sounds compose places by selecting two sounds that function differently in the same public space. (An example is how a whistle sound functions differently from cheering in a sports arena or how laughter versus whispering functions in a movie theater.) With this unit I also introduced discussion on the limits of "invisibility" as a metaphor, encouraging how an act of analysis as "uncovering" the invisible could be translated to other senses and ways of knowing, such as ear training, inscribing, recording, or witnessing. This past fall of 2014, students went further with the idea of reading as listening or witnessing by collecting "listening data" of ten experiences of "listening to music in an unlikely context" (like a television series or a casual Italian restaurant) as an alternative way to analyze how 
sound composes spaces. For this project, students selected spaces or listening contexts from the gym to the supermarket, American Horror Story, or fantasy RPGs and then collected ten listening experiences based on music and its function within the space or context. In order to prepare for this project, we first engaged in ear training activities that were both literal and metaphorical, such as the ones suggested above.

If the end goal of basic writing is to make students more aware, sensitive, and in control of their own literacies and composing choices (Carter's "rhetorical dexterity"), then student readers need to find new ways of reading that are flexible and multimodal, and which help them to build their own reader identities. Reading must be presented as a practice that does justice to authorial choice and reader complexity, rather than holding to a romanticized notion of hide-and-seek or Simon Says. Instead, students must be afforded the opportunity to genuinely understand the choices of others so that they might in turn choose to "shout" their own writing choices to reader-listeners or else at other times choose to withhold, and remain "invisible," "silent," or unperceived.

\section{Acknowledgements}

I would like to thank my students over the past three years who have taught me so much about the use of the metaphors described in this article. Also, many thanks to Hope Parisi for all of her substantial, generous, and patient feedback.

\section{Notes}

1. The second coder's assignment of responses to categories matched mine with a simple reliability of .83 and a Kappa Coefficient for inter-code reliability of .61.

\section{Works Cited}

Ashley, Hannah, and Katy Lynn. "Ventriloquism 001: How to Throw Your Voice in the Academy." Journal of Basic Writing 22.2 (2003): 4-26. Print.

Bird, Barbara. "A Basic Writing Course Design to Promote Writer Identity: Three Analyses of Student Papers." Journal of Basic Writing 32.1 (2013): 62-96. Print.

Blau, Sheridan. "Invisible Writing: Investigating Cognitive Processes in Composition." College Composition and Communication 34.3 (1983): 297-312. Print. 
Brandt, Deborah. "Sponsors of Literacy." College Composition and Communication 49.2 (1998): 165-85. Print.

Carter, Shannon. "Redefining Literacy as Social Practice." Journal of Basic Writing 25.2 (2006): 94-125. Print.

Ceraso, Steph."(Re)Educating the Senses: Multimodal Listening, Bodily Learning, and the Composition of Sonic Experiences." College English 77.2 (2014): 102-23. Print.

Clark, J. Elizabeth. "The Digital Imperative: Making the Case for a 21stCentury Pedagogy." Computers and Composition 27 (2010): 27-35. Print.

Consigny, Scott. “Transparency and Displacement: Aristotle's Concept of Rhetorical Clarity." Rhetoric Society Quarterly 17.4 (1987): 413-19. Print.

Fishman, Jenn, Andrea Lunsford, Beth McGregor, and Mark Otuteye. "Performing Writing, Performing Literacy." College Composition and Communication 57.2 (2005): 224-52. Print.

Ihde, Don. Listening and Voice: Phenomenologies of Sound. Second. Albany: State University of New York Press, 2007. Print.

Lunsford, Andrea. "Writing, Technologies, and the Fifth Canon." Computers and Composition 23 (2006): 169-77. Print.

Ratcliffe, Krista. "Rhetorical Listening: A Trope for Interpretive Invention and a 'Code of Cross-Cultural Conduct.'” College Composition and Communication 51.2 (1999): 195-224. Print.

Roozen, Kevin. “Comedy Stages, Poets Projects, Sports Columns, and Kinesiology 341: Illuminating the Importance of Basic Writers' Self-Sponsored Literacies." Journal of Basic Writing 31.1 (2012): 99-132. Print.

Schafer, R. Murray. The Soundscape: Our Sonic Environment and the Tuning of the World. Rochester, Vermont: Destiny Books, 1994. Print.

Selfe, Cynthia. "The Movement of Air, the Breath of Meaning: Aurality and Multimodal Composition." College Composition and Communication 60.4 (2009): 616-63. Print.

Smith, Cheryl Hogue. "Interrogating Texts: From Deferent to Efferent and Aesthetic Reading Practices." Journal of Basic Writing 31.1 (2012): 59-79. Print.

Strauss, Anselm, and Juliet Corbin. "Grounded Theory Methodology: An Overview." Handbook of Qualitative Research. Ed. Norman K. Denzin and Yvonna S. Lincoln. Thousand Oaks: Sage Publications, 1994. 27385. Print.

Street, Brian. "What's 'New’ in New Literacy Studies? Critical Approaches to Literacy in Theory and Practice." Current Issues in Comparative Education 5.2 (2003): 77-91. Print. 
How is this publication thinking about the future?

By becoming part of the past.

This publication is available from

ProQuest Information and Learning

in one or more of the following ways:

- Online, via the ProQuest*

information service

- Microform

- CD-ROM

- Via database licensing

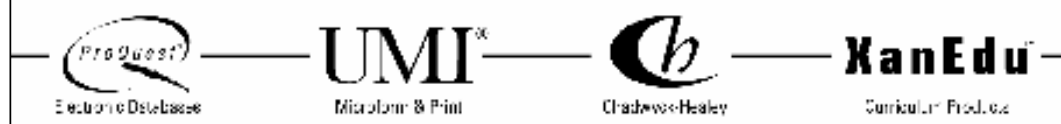

Fir arrse inforrration, rall

I-800-52I-0600, cxt. 2888 (US) ur oI-734-76I-4700 (Internatsond)

swaw.il.procpuest.rom

From:ProC Cuest 


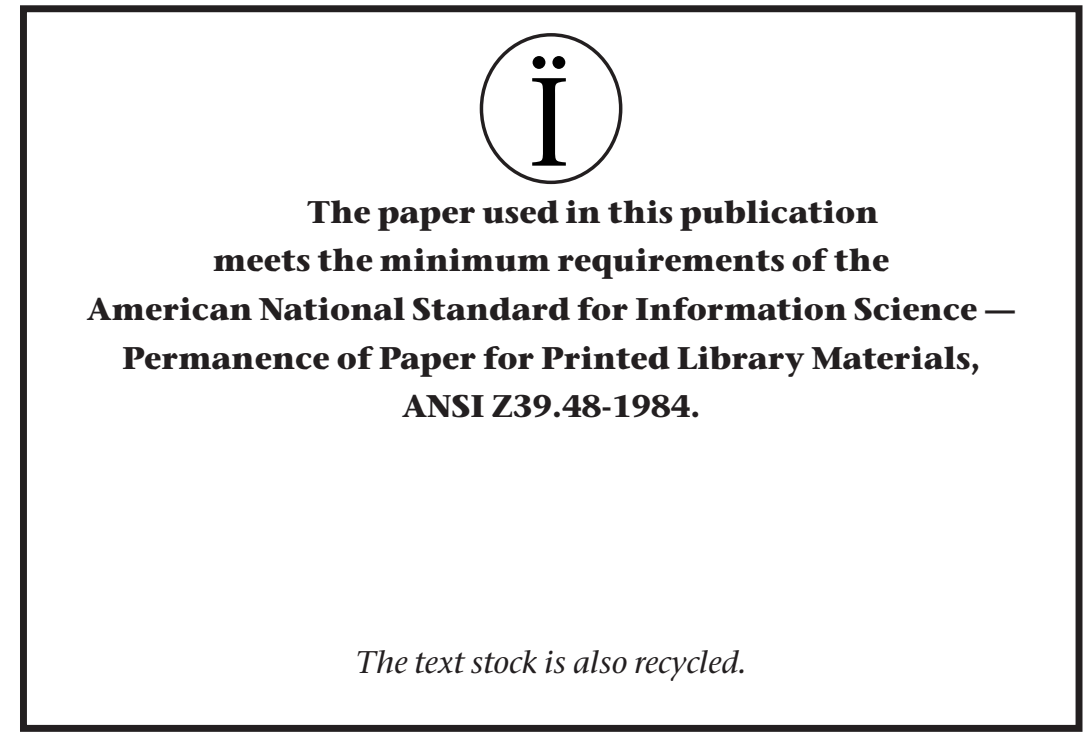




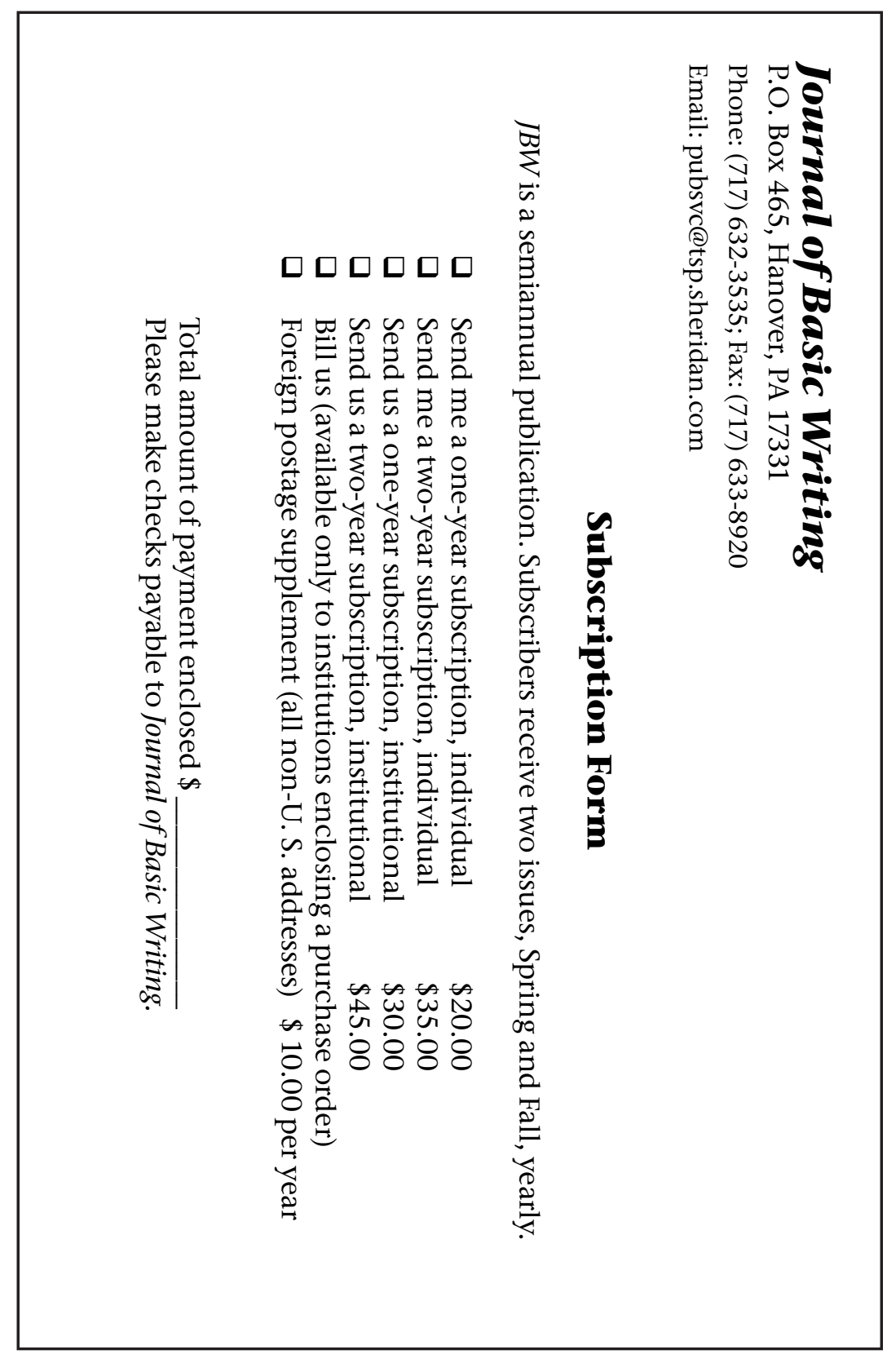



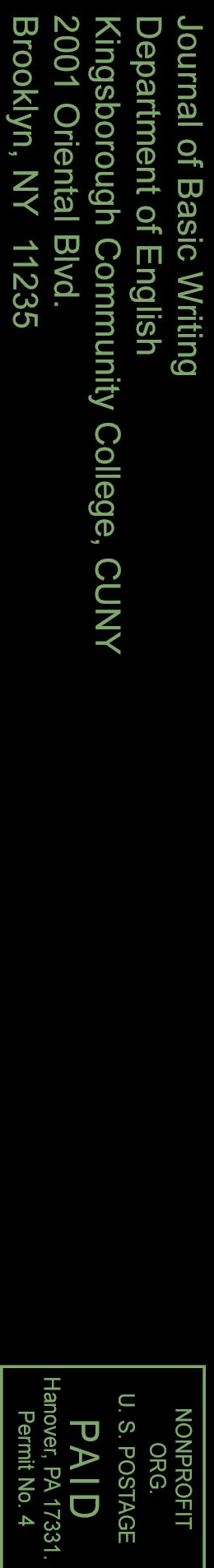